\title{
Landscape experiences as a cultural ecosystem service in a Nordic context
}

Concepts, values and decision-making 

2 norden 



\section{Landscape experiences as a cultural ecosystem service in a Nordic context}

Concepts, values and decision-making 
Landscape experiences as a cultural ecosystem service in a Nordic context

Concepts, values and decision-making

Henrik Lindhjem, Rasmus Reinvang and Marianne Zandersen

ISBN 978-92-893-4239-1 (PRINT)

ISBN 978-92-893-4241-4 (PDF)

ISBN 978-92-893-4240-7 (EPUB)

http://dx.doi.org/10.6027/TN2015-549

TemaNord 2015:549

ISSN 0908-6692

(C) Nordic Council of Ministers 2015

Layout: Hanne Lebech

Cover photo: ImageSelect

Print: Rosendahls-Schultz Grafisk

Printed in Denmark

This publication has been published with financial support by the Nordic Council of Ministers. However, the contents of this publication do not necessarily reflect the views, policies or recommendations of the Nordic Council of Ministers.

\section{www.norden.org/nordpub}

\section{Nordic co-operation}

Nordic co-operation is one of the world's most extensive forms of regional collaboration, involving Denmark, Finland, Iceland, Norway, Sweden, and the Faroe Islands, Greenland, and Åland.

Nordic co-operation has firm traditions in politics, the economy, and culture. It plays an important role in European and international collaboration, and aims at creating a strong Nordic community in a strong Europe.

Nordic co-operation seeks to safeguard Nordic and regional interests and principles in the global community. Common Nordic values help the region solidify its position as one of the world's most innovative and competitive.

\section{Nordic Council of Ministers}

Ved Stranden 18

DK-1061 Copenhagen K

Phone (+45) 33960200

www.norden.org 


\section{Contents}

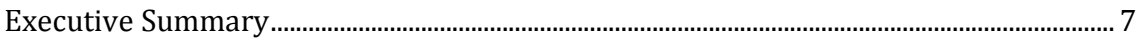

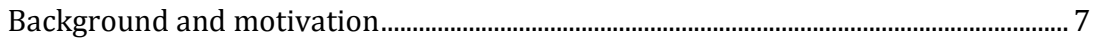

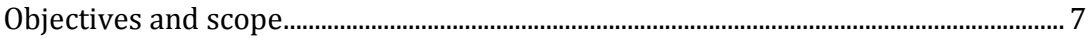

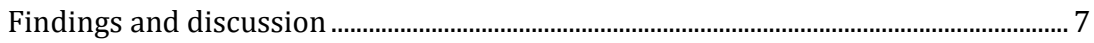

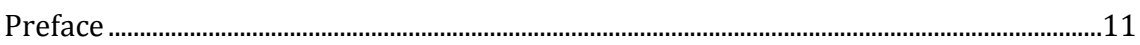

1. Comprehensive summary and conclusions ................................................................13

1.1 Background and motivation....................................................................................13

1.2 Objectives and scope .......................................................................................

1.3 Findings and discussion ...................................................................................15

1.4 Concluding remarks: Further work - towards bridging the gap ....................26

2. Introduction .....................................................................................................................29

2.1 Background and motivation: The rising challenge of assessing

values of landscape experiences and impacts...................................................29

2.2 Overall objective, activities and scope ................................................................31

2.3 Structure of the report...........................................................................................35

3. Landscape experiences as a cultural ecosystem service - How to make

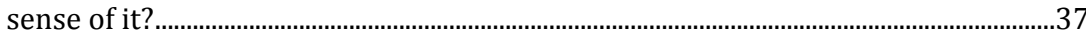

3.1 What do we mean by "landscape" and "landscape experiences"? .................37

3.2 What do natural science, economics and sociology traditions say about landscapes and landscape experiences? ....................................................40

3.3 What do we mean by "cultural ecosystem services"? ?........................................53

3.4 Landscape experience as a cultural ecosystem service.....................................59

3.5 Conclusions and operationalisation of landscape experience as an ecosystem service

4. People's preferences for landscape experiences - methods, values and

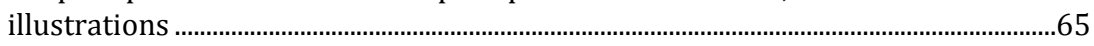

4.1 Introduction ...........................................................................................................65

4.2 How can we illustrate and measure people's landscape preferences?............................................................................................................66

4.3 Non-monetary surveys of landscape preferences.............................................

4.4 Monetary valuation of landscape and landscape experiences........................83

4.5 Examples and illustrations of the variety and magnitude of landscape experiences........................................................................................101

4.6 Summary and some key points...........................................................................108 
5. How are values of landscape experiences currently treated in assessments \& decision-making?..............................................................................111

5.1 Introduction ................................................................................................111

5.2 Common notions of landscape in the Nordic countries - a look at landscape images on Google.

5.3 Denmark: Landscape experiences in physical planning and other decision-making contexts........................................................................................120

5.4 Norway: Landscape experiences in physical planning and other decision-making contexts...................................................................................131

5.5 Examples from Sweden, Finland and Iceland..................................................148

5.6 Summary and some key points..........................................................................159

References..............................................................................................................................165

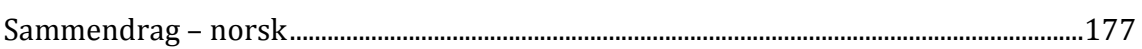

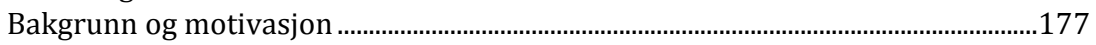

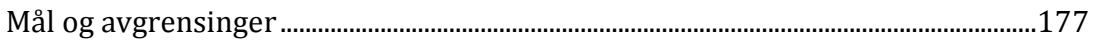

Diskusjon og konklusjoner..........................................................................................177

Annex I: List of interviewees...........................................................................................181

Annex II: CICES classification of cultural ecosystem services.........................................183

Annex III: Landscape images from the Nordic countries ..................................................185 


\title{
Executive Summary
}

\author{
Background and motivation
}

Cultural ecosystem services (ES), one of the four main ES categories, is consistently recognized as highly important, but is often not considered further in scientific ES research or thoroughly in policy assessments. The varied experiences people derive from landscapes constitute a substantial part of such cultural services. Reviewing results from studies investigating people's preferences for landscapes in the Nordic countries and internationally may be useful for understanding how and how much people value different types of landscape experiences. This is necessary in order to improve the inclusion of such values in decision-making. Given the large unprecedented landscape changes many of the Nordic countries are undergoing, there is a growing need to find ways to better include the value of (often cumulative) landscape impacts into relevant policy assessments that affect landscapes.

\section{Objectives and scope}

This report aims to synthesize the available knowledge about the magnitude and value of people's landscape experiences as a cultural ecosystem service (ES) in a Nordic context, and investigate current practices and examples of how landscape impacts are incorporated (or not) into policy assessments and decision-making contexts. Finally, we draw out lessons in order to begin to bridge this potential gap.

\section{Findings and discussion}

The European Landscape Convention (2000) adopts a broad understanding of landscape: "Landscape means an area, as perceived by people, whose character is the result of the action and interaction of natural and/or human factors." The Convention's article 5, emphasises an obligation to ensure the participation of the public in the definition and implementation of landscape policies, and requires the parties to the Con- 
vention to establish necessary procedures. Hence, people's preferences for landscape experiences should count (more) in policy processes with significant landscape impacts. We consider "landscape experience" as a form of cultural ES derived from landscapes, which is relevant for at least six types of commonly recognized cultural ES:

- Recreational: Opportunities for tourism and recreational activities.

- Aesthetic: Appreciation of natural scenery (other than through deliberate recreational activities).

- Education and science: Opportunities for formal and informal education and training.

- Inspiration for culture, art, design.

- Cultural heritage and identity: Sense of place and belonging.

- Spiritual and religious inspiration.

A number of indicators and methods have been developed to quantify and value landscape change and landscape attributes in monetary or non-monetary terms, based on people's preferences as stated in surveys or revealed in market behaviour. We surveyed the literature on forest and agricultural landscapes and looked specifically for economic studies that quantify negative effects of landscape intrusions caused by roads, transmission lines and wind turbines etc. The review of the noneconomic literature shows that there are many common attributes that can be physically measured in landscapes that people tend to like (such as openness, views, water bodies etc.) that people or dislike (such as technical installations and roads). The economic landscape valuation literature, though not large in the Nordic countries, demonstrates i) that existing methods are useful for assessing welfare impacts of landscape change, and ii) that the economic significance of landscapes for people's welfare is potentially large.

The survey of how Nordic countries currently treat impacts on landscapes in assessments and decision-making shows diversity: The landscapes of the different countries vary, as well as the perceptions and importance attributed to certain landscapes. All countries are party to the Convention, but the degree to which national landscape policies have been formulated varies, as do landscape classification and mapping methods. At the sector level, we see that different sectors to a limited extent (if at all) take into account landscape ES and the values of non-experts - but that there are different initiatives in the direction of improving inclusion of people's preferences. At the project level, 
impact assessments and cost-benefit analyses are often carried out without quantification of landscape impacts or assessment of the value of such impacts for human welfare. Furthermore, landscape policies or descriptions of landscape values for a particular area in which the project will take place are often lacking, which makes it unclear when impacts should be considered critical. Hence, there are clear weaknesses in current guidelines and practices that should be addressed. Some of the necessary tools and methods for doing so are available, and the next step can build on the ES framework and utilize existing monetary (or non-monetary) valuation methods already tried and tested in real world landscapes.

This project was conceived as part of a two-phase project. The second phase, starting in 2015, aims to develop a framework based on the ES approach in consultation with decision-makers, and explore and test how this approach can address some of the gaps we have found in current practices. 



\section{Preface}

This report has been written by Henrik Lindhjem (Vista Analysis and Norwegian institute for nature research), Rasmus Reinvang (Vista Analysis) and Marianne Zandersen (Danish Centre for Environment and Energy (DCE)/Department of Environmental Science, Aarhus University (AU). Kristin Magnussen (Vista Analysis) has reviewed the report.

We would like to thank the following for their contributions, particularly in providing us with case study examples and references to literature: Peter Fredman (The European Tourism Research Institute at Mid Sweden University and Norwegian University of Life Sciences), Göran Bostedt (Swedish University of Agricultural Sciences) and Liisa Tyrväinen (The Finnish Forest Research Institute (Metla)). We would also like to thank other academics and practitioners we have spoken to for this report (see Annex I).

Any errors or omissions remain the responsibility of the authors.

This project was funded through the Terrestrial Ecosystem Group (TEG) of the Nordic Council of Ministers.

Henrik Lindhjem

Vista Analysis AS

May 2015 



\section{Comprehensive summary and conclusions}

\subsection{Background and motivation}

Cultural ecosystem services (ES), one of the four ES categories coined by the Millennium Ecosystem Assessment (2005), is consistently recognized as highly important, but is often not considered further in scientific ES research or thoroughly in policy assessments. The varied experiences people derive from landscapes constitutes a substantial part of these cultural services. The scientific literature about the value (in monetary or non-monetary terms) of people's landscape experiences is still generally found lacking in the Nordic countries. However, there are specific studies, e.g. in the area of forest recreation and multiple use management, where several Nordic countries have a fairly good knowledge base. Recently, new studies, for example of wind power externalities, have emerged and the interest in the topic is increasing. Internationally, there is more knowledge of landscape values from the academic literature.

Piecing together results and lessons from the Nordic countries and international literature may be useful for understanding how and how much people value different types of landscape experiences. This is necessary to be able to better taking such values into account in decision-making. There are in the Nordic planning and impact assessment tradition several guidelines and tools considering how landscape could or should be included in various types of analyses and decision-making contexts. Given the large unprecedented landscape changes many of the Nordic countries are undergoing, for instance due to development of renewable energy infrastructure, there is a growing need to find ways to better include the value of (often cumulative) landscape impacts into relevant policy assessments that affect landscapes. This includes, for example, spatial planning, environmental impact assessment and cost-benefit analysis, as well as decision-making that affect landscapes more generally. 


\subsection{Objectives and scope}

This report aims to synthesize the available knowledge about the magnitude and value of people's landscape experiences as a cultural ecosystem service (ES) in a Nordic context, and investigate current practices and examples of how landscape impacts are incorporated (or not) into policy assessments and decision-making contexts. Finally, we draw out lessons in order to begin to bridge this potential gap.

The report aims to utilize current knowledge from research and our own investigations of current policy practices. We are especially interested in people's own judgments of the value of landscape experiences, rather than scientific or other experts' assessments. This is not to say that other types of knowledge from experts are unimportant as a part of a comprehensive basis for decision-making, only that we hypothesize that people's preferences for landscapes as somewhat under-researched and under-appreciated and not at the forefront of current, practical landscape analyses.

The report aims primarily to cover literature and experiences from Denmark, Norway and Sweden. We do, however, also draw on selected international literature, and provide short examples from Finland and Iceland. We do not aim to survey the whole literature or all policy assessments and decision-making contexts where landscape experiences (and their values) may be affected, as this is a task beyond the scope of this project. Instead, we provide examples and illustrations in an explorative manner and try to draw out lessons that may be of more general significance. We relate our survey work here to the definition of landscape in the European Landscape Convention, which is broad (see definition below).

Even if the Landscape Convention also encompasses purely urban landscapes, we choose to focus attention here on landscapes with a larger degree of natural characteristics, though not only the unique or special landscapes at larger scales. In terms of the role of cultural heritage, or particularly cultural monuments, in landscapes and for landscape experiences, this is clearly important, and in some situations difficult (or not even meaningful) to distinguish from other elements and characteristics of the landscape. We do not investigate the cultural heritage aspect specifically in this report, since another NMR-report 
aims to look into the connection between cultural heritage and ES. ${ }^{1}$ Method-wise, this report is based on a literature and document review, primarily, but we supplement this information with semi-structured interviews with a small selection of experts, bureaucrats and academics (in different fields) that are experienced in the area of landscape assessment and analysis.

\subsection{Findings and discussion}

\subsubsection{The meaning of landscape and landscape experiences}

The term "landscape" has a variety of meanings and connotations. In Finland, there are reportedly more than 40 different definitions of the word "landscape". The strength of the concept lies in the fact that it is easy to understand and most people will associate it with their own aesthetic experiences of certain characteristic features of an area of land. The term "landscape" is a complex construct with many layers of meaning and interpretation and is difficult to define precisely, as it encompasses subjective (the perception of a certain piece of land) as well as objective (the piece of land itself) elements.

The European Landscape Convention (2000) adopts a broad understanding of landscape: "Landscape means an area, as perceived by people, whose character is the result of the action and interaction of natural and/or human factors." (European Landscape Convention §1). According to the Convention, a landscape is a multisensory experience of physical surroundings that forms a whole and which can be constituted by natural (wild), rural, peri-urban or urban elements in various degrees. The European Landscape Convention's article 5, emphasises an obligation to ensure the participation of the general public in the definition and implementation of landscape policies, and requires the parties to the Convention to establish necessary procedures.

\footnotetext{
${ }^{1}$ Norwegian Institute for Cultural Heritage Research (NIKU) leads the project entitled "Cultural heritage - an ecosystem service asset? A study of possibilities."
} 
In this study, we consider "landscape experience" as a form of "ecosystem service" (ES), or more specifically landscapes and their characteristics as an important factor in the "production" of cultural ES, i.e. a specific sort of benefit that people obtain from ecosystems/nature.

\subsubsection{What do natural science, economics and sociology say about landscapes and landscape experiences?}

Having defined the concept of "landscape", we briefly describe how three different disciplines have considered and analysed landscapes, and how the value of landscapes (and landscape experiences) may be divided into three value domains: the ecological, economic and socio-cultural (Millennium Ecosystem Assessment 2005). These are typically analysed and emphasised by different disciplines. We provide examples of this below, and refer to the main text for a more comprehensive presentation of different traditions.

In recent years, much effort has been put into scientific mapping of physical landscapes. In Norway, for instance, a geographer or landscape architect who used his own professional opinion to divide a certain area into landscape regions has typically done landscape mapping. Often landscapes would be characterized with concepts such as open/closed, large scale/small scale, concave/convex. The geographer or landscape architect would also often give the different landscapes a qualitative rating, based on his professional opinion.

Current landscape mapping often utilize statistical analysis of the factors that create variation in the landscape at various scales. The focus is on identifying patterns of physical landscape variation and understanding what creates these patterns. By identifying groups of landscape factors that often occur together, different characteristic landscape types occur. At a macro level, landscape variation can be divided into certain major "land forms" (such as valleys, hills, plains, mountains), which again can be broken down on finer scales using topographic characteristics. Such a process can generate detailed maps of landscape characteristics and distribution of sets of characteristics, but does not take into account cultural preferences.

In contrast to the natural science tradition, economics puts the anthropocentric perspective centre stage. Much of economics is concerned with the problem that people's wants and desires are unlimited, while the resources available to satisfy these are scarce. Until the 1970s, nature and natural resources were either seen as inputs into production of goods and services for human consumption, or as unin- 
tentionally impacted by economic activities in the "real" economy (i.e. as externalities such as pollution and land use change). Landscape impacts were thus seen as "incidental" consequences (positive or negative) of classical production and consumption. Even if "designed" and "deliberate" landscapes of private parks and gardens have always been important elements of the wealthier part of society, "public landscapes" available to everybody first became a subject of interest once the general population became richer and the interest in quality of life more generally increased.

There are a range of economic methods that can be used to derive people's values of landscapes and landscape experiences, based on their actual behaviour in markets (revealed preferences) or as expressed in survey settings (stated preferences). It is also possible to use values from the literature and transfer to the relevant decision-making context (so called benefit transfer methods). Landscape economics, then, lets the people speak its preferences and from that derive their priorities and values - as the main basis for policy prescriptions. This is contrary to the expert views for example of the landscape architect tradition, and very much in tune with the spirit of how landscape is defined under the Landscape Convention, as discussed above.

The research of sociology and cultural studies shows that attitudes to and preferences for certain types of landscapes are conditioned by whom it is that experiences. Age, social and economic status, ethnic origin, familiarity, place of upbringing and residence (particularly whether urban or rural), and environmental value orientations, are examples of factors influencing landscape experience. Landscape experience is conditioned by culture. The value of certain landscape will be related to the degree to which it corresponds with certain symbolic meanings attributed to it (or elements within it) by different types of users.

We may distinguish between two basic attitudes towards nature in the Nordics; a traditional and agrarian-based attitude ("nature exists to be used by man") and a historically more modern or urbanized attitude. Studies show that holders of a more anthropocentric environmental value orientation are generally less opposed to manmade change in traditional landscapes than others. The "modern" or urbanized attitude arose with the romanticist movement in the 19th century where urban elites saw the rural and wilderness landscapes as representations of the true and pure life, and a place for recreation and spiritual renewal. This attitude has today become quite mainstream and underpins a culture in which the urban population in the Nordics constitute the majority and "consume" nature and traditional landscapes outside of the urban areas 
as places that should remain "pure an untouched" for recreation and mental renewal ("charging the batteries").

It is also clear that different nations will have different landscape preferences. In the romanticist traditions of the different Nordic countries, different landscapes have been charged with special values and roles in the development of national identities. (For a Norwegian a mountain landscape may symbolize the nation, while for a Finn boreal forest lakes serve much the same cultural role). A number of studies we review also show that landscape preference and use also differ between groups (see below). The culture of the Sami minority, for example, involves a complex relationship with the nature outside of urban areas that give certain landscapes values for them that are not obvious for the majority population.

\subsubsection{Landscape experience as a cultural ecosystem service}

Man benefits in a multitude of ways from ecosystems. Collectively, these benefits are known as ecosystem services (ES). The ES concept was popularized by the Millennium Ecosystem Assessment (2005), which grouped ecosystem services into four broad categories: (1) provisioning (e.g. food and materials)), (2) regulating (e.g. control of climate and disease); (3) Cultural (e.g. spiritual and recreational benefits); (4) Supporting (normally seen as services that are necessary for the production of all other ES). In this set-up, landscape experience is a form in which ecosystems/nature brings benefit to man and would fall within the category "cultural ES". De Groot et al. (2010), a study that looks particularly at the relationship between ES and landscapes, list six main categories of cultural ES involving landscape:

- Recreational: opportunities for tourism and recreational activities.

- Aesthetic: appreciation of natural scenery (other than through deliberate recreational activities).

- Education and science: opportunities for formal and informal education and training.

- Inspiration for culture, art, design.

- Cultural heritage and identity: sense of place and belonging.

- Spiritual and religious inspiration. 
The view we emphasised by the ES framework is that analysis of landscape experience and the value (economic or socio-cultural) of landscapes and landscape experiences have an important democratic element when based on the preferences of the people who are the "experiencers", rather than primarily on views of experts or planners. This is an important principle of welfare economics, and the underlying motivation for investigating what the literature more specifically says about people's preferences. This is also in line with the European Landscape Convention's article 5, which obliges parties to ensure participation of the general public in the definition and implementation of landscape policies.

\subsubsection{Measuring and illustrating preferences for landscape and landscape experiences}

It is perhaps overly ambitious to come up with a unifying theory backed up by empirical data - of preferences for landscapes that may be readily used by policy-makers as basis for making priorities on behalf of those who are affected by landscape change. Having said that, a number of indicators and methods have been developed to quantify and value landscape change and landscape attributes (in monetary or nonmonetary terms). These methods contribute to our understanding of preferences and the welfare impacts of landscape change.

The direct monetary valuation methods include a set of methods that are based on revealed preferences, i.e. how people behave and reveal values in actual markets. Hedonic pricing methods, for example, derive value of surrounding environmental characteristics (such as views, park features, landscape elements etc.) from the prices of houses and recreational homes. The indirect valuation methods utilize surveys where people state their preferences in a hypothetical setting, usually deriving their willingness to pay to achieve a landscape gain or avoid a loss of landscape benefits. This can either be done directly through asking willingness to pay (contingent valuation method) or indirectly by characterizing the landscape or experience with different quality attributes (e.g. degree of openness, tree or other vegetation cover, views etc.) and a public cost, that could take different values/scores.

In addition to these valuation methods, it is possible to use benefit transfer methods, where values from the literature are transferred to a relevant "policy site", where there is need for information about a landscape change. Whether this approach is advisable or not will among others depend on the decision context and the required precision in the 
benefit estimate compared for example to the cost in a cost-benefit analysis. The method has been used for landscape values in the past, but it may be harder methodologically than for other environmental goods, due to the complexity of landscape values and especially because they tend to be very site specific.

The non-monetary valuation methods are a less clearly defined group of methods than the monetary valuation methods that have their origin in different disciplines and subjects. One set of methods that are of particular interest to us, and that we review in this report, are the preference survey methods. These methods are similar to the indirect valuation methods in that they often use surveys, combined with photos (and sometimes 3D visualisations) to reveal people's preferences for different landscape characteristics. However, these studies obtain landscape preferences without investigating monetary values of changes in the landscape, and are therefore harder to use for cost-benefit analysis.

\subsubsection{What does the voice of the people say?}

We provided examples of Nordic and some international studies within the literature that investigate in particular people's preferences for landscapes - i.e. what characterize landscapes people prefer for viewing and for a range of activities thy are engaged in? We surveyed forest and agricultural landscapes and looked specifically for economic studies that quantify negative effects of landscape intrusions caused by roads, transmission lines and wind turbines etc.

The review of the non-economic literature shows that there are many common attributes that can be physically measured in landscapes that people tend to like. Hence, it is clear that preferences and cultural ES from landscapes are not completely detached from the physical or biological attributes of landscapes. Some of the common preference elements are for example the liking for openness in the landscape, natural elements, but also signs of "traditional" agricultural or forest practices, including presence of animals, views and water, and the disliking of industrial production (agriculture or forestry) and the intrusion of power lines, high impact roads, wind turbines etc. The literature is quite clear on these points.

Even if there are common elements that people prefer, there is also heterogeneity (as with preferences for most things in life). It may give higher positive welfare impacts for a higher number of people if landscape management to some extent is diversified rather than based on the "average person". For example in the case of recreation, there may 
be scope to diversify practices depending for example on whether people are used to or prefer areas of high degree of naturalness or are used to landscapes with higher visible human impacts.

\subsubsection{Economic values and magnitude of landscape experiences are generally substantial}

The economic valuation literature, though not large in the area of landscape valuation in the Nordic countries, demonstrates both that the methods are useful for assessing welfare impacts of landscape change, and that the economic significance of landscapes for people's welfare is potentially large. We investigated national-level estimates of the welfare effect of recreation and outdoor activities in several of the Nordic countries (most of these studies do not explicitly use the term ES). The "everyday landscapes" people use for their daily and weekly activities are clearly important, as are special landscapes such as national parks and mountain areas, where people have more highly valued, but rarer experiences during holidays and weekends. For both types of activities, quality of landscapes is important both for the activity levels in the countries and the value experienced from each trip/activity. Further, several studies demonstrate people's willingness to pay (both actually in markets and hypothetically stated in surveys) is substantial to avoid power lines and other intrusions, and for improvements in forest and agricultural practices that bring the best and most preferred elements out of the landscapes.

\subsubsection{Examples of the scope of more unusual cultural ES associated with landscapes}

We provide examples, some short and some more detailed, of the types and range of cultural ES associated with landscapes in the Nordic countries. While the importance of recreation activities has been welldocumented in monetary valuation studies, we also provide more unusual examples related to the spiritual, identity, educational and other aspects of importance for cultural ES. In this area, literature is immature and examples hard to come by. In some cases, specific types of such cultural ES are shared by relatively small groups and may involve specific sites (e.g. the 3,000 member strong Christian orthodox congregation in Oslo, which considers a local forest lake to be holy). In other cases specific types of cultural ecosystem services are shared by larger groups of the population (e.g. school children on educational outings in local na- 
ture and landscape) and may involve landscape on a large scale (e.g. pilgrims traversing the $546 \mathrm{~km}$ route from Selånger in Sweden, through historical landscapes and to the grave of St. Olav in Trondheim Norway).

Landscape experience as cultural ecosystem service thus comes in various forms, shapes and scales, and it provides an additional layer to the more "physical" or purely "aesthetic" assessments of landscape value. It may be noted that landscape experience as cultural ecosystem service could be of special importance in economies with increasing focus on value creation related to consumption of (unique) experiences.

\subsubsection{Promising developments in Denmark and Norway, but landscape values far from fully incorporated}

All the Nordic countries have ratified the European Landscape Convention and work in various ways to implement its intentions. Based on the more comprehensive reviews of Denmark and Norway, we made brief assessments of how landscape experiences are taken into account.

In Denmark, landscape impacts are gradually taken more into account. Recognising the increasing pressure on the Danish landscape the Danish Ministry of Environment initiated a process from 2003-2005 to develop a systematic and coherent assessment using a framework for defining landscape character. While it is voluntary to apply the landscape character method, the State urges local authorities to carry out the method, which is becoming widespread as a support tool for local decision making. The landscape character method is made for and by experts, not aimed at the larger public. To counter this bias, the Ministry of Environment pioneered a Landscape Atlas in 2014 in cooperation with a municipality and local stakeholders in order to illustrate landscape mapping in a popular way and increase the public interest in the quality of local landscapes.

The increasing development and application of the landscape character method in Denmark, shows an emerging recognition of landscape forming a whole as opposed to an area of separate functions. Danish municipalities are starting to take up the new approach and to make the connections between service, place of living, production and landscape in their planning. However, despite a clear division between towns and the countryside in how the physical planning is legislated and managed, the Danish rural landscape is de facto in a process of urbanisation, especially close to urban areas: Since the 1990s, non-agricultural enterprises are allowed to establish themselves in existing farm buildings and to develop these. Both processes tend to involve planting, change and cover 
of previously open vistas. These trends towards an increasing urbanisation of the rural landscape and change of visual character cannot be regulated through Local Plans, as these do not apply in the "open land" according to the Planning Act.

Projects that require an Environmental Impact Assessment need to consider impacts on the landscape. A Ministerial guideline exists since 2008 on how to incorporate landscape considerations in the different phases of EIAs, describing and exemplifying how to assess landscape impacts in the three EIA phases: Screening, Scoping and the full EIA. However, Ministerial manuals on carrying out Cost Benefit Analyses in the area of transport and energy do not require impacts on landscape to be quantified and valued in monetary terms.

In terms of (cultural) ecosystem services, current tools in landscape assessment do not apply this concept. There is an evident lack of inclusion of the value of landscape services, such as recreation, into environmental impact assessment or cost-benefit analysis. There is also a clear lack of studies investigating how visitors and people in general perceive landscapes, landscape changes and the importance for recreational quality.

In Norway there is a certain awareness of the importance of landscapes and the benefits humans derive from landscapes, as reflected in various laws, including in the Nature Diversity Act emphasising the importance of diversity of landscapes. A large landscape mapping exercise covering the whole country is currently taking place and several guidelines for assessing, characterising and valuing (in non-monetary terms) landscapes have been developed by the Norwegian Environment Agency in the last five years. These guidelines to a limited degree take into account preferences and values of non-experts, and do not ensure incorporation of non-expert views in EIAs, CBAs or spatial planning. The guidelines to a large degree describe expert-driven processes emphasising especially visual and aesthetic aspects of landscapes, and not so much the services or benefits derived from landscapes that could be utilised in for example a CBA. The ES concept has not yet made its way into the guidelines. Using the ES approach may be a promising avenue to better emphasise human benefits over landscape aesthetics per se in landscape assessments and analysis.

Further, very few, if any, CBAs have been carried out for large energy infrastructure projects in Norway containing preference-based (monetary) valuation of landscape impacts. This is a clear weakness, and is likely due to the fact that few comprehensive studies are available providing examples of valuation that can be used. It may also be related 
to the fact that a methodological approach for assessing such impacts as "un-priced" effects have been well-established from road project EIA analyses in Norway. This is also reflected in the guidance on CBA from the Ministry of Finance and Norwegian Government Agency for Financial Management (DFØ). In our view, there is also a potential to increase the consciousness about the landscape-sensitive aspects of regular commercial farming and forestry activities, as these activities are also very important for the values people derive from "everyday landscape" experiences. Research shows that it is not just the large impacts on "spectacular landscape" changes (such as wind power projects and fjord-crossing power lines that are important), but also other activities and cumulative impacts that "go under the radar" and that may shape landscape in ways that may oppose the preferences of many people.

Finally, a challenge in Norway as in many of the other Nordics is that much of the responsibility of landscape changing activities is delegated to the local level, when in effect many types of landscapes may be public goods of regional or national importance. The municipalities in need of economic development in the face of urbanisation and other trends, do not always have incentives to take national interests into account.

\subsubsection{Examples from Sweden, Finland and Iceland - a mixed picture}

In Sweden, landscapes have traditionally been treated by different sectors and there has, by some accounts, not been a real, overall landscape policy. There are signs that this is changing as work on a national landscape strategy was initiated in 2012. In Sweden, physical planning mainly takes place at the municipal level and is governed by the Building Act. In 2011, the Building Act was adjusted to ensure that the physical planning to a larger extent integrates the "big picture" and becomes more coherent and strategic. The changes include the responsibility of municipalities to explicitly describe how they integrate national and regional concerns and priorities, especially those related to sustainable development. As a Swedish landscape policy is further developed at national and regional levels in the coming years, the revised Building Act will help ensure that this policy is taking into account down to the municipal level.

There is significant activity in Sweden by key stakeholders related to how landscape concerns can become better integrated. A research project under the Vindval program on wind energy, documents that landscape assessments related to wind power development in Sweden often 
fails to fully integrate the perspectives and values of the non-experts who are often residents in the affected area. The study concludes that more participatory methods are needed in landscape assessment related to wind power development in Sweden. In the "Landscape in long-term planning" project, the Swedish Transport Administration has developed a methodology combining the more traditional and expert-driven landscape assessment approach with a participatory process. This enables regional mapping of landscape values in a way that reflects the view of experts and well as non-experts. These Swedish experiences seem relevant for other Nordic sector authorities.

Finland does have a national landscape policy. According to the national land use objectives set in the Land Use and Building Act, valuable landscapes must be taken into account in land use planning. For example, they must be marked in the Regional Land Use Plans. In 1995, the Finnish Government designated 156 areas as Nationally Valuable Landscapes. They represent the cultural landscapes of Finland, and their value is based on culturally significant natural diversity, cultivated agricultural landscapes and traditional architecture. In 1992, a Landscape Area group set up by the Ministry of Environment divided Finland into ten regional landscapes, based on the regional variation of natural and cultural characteristics. The Nationally Valuable Landscapes were selected in order to represent the most important features of each region. The division into regions also ensured flexibility at the regional level with regards to how to secure Nationally Valuable Landscapes within the region. At the moment, the Finnish Ministry of the Environment is updating the assessment of Finnish landscapes. In addition to Nationally Valuable Landscapes, Regionally Valuable Areas are also included in the inventory project, which runs from 2010-2014. We also briefly assessed the EIA of a wind power project in Finland, in which the landscape assessment was carried out with a scientific and expert-driven methodology not including ES perspectives on landscape.

Iceland is a thinly populated country with a very special geology and unique and varied landscapes. Landscape policy is a relatively recent issue in Iceland, but has come into focus in the academic and political milieu in recent years. The revised Planning Act of 2012 highlighted that one of the goals of the act is to preserve valuable landscapes. Iceland's unique nature and huge wilderness areas means that Iceland fits poorly into vegetation-based landscape classifications used elsewhere in Europe. With the Icelandic Landscape Project, a system has been developed to classify the main Icelandic landscape types. The system is natural science-oriented and does not take into account aesthetic or perceptual 
factors. The cultural dimension of landscape is strong in Iceland, where appreciation of landscapes is interwoven with the national Icelandic identity and Icelander's sense of themselves - according to former Minister of Environment Svarvadottir.

\subsection{Concluding remarks: Further work - towards bridging the gap}

The survey of the Nordic countries shows many variations: The landscapes of the different countries vary, as well as the perceptions and importance attributed to certain landscapes in each country. All countries are party to the Convention, but the degree to which national landscape policies have been formulated varies, and landscape classification methods at the national level also vary. At the sector level, we see that different sectors to a limited extent (if at all) take into account the wider perspectives of landscape as an ecosystem service and the values of nonexperts - but that there are different initiatives in the direction of improving inclusion of non-expert values, based for example on monetary valuation studies or in other ways. At the project level, EIAs and CBAs are often carried out without detailed guidelines for landscape assessment. Moreover, often there are no landscape policies or descriptions of landscape values for the area in which the project will take place, which makes it unclear when impacts should be considered critical. This often leads to scientific and expert-driven assessments of landscape impacts that may not always reflect landscape values held by society as a whole or the local population fully. There is also a limited base of landscape valuation studies to draw from in the Nordic countries or specific studies commissioned as part of the impact assessment processes related to large infrastructure projects. This makes the inclusion of such values in CBA, for example, difficult or impossible. Transfer of values from international studies may not be precise enough. Hence, there are weaknesses in current guidelines and practices that should be addressed. In addition, the documentation provided here about people's preferences and values associated with landscape experiences show the potential magnitude of the values we may currently be missing.

This project was conceived as part of a two-phase project. The second phase, starting in 2015, aims to develop a framework based on the ES approach in consultation with decision-makers, and explore and test how this approach can address some of the gaps we have found in current practices. This framework will be based on this report and possibly 
best practices we remain to identify (from Nordic organizations or countries not reviewed here, for example from the EU, UK and US). The academic literature is currently also moving towards analysing ways to combine and unify the ES framework with landscape analysis in practice (see e.g. recent special issue last autumn in the journal Landscape Ecology on "Integrating Ecosystem Services in Landscape Planning"). This will also provide useful input for further work. 



\section{Introduction}

\subsection{Background and motivation: \\ The rising challenge of assessing values of landscape experiences and impacts}

\subsubsection{The value of landscape experiences as a cultural ecosystem services - important, but not much studied}

Cultural ecosystem services (ES), one of the four ES categories coined by the Millennium Ecosystem Assessment (2005), is consistently recognized as highly important, but is rarely considered further in scientific ES research or thoroughly in policy assessments. They are often thought of as being "intangible", "subjective" and difficult to quantify in biophysical or monetary terms (Daniel et al. 2012). The varied experiences people derive from landscapes constitutes a substantial part of these cultural services. A number of elements contribute to the experiences; such as the aesthetic (the perceived harmony and beauty of the landscape), the cultural (the resonance with personal and regional or national history, mythologies and stories), and the spiritual (the sense of opening for or connectedness with something larger than man, which often is linked with recreational qualities and physical and mental health benefits).

The value of landscape experiences are often connected with underlying ecological structures, functions and land cover patterns that can be identified in computer visualizations of landscape changes and surveys of people's preferences for landscape elements. Hence, there is often a direct bridge between observable biophysical elements and people's preferences for landscape characteristics they enjoy. Even so, the value of landscape experiences can in many cases also be explained by factors purely in the subjective domain, for example a person's personal connection with a specific place (e.g. from childhood). It may therefore be difficult only to consider landscape experiences in relation to biophysical observables, even though that is more convenient both from research and policy perspectives.

The scientific literature about the value (in monetary or nonmonetary terms) of people's landscape experiences is still generally 
found lacking in the Nordic countries, for example as pointed out by the Nordic TEEB study and the Nordic valuation database, two reports (part) funded by the Nordic Council of Ministers (NCM 2007; Kettunen et. al 2013). However, there are also specific studies, e.g. in the area of forest recreation and multiple use management, where several Nordic countries have a fairly good knowledge base (Lindhjem and Magnussen 2012; Lindhjem 2007). Internationally, there is more knowledge, for example about agricultural landscapes (e.g. Bergstrom and Ready 2009).

Piecing together results and lessons from the Nordic and international literature, may be useful for our understanding of how and how much people value different types of landscape experiences. This is necessary to be able to better taking such values into account in decision-making.

\subsubsection{Landscape experiences in decision-making - current practice, some way to go?}

There are in the Nordic planning and impact assessment tradition several guidelines and reports considering how landscape could or should be included in analysis. In Norway for instance, the handbook V712 (former handbook 140) from the State Road Administration (Statens Vegvesen $2014)^{2}$ gives a thorough description of how impacts on the landscape should be evaluated using a system for unpriced effects. This handbook is used in several sectors, and the Directorate for Nature Management $(D N)^{3}$ has developed guidelines for landscape analysis for use in planning and impact assessment (DN 2010, 2011).

Likewise, in Sweden, for example Trafikverket has published reports on landscape in long term planning (Trafikverket 2012: 140). In Denmark, the Nature Agency encourages all municipalities to apply the landscape character method to ensure a common framework for assessing landscape values. The purpose of the method is to identify the landscape characteristic areas that we should pay particularly attention to when the rural landscape undergoes change. Specific methods to safeguard landscape qualities and develop integrated architecture when introducing large elements in the landscape have also been developed for biogas plants (Danish Ministry of the Environment, 2011). Although these new reports and guidelines build on the European Landscape Convention

\footnotetext{
2 http://www.vegvesen.no/Fag/Veg+og+gate/Planlegging/Grunnlagsdata/Konsekvensanalyser

${ }^{3}$ Now reorganised under the new name "Norwegian Environment Agency".
} 
(from year 2000) and recognize landscape as a value and a resource, they do not recognize or incorporate the ES approach or consider landscape experiences explicitly. Further, they do not always consider the importance for the general population and affected users (as welfare economics prescribe), at least not in a consistent way that may be compared with costs in for example cost-benefit analysis (CBA) of public projects and polices that have landscape impacts.

Given the large unprecedented landscape changes many of the Nordic countries are undergoing due to for example energy infrastructure, there is a growing need to find ways to better include the value of such often cumulative landscape impacts into available policy assessments (e.g. CBA, impact assessments, spatial planning) and decision-making that affect landscapes more generally. Though the Nordic landscapes have many common features and similarities there are also huge variations, both across borders and within each country due to large nature given differences in landforms, climate and biology and the vast range in the east-west and north-south direction. (An early discussion of the Nordic landscapes in light of the then new European convention on landscapes is given in NCM (2003)). ${ }^{4}$ The Nordic perspective is therefore of great importance in order to understand if and how different landscapes may give rise to different perspectives on landscapes and which forms and elements are most important for people's preferences, experiences and values.

\subsection{Overall objective, activities and scope}

\subsubsection{Objective}

This report aims to synthesize the available knowledge about the magnitude and value of people's landscape experiences as a cultural ecosystem service (ES) in a Nordic context, and investigate current practices and examples of how landscape impacts are incorporated (or not) into policy assessments and decision-making contexts. Finally, we draw out lessons in order to begin to bridge this potential gap.

\footnotetext{
${ }^{4}$ More recently in 2013, a report from Nordic Council of Ministers summarizes a Nordic seminar to discuss landscapes in municipality planning in the context of energy infrastructure. See NCM (2013).
} 
The report aims to utilize current knowledge from research and our own investigations of current policy practices to make a bridge towards direct policy relevance. The report contains demonstrations of the magnitude and value (importance) of landscape experiences and develops suggestions and examples to capture such values in actual decisionmaking that impact landscapes to maximise the welfare people derive from well-managed landscapes. Hence, we are primarily interested in people's own judgments of the value of landscape experiences, rather than scientific or other experts' assessments. This is not to say that other types of knowledge from experts are unimportant as a part of a comprehensive basis for decision-making, only that we hypothesize that people's preferences for landscapes as somewhat under-researched and not at the forefront of current, practical landscape analyses. That is also what we want to investigate further in this report.

\subsubsection{Activities}

More specifically, the project consists of the following sub-objectives or activities (Chapter in brackets):

1. Define and clarify the concept and make a typology of landscape experiences within the cultural service category (Chapter 3.1, 3.3-3.5).

2. Survey the current literature documenting the knowledge on:

a) Methods and indicators that can illustrate and measure people's landscape preferences (Chapter 4.1-4.2).

b) Landscape as a value and a resource (as expressed and analysed in different natural and social science traditions) (Chapter 3.2, weaved in with the discussion of the landscape concept).

c) People's expressed preferences for important landscape elements in different landscapes (agriculture, forests, mountains, coasts) (Chapter 4.3).

d) Monetary valuation of such landscape elements for people's experiences (e.g. studies from environmental economics) (Chapter 4.4).

e) Note any documented differences in preferences between countries (Chapter 4.5, and an illustration provided in chapter 5.2).

3. Investigate the likely magnitude, coarsely, of the most important landscape experiences measured by use of simple indicators (such as 
recreational or tourism data connected with landscape types (Chapter 4.5)).

4. Through document review and interviews with policy-makers and relevant bureaucrats (Chapter 5):

a) Investigate current practices and de facto examples of how landscape impacts currently are incorporated into policy assessments (such as cost-benefit analysis, impact assessments, spatial planning).

b) Investigate differences between Nordic countries in such practices.

Finally, we summarize lessons of relevance for policy making in the summary and conclusions.

\subsubsection{Scope and methods}

The report aims primarily to cover literature and experiences from Denmark, Norway and Sweden. We do, however, also draw on selected international literature, and provide short examples also from Finland and Iceland. Denmark and Norway seem to be fairly advanced compared to the other Nordic countries in mapping and treatment of landscape impacts in some contexts. Further, Denmark and Norway represent differences in geography and landscapes that are interesting to study. Sweden is closer to Norway in terms of geography, landscapes and climate, though lacking the variation and the dramatic mountainous coast of Norway. It is likely that the physical differences between the Nordics may also have given rise to differences in people's preferences and values and in the practices of decision-makers. To the extent possible, we will look for such differences.

We do not aim to survey the whole literature or all policy assessments and decision-making contexts where landscape experiences, and their values, may be affected. It is also not possible to detect all possible differences between current practices in different sectors and written guidelines for how impact on landscapes and landscape experiences should be treated. That would be too ambitious for a small project like this. Instead, we provide examples and illustrations and try to draw out lessons that may be of more general significance. One aim is to contribute to better guidelines and practices, but there are of course many steps we cannot control from this to impacts on actual decisions and physical changes in landscapes. A further note which is in order here is that landscapes are the physical basis for a number of other ES, in addition to the cultural services that we emphasize here. Hence, improved practices 
regarding the inclusion of cultural service aspects should be considered in tandem with the inclusion (and potential trade-off) of other services.

We relate our survey work here to the definition of landscape in the European Landscape Convention, which is broad. ${ }^{5}$ The concept, which we discuss at length in the next chapter, includes both natural and cultural (human transformed) landscapes and different spatial dimensions, for example from the micro level landscapes within a forest to the grand vistas of valleys, fjords and mountains. We try to couple this definition with concepts of landscape experiences as discussed in the ES literature. We consider how landscape and landscape experiences can suitably fit within the current framework of cultural ES, and do not aim to reinvent or reshuffle this much-used framework to make space for "landscape services" (for example as a separate category of cultural ES). The aim is rather to see if and how the concept of landscape and landscape experiences may bring something useful and new to the cultural service discussion and (perhaps more importantly) to operationalizing the concept in management practices.

Even if the definition of the Landscape Convention also encompasses purely urban landscapes, we choose to focus attention here on landscapes with a larger degree of natural characteristics, though not only the unique or special landscapes. For the ES concept to be of relevance, some extent of natural ecosystems has to be present in the landscape. Further, it is the speed of transformation of more natural landscapes that also motivate the need to assess current practices (see above). However, it is important to note that "everyday landscapes" around where most people live are probably the most important to people's, and therefore society's, wellbeing.

In terms of the role of cultural heritage, or particularly cultural monuments, ${ }^{6}$ in landscapes and for landscape experiences, this is clearly important, and in some situations difficult (or not even meaningful) to distinguish from other elements and characteristics of the landscape. We do not investigate the cultural heritage aspect specifically in this report,

\footnotetext{
${ }^{5}$ We acknowledge that there are also other international processes and environmental agreements (such as the UN Convention on Biodiversity) that are relevant for the discussion of ecosystem services from landscapes. However, we focus primarily on the Landscape convention here.

${ }^{6}$ According to Wikipedia "cultural heritage is the legacy of physical artifacts and intangible attributes of a group or society that are inherited from past generations, maintained in the present and bestowed for the benefit of future generations. Cultural heritage includes tangible culture (such as buildings, monuments, landscapes, books, works of art, and artifacts), intangible culture (such as folklore, traditions, language, and knowledge), and natural heritage (including culturally significant landscapes, and biodiversity)".
} 
since another NMR-report aims to look into the connection between cultural heritage and ES. ${ }^{7}$ Even so, the term "cultural" (appropriately or not) is used as one of the four main categories of ES, so making a clear distinction between "nature" and "culture" is never going to be straightforward or even possible. Pragmatically we choose not to emphasise built heritage/cultural monuments as part of landscapes or as a component of landscape experiences in this report.

Method-wise, this report is based on a literature and document review, primarily, but we supplement this information with semistructured interviews with a small selection of experts, bureaucrats and academics (in different fields) that are experienced in the area of landscape assessment and analysis.

This project was conceived as part of a two-phase project. The second phase (starting in 2015) aims to develop a methodological framework based on the ES approach, in consultation with decision-makers, and discuss whether and how this approach can address some of the potential weaknesses we hypothesize are present in current practices. This would be based on steps 1-4 above, and any best practices from other countries. This framework would then be tested / illustrated in a small selection of case studies covering different sectors, landscapes, and types of impacts (e.g. wind power, power transmission lines or other installations or other landscape changes) that may illustrate different values of landscape experiences and howpolicy-decisions perhaps could be different, given incorporation of such values. On that basis, recommendations would be given for improved practices. For the first phase reported here, we hence do not go down this route. But we do provide some insights that may still be valuable for future landscape analysis.

\subsection{Structure of the report}

The structure of the report generally follows the logic of activities 1-4, mentioned above. In chapter 3 we define the key concepts of "landscape" and "landscape experiences" in the context of ES and the European

\footnotetext{
${ }^{7}$ Norwegian Institute for Cultural Heritage Research (NIKU) leads the project entitled "Cultural heritage - an ecosystem service asset? A study of possibilities." We acknowledge that there has also been work ongoing for several years in many of the Nordic countries on assessing and incorporating the importance of cultural heritage and landscapes. We do not cover this as our point of entry is ecosystem services, and the contribution of the environment.
} 
Landscape Convention from 2000. We also bring in perspectives from natural science, economics and sociology on landscapes (i.e. literature related to activity 2 .b above). We then discuss ways to operationalize the concept of landscape experiences for our purpose as basis for the literature review and for finding indicators to say something about the magnitude of such experiences.

Chapter 4 first discusses ways to measure and illustrate cultural ES (for example indicators) and the "toolbox" of methods in different fields of the literature to measure and value landscape experiences. We then provide a review of important literature that either surveys people's landscape preferences without using monetary measures of value, or derive monetary values of landscape change from revealed or stated preference methods from environmental economics (cf. explanation in Chapter 3.2.2). This literature review does not aim to be comprehensive or to cover all countries equally well. We discuss in Chapter 4.5 some specific illustrations and examples (using available data and statistics) of the magnitude of important landscape experiences in the Nordics. Chapter 4.6 summarises key points.

Chapter 5 reviews some current guidelines and practices of incorporating landscape impacts and values into selected types of landscape assessments and decision-making contexts in the Nordic countries, such as strategic and project level environmental impact assessments, spatial planning and cost-benefit analysis (activity 4). These guidelines and practices are compared to the values and importance of different landscape experiences from chapter 4, to identify gaps in current practices, and especially guidelines and other documents we have been able to check. We also illustrate in Chapter 5.2 some interesting differences in how landscapes are perceived and visualised on Google for all the Nordic countries, underlining both the physical differences and the likely differences in preferences for landscapes. This is worth keeping in mind when considering how landscape experiences are treated in the various contexts and countries.

Finally, we summarize lessons of relevance for policy making in the summary and conclusions, and outline some areas of future work (second phase of the project). 


\section{Landscape experiences as a cultural ecosystem service - How to make sense of it?}

\subsection{What do we mean by "landscape" and "landscape experiences"?}

The term "landscape" has a variety of meanings and connotations. In Finland there are reportedly more than 40 different definitions of the word "landscape" (NCM 2003). The strength of the concept lies in the fact that it is easy to understand and most people will associate it with their own aesthetic experiences of certain characteristic features of an area of land, such as the majestic fjord landscapes on the Norwegian west coast or the rolling and bountiful agricultural landscapes of the Danish island of Funen.

But the term "landscape" is a complex construct with many layers of meaning and interpretation and is difficult to define precisely, as it encompasses subjective (the perception of a certain piece of land) as well as objective (the piece of land itself) elements (Wylie 2007). Landscape is to some extent a cultural construct, where an individual's perception of landscape "reveals his attitude towards it and generates emotions ranging from distrust and fear to reassurance and delight. These may arise from the view of a real landscape or from the imagery of poet, painter, or writer" (Hunter 1985).

Swanwick (2009) notes that the visual and aesthetic paradigm relating to landscape has been paramount, referring to the UK, since the $18^{\text {th }}$ century and the writing of aesthetic philosophers about concepts of the beautiful, the sublime, and, later, the picturesque. But in the last 25 years the more technical view of landscape as a territory or a spatial unit has become at least as important. This is linked with technological developments, especially GIS, allowing for mapping with a much larger degree of detail and at lower cost than previously, and the integration of mapping tools in planning. 
The term "landscape" is used in a wide variety of contexts and traditions, such as the arts, cultural heritage conservation, landscape architecture, and engineering. How landscape is understood and what is considered to constitute "landscape" often differs between such traditions. Moreover, the word "landscape" is often used imprecisely and is frequently treated as interchangeable with a variety of other words, including "nature", "countryside", "place" and "environment" (Research Box et al. 2009; Swanwick 2009).

Contemporary English dictionaries commonly define landscapes as "the portion of land or scenery which the eye can view at once" (Wylie 2007). Most then go on to note that the term may refer to a picture or image of the land, as well as the land itself. However, as noted by Van der Heide and Heijman (2012) a geographical area may be visualized by its landscape, but the latter is not the area itself. Besides landscape, an area has more characteristics, e.g. the quality and quantity of the land it comprises and climatic conditions. The land may be seen as a substrate and main determinant of land-use and its resulting landscape (Van der Heide and Heijman 2012). In this approach, landscape represents the visual aspect of the land use of a geographical area, containing physical components such as trees, grass, houses and roads but also land type diversity. Hence, the visual landscape is linked to the landscape structure made up of physical characteristics. It is also clear that landscapes are not all about the visual aspect, but about smells, sounds, touch and even taste all the aspects that are important in the appreciation of landscapes.

While the concept of "landscape" historically is related to aesthetic ideals and maybe especially has been operationalized in relation to efforts to preserve cultural heritage, it is today understood more broadly as having to do with the relationship between people and place, and the many different facets of this relationship (Swanwick 2009). While landscape earlier tended to be defined by an elite, assessments and valuations of landscape today tend to a larger extent to take into account the perceptions of "ordinary people". We all experience landscape and a landscape can mean a small patch of urban wasteland, an urban park, an expanse of lowland plain or a mountain range.

The European Landscape Convention (2000) ${ }^{8}$ adopts exactly this broad understanding of landscape: "Landscape means an area, as perceived by

${ }^{8}$ The convention promotes the protection, management and planning of European landscapes and organises European co-operation on landscape issues. It entered into force in 2004 and has as of February 201538 country 
people, whose character is the result of the action and interaction of natural and/or human factors" (European Landscape Convention §1).

In the Explanatory Notes, it is further noted that: "Landscape' is defined as a zone or area as perceived by local people or visitors, whose visual features and character are the result of the action of natural and/or cultural (that is, human) factors. This definition reflects the idea that landscapes evolve through time, as a result of being acted upon by natural forces and human beings. It also underlines that a landscape forms a whole, whose natural and cultural components are taken together, not separately" ${ }^{\prime 9}$ (European Landscape Convention, Explanatory Report §38).

In the Guidelines for implementation, it is further noted that:

\begin{abstract}
"The concept of landscape in the convention differs from the one that may be found in certain documents, which sees in landscape an "asset" (heritage concept of landscape) and assesses it (as "cultural", "natural" etc. landscape) by considering it as a part of physical space. This new concept expresses, on the contrary, the desire to confront, head-on and in a comprehensive way, the theme of the quality of the surroundings where people live; this is recognised as a precondition for individual and social well-being (understood in the physical, physiological, psychological and intellectual sense) and for sustainable development, as well as a resource conducive to economic activity.
\end{abstract}

Attention is focused on the territory as a whole, without distinguishing between the urban, peri-urban, rural and natural parts, or between parts that may be regarded as outstanding, everyday or degraded; it is not limited to cultural, artificial and natural elements: the landscape forms a whole whose constituent parts are considered simultaneously in their interrelations. (-) The sensory (visual, auditory, olfactory, tactile, taste) and emotional perception which a population has of its environment and recognition of the latter's diversity and special historical and cultural features are essential for the respect and safeguarding of the identity of the population itself and for individual enrichment and that of society as a whole."

According to the Convention, a landscape is a multisensory experience of physical surroundings that forms a whole and which can be constituted by natural (wild), rural, peri-urban or urban elements in various degrees. Article 5, emphasises an obligation to ensure the participation of the general public in the definition and implementation of landscape

ratifications, including all the Nordic countries. For more information, see: http://www.coe.int/t/dg4/ cultureheritage/heritage/Landscape/default_en.asp

${ }^{9}$ Note that this last sentence underscores why it is difficult to separate nature from culture when using the definition of landscape adopted by the Landscape Convention, as mentioned in Chapter 1. 
policies, and requires the parties to the Convention to establish necessary procedures.

In this study, we consider "landscape experience" as a form of "ecosystem service", or more specifically landscapes and their characteristics as an important factor in the "production" of cultural ES, i.e. a specific sort of benefit that people obtain from ecosystems/nature (the term "ES" is defined in chapter 3.3 below). Landscape experience as a form of ES thus involves the benefit a person or persons obtain from experiencing landscapes. As we shall see below (3.3) these benefits can be of various types.

\subsection{What do natural science, economics and sociology traditions say about landscapes and landscape experiences?}

Having defined the concept of "landscape", we briefly describe how three different disciplines have considered and analysed landscapes, and how the value of landscapes (and landscape experiences) may be divided into three value domains: the ecological, economic and sociocultural (MEA 2005). These are typically analysed and emphasised by different disciplines. This section provides a backdrop to our discussion of landscape experiences as a so-called cultural ES, and to the more specific literature review in Chapter 4 and the practices and guidelines in Chapter 5.

\subsubsection{Natural science-landscape mapping and landscape ecology}

From the point of view of the natural scientist a landscape is constituted by a physical reality in the form of physical elements, geological forms, and living organisms.

The Landscape Convention distinguishes between mapping and analysis of landscape. Mapping of landscape types involves demarcation, classification and description of landscape areas. The aim of landscape mapping is to provide neutral and verifiable information about landscape that subsequently can be used for different analytic purposes. Landscape mapping is a method that functions in parallel with analytic methods involving non-observable landscape elements, such as cultural references and aesthetic assessments. Landscape mapping is thus differ- 
ent from landscape analysis, in which the purpose is to assess certain qualities of a landscape in relation to a certain form of use or goal.

Historically, much effort has been put into scientific mapping of physical landscapes but this has proven to be difficult to do in a standardized manner. In Norway, for instance, landscape mapping has historically been done by a geographer or landscape architect who used his own professional opinion to divide a certain area into landscape regions (MD 2013). Often landscape would be characterized with concepts such as open/closed, large scale/small scale, concave/convex, without there being a specific definition of these concepts. The geographer or landscape architect would also often give the different landscapes a qualitative rating, based on his professional opinion. Such mapping provides potentially much valuable information about different areas, but it has been argued that the lack of precise definitions of landscape types often makes it difficult to compare and aggregate information from different areas (MD 2013). Without a standardised landscape typology, it is not possible to determine how common or rare, typical or representative different geographical landscapes are. In Norway, work is currently in progress to establish a landscape typology system ("NIN-landskap") that can be used to map the natural elements of landscapes in a neutral and verifiable manner across Norway at a scale of 1:50,000. NIN-landskap aims to become a tool enabling nature management and spatial planning to better take landscape values into account. ${ }^{10}$

Modern landscape mapping, as exemplified by NIN-landskap, is based on a statistical analysis of the factors that create variation in the landscape at various scales. The focus is on identifying patterns of physical landscape variation and understanding what creates these patterns. By identifying groups of landscape factors that often occur together, different characteristic landscape types occur. At a macro level, landscape variation can be divided into certain major "land forms" ("landskapsformer"). This provides a map showing overall characteristics of the landscape (which usually also constitute visual characteristics) in a certain region, such as fjords, valleys, plains, hills, mountaintops. These main landscape forms often also reveal how the landscape has been created and shaped by geological and other land-shaping processes. In the

\footnotetext{
${ }^{10}$ It is noted that in the Norwegian context there is an ongoing discussion of the usefulness of NIN for covering the totality of landscapes, i.e. including the cultural heritage elements (Haveraaen pers comm). There is ongoing work in Norway mapping cultural heritage landscapes of national interest (see wwww.riksantikvaren.no/ Tema/Landskap).
} 
Norwegian classification system, there are 10 such main types of landscapes (incl. 4 main marine landscape types).

At a finer scale, other criteria than landscape form become important when distinguishing between landscape types. In the Norwegian system, 10 different landscape gradients have been statistically identified as important to capture the main landscape variations at a finer level. "Gradient" refers to a gradual variation of several landscape characteristics. 8 of these are geo-ecological landscape gradients and two of them are spatial-use gradients. Examples of NIN-landskap geo-ecological gradients are the degree to which an area is characterized by marshes and the degree to which an area is above or below the forest boundary. The two spatial-use gradients are the degree to which an area has infrastructure and the degree to which an area is dominated by agriculture. The NINlandskap system uses a detailed set of criteria for demarcation of areas and borders between different types of areas, minimum area size etc. Based on this set of criteria, the NIN-landskap system can distinguish between landscape areas at a detailed level. The system was tested in Nordland county in Norway, a county with a long coast line and a varied topography, and identified 3,041 distinct landscape areas.

In Denmark, the landscape character method is increasingly being implemented in municipalities. It acts as a basis for improved decision making and permitting processes where planners classify landscape in characteristic areas. Within each area, those places that represent the highest quality experience are designated along with those places that are in need of change (i.e. representing weak landscape experiences). The method is designed as a technical tool for in particular planners. A Landscape atlas of the island of Langeland (Danish Nature Agency 2014) has recently been published as an illustration of how to translate the technical information of the landscape character method and making this assessment accessible for laymen and local politicians. We return to landscape mapping and the landscape character method in chapter 5.

This system has not as one of its aims to assess suitability of different landscape types for landscape experiences of various sorts (as discussed subsequently). However, it is clear up front that some physical mapping and categorisation of landscape types (even though perhaps not as detailed as in Nordland), may be very useful for linking certain landscape types to specific human uses, their preferences for different types of landscapes and ultimately wellbeing derived from landscapes and landscape experiences. What needs to be added is the spatial distribution of landscape functions and services, not just mapping and classification of landscapes in the form of physical land cover types or land cover related 
land uses (de Groot et al. 2010). Landscape ecology is a distinct discipline and is defined by the International Association for Landscape Ecology (founded 1982) as the study of spatial variation in landscapes at a variety of scales (IALE 2014).11 Landscape ecology is broadly interdisciplinary and includes study of the biophysical and societal causes and consequences of landscape heterogeneity, linking natural sciences with related human disciplines. Landscape ecology characteristically put emphasis on the relationship between pattern, process and scale, and focus on broad-scale ecological and environmental issues. Key research topics include ecological flows in landscape mosaics, the relationship of human activity to landscape pattern, process and change, and the effect of scale and disturbance on the landscape.

From a landscape ecology perspective, spatial heterogeneity in service provision is a result of differences in biophysical and socioeconomic conditions at different scale levels (de Groot et al. 2010). Landscape ecologists such as Ryan (2011) notes that landscape modelling still remains disconnected from the socio-political realities of the communities and regions that are the subject of studies. He underlines the necessity of describing the social landscape in spatial terms, and states that, in the future, landscape planners will need to know as much about the social landscape as they do about the physical landscape before embarking on planning actions. Ryan also provides several examples of use of GIS models that incorporate sociological realities in a quantified manner. Mapping of the preferences of social groups (or individuals) using GIS tools would allow researchers to understand the relative amounts of different preferences and the relationships between different social groups to different landscape types and the urban fabric. Such methods are, however, still not standardized and widely used in planning.

Ecological value encompasses the health state of a system measured with ecological indicators such as diversity and integrity (de Groot et al. 2010). Hence, the pure ecological/natural science tradition has considered the function of landscapes and landscape level ecosystems with this in mind. For example, connectivity between ecosystems across the landscape is considered ecologically valuable, and important for ES provision (Mitchell et al. 2013). Physical and biological mapping of landscapes has

${ }^{11} \mathrm{http}: / /$ www.landscape-ecology.org/index.php?id=2 
also been conceived as a way to classify how rare (and hence worth protecting) specific types of landscapes are.

\subsubsection{Economics-landscape experiences are seen to provide utility and welfare}

In contrast to the natural science tradition, economics puts the anthropocentric perspective centre stage. Much of economics is concerned with the problem that people's wants and desires are unlimited, while the resources available to satisfy these are scarce. Until the 1970s, nature and natural resources were either seen as inputs into production of goods and services for human consumption, or as unintentionally impacted by economic activities in the "real" economy (i.e. as externalities such as pollution and land use change). Landscape impacts were thus seen as "incidental" consequences (positive or negative) of classical production and consumption. Even if "designed" and "deliberate" landscapes of private parks and gardens have always been important elements of the wealthier part of society, "public landscapes" available to everybody first became a subject of interest once the general population became richer and the interest in quality of life more generally increased (van der Heide and Heijman 2012).

The interest also among economists grew as the scale of human impacts on the environment, including landscapes, became evident. As landscapes are typically public goods that are underprovided ("overconsumed") in a free market economy, economists' prescribe government regulation to ensure sufficient provision and to avoid landscape degrading activities that in many cases benefit the few on the expense of the many.

Colin Price, by some considered the father of "landscape economics", note that one of the reasons economists were reluctant to touch the topic, was the strong and inherent subjectivity of the value of landscapes (Price 1978). The value of landscapes goes beyond the mere direct instrumental value of its spatial and ecological components, such as trees, hedgerows and ponds. Price underscores the aesthetic value of landscapes as crucial. The experiences of landscapes, how they are looked at and interpreted, and the inspiration drawn from them has for centuries been the subject of countless works of painted art, music and literature. Here landscapes show their intrinsically aesthetic and emotional value. As pointed out by van der Heide and Heijman (2012) for landscapes this category of value is much more important than for, say, nature or biodiversity. And many economists have traditionally been a bit uneasy about 
this non-instrumental type of value of aesthetics that is an end in itself rather than a means to some other end. However, as we shall see below, the introduction of the concept of ES, have opened the discussion of a range of benefits of landscapes for human benefit, including the more intangible ones under the heading of "cultural ES".

Much of what environmental economists do is to assess the value of changes in environmental resources and amenities, to compare with competing uses, many of which produce goods and services that are traded and valued in the market place. The valuation of landscapes and the damage done to them is hence also an important element of landscape economics. The total economic value (TEV) of a landscape change is defined as the total willingness (measured in monetary terms $)^{12}$ of the affected population to give up other goods and services to avoid a negative change or to achieve a positive one. Or as Price (2012: 71) notes as the purpose of landscape valuation: “...to discover people's subjectively felt aesthetic desires, and to trade those off against other desires and the resources needed to meet those desires, in a reasonable and consistent manner." 13

TEV consists of both use and non-use values. The use category is normally divided into direct (e.g. consumptive use of land for power lines), indirect value (e.g. as non-consumptive recreational activity in the landscape or viewing the landscape from a vista point) and option value (future direct or indirect use). Non-use value may be divided into bequest value (i.e. future generations) or existence value, i.e. human benefit independent of own use of a resource. Using a wide interpretation of "landscape experiences", which seems most appropriate on the basis of the above discussions, the value of such experiences may not just be related to use, but could come from desire to protect beautiful landscapes and experiences such landscapes give rise to, just for the knowledge that this exists independently of own use.

TEV of a landscape change is the sum of the welfare change (value) for each individual summed over the whole affected population. It is clear that small changes in the landscapes for the many (e.g. the "everyday landscape" people most often experience) may constitute a larger total welfare change than an impact in a particularly valuable or spec-

\footnotetext{
12 As willingness to pay (WTP) or willingness to accept (WTA) compensation.

${ }^{13} \mathrm{He}$ adds that if scenic preference is contrary to ecological sustainability, that too requires trade-off. In other words, (insufficiently informed) human preferences may (or should) in such cases be overruled by other considerations.
} 
tacular landscape, visited by relatively fewer (e.g. because of remoteness). The exception is of course if there are substantial non-use values attached to these rare and spectacular landscapes.

There are a range of economic methods that can be used to derive people's values of landscapes and landscape experiences, based on their actual behaviour in markets (revealed preferences) or as expressed in survey settings (stated preferences). It is also possible to use values from the literature and transfer to the relevant decision-making context (so called benefit transfer methods). We will return to these methods, and some of the complexity of landscape as a good for valuation (e.g. whether considered as a holistic concept or as consisting of multiple characteristics for which people have preferences), in Chapter 4.2.

Landscape economics, then, lets the people speak its preferences and from that derive their priorities and values - as the main basis for policy prescriptions. This is contrary to the expert views for example of the landscape architect tradition, and very much in tune with the spirit of how landscape is defined under the Landscape Convention, as discussed above.

While people's preferences from landscape economics are typically expressed in monetary terms, there is cultural and sociological importance (socio-cultural value) of landscapes that may be difficult to capture by standard economics, and there may be considerable heterogeneity in a population. There are also issues of equity and distribution, important in economics, but more carefully analysed in other social sciences. Both population heterogeneity and equity issues may be important concerns in targeting landscape policies. We turn to such issues next.

\subsubsection{Sociology - cultural aspects of landscape experience and valuation}

Attitudes to and preferences for certain types of landscapes are conditioned by whom it is that experiences. Age, social and economic status, ethnic origin, familiarity, place of upbringing and residence (particularly whether urban or rural), and environmental value orientations, are factors influencing landscape experience (Buijs et al. 2009, Research Box et al. 2009, Swanwick 2009, Vacher 2011, Ween and Abram 2012, Ween and Lien 2012).

Landscape experience is conditioned by culture. As pointed out by Kirchhoff (2012), the value of certain scenery will be related to the degree to which it corresponds with certain symbolic meanings attributed 
to it (or elements within it) by different types of users. In the Scandinavian anthropological literature we may distinguish between three basic attitudes towards nature in Scandinavia (Vacher 2011, Ween and Abram 2012, Ween and Lien 2012). While these basic attitudes do not represent the whole spectre of attitudes towards landscape in Scandinavia, they do reveal fundamental differences that are important to take into account.

The first attitude may be termed an agrarian-based and more traditional attitude towards nature and landscape, in which man lives in close contact with nature and interacts directly with it in order to secure the basic means of existence. Farmers, fishermen and rural dwellers often perceive the land and landscape within the routine rhythms and progression of work; the landscape constitutes a context that primarily is experienced and read from the perspective of securing basic means of existence and handling risk (Buijs et al. 2009, Vacher 2011, Ween and Abram 2012). This fosters attitudes and preferences in which different forms of subjugation and control over nature often are perceived as good, and where traits representing a successful management of nature and landscape are perceived as comforting and even beautiful. In the modern Scandinavian societies, a gradually shrinking minority of the population is today directly engaged with land and landscapes as part of subsistence activities.

The second attitude may be termed a modern or urbanized attitude to nature and landscape (Buijs et al. 2009, Vacher 2011, Ween and Abram 2012), arising with the romanticist movement in the 19th century and adhered to especially by the urban population. Since the 19th century, urban elites in Europe saw the rural and wilderness landscapes as representations of the true and pure life, and a place for recreation and spiritual renewal. ${ }^{14}$ As living standards rose in the Nordic countries in the 20th century and urban populations grew, large parts of the population adopted an attitude in which the nature and landscape outside the cities were seen to be places of recreation and, to some extent, spiritual renewal. This development has lead to the current situation in the Nordic countries of seasonal mass tourism from the cities and into preferred natural landscapes, in Denmark typically coastal landscapes and in Norway typically coastal and mountain landscapes. In the modern Scandina-

\footnotetext{
${ }^{14}$ Specific natural landscapes also played an important part in constructing national identities as the Nordic nation states developed, such as the open beech forest in Denmark and the mountains and fjords in Norway.
} 
vian societies the great majority of the population "consume" landscapes by actively gaining access to it for recreation.

The Sami minority represents a third attitude towards nature in Scandinavia. The Sami word that most closely corresponds to the Norwegian utmark (uncultivated land, further away from where people live) is meacchi, which also refers to a commons, but instead of being based in notions of the right to roam, it is used according to unwritten rules agreed upon by local Sami communities (Ween and Lien 2012). According to the anthropologists Ween and Lien (2012), embedded in the meacchi concept is a complex network of user rights associated with particular places, resources and family history. A northern landscape that is seen by non-Sami Norwegians as a wide commons free for use (and which is sanctioned by Norwegian law to be such a commons), may for the Sami represent other notions and values reflecting family history, traditional rights linked to a well-defined portfolio of subsistence activities, as well as spiritual meanings. In Sami religion and tradition, landscape features such as mountains or lakes are often considered holy and certain places may be important as dwellings for mythical beings. The meaning of landscape in traditional Sami areas and in areas with a living Sami culture will thus differ from areas without such a culture.

These three different attitudes towards nature and landscape in Scandinavia may at times create conflicts. Norwegian studies show that people not engaged in agrarian industries prefer traditional agricultural landscapes to more modern agricultural landscapes, as well as landscapes dominated by natural elements or where the man-made elements are perceived to be in harmony with the natural elements (Strumse 2012). At times, the urban population's preference for untouched or traditional landscapes collides with the rural population's need and preference for harvesting with modern methods and technology. ${ }^{15}$ There have also been cases where infrastructure projects have failed to take into account Sami experiences of landscape, causing conflicts with the Sami population.

At a more detailed level, it is clear that it is possible to distinguish between different user typologies. Drawing on important studies from the UK and the Netherlands, we discuss this in more detail below. An extensive survey in the UK (Research Box et al. 2009), for example, distin-

\footnotetext{
${ }^{15}$ One example of such a conflict is the debate in Norway about conservation of wolves and other carnivores, where urban people are typically in favour.
} 
guished between 20 different user typologies, some examples being the "traditional working the land" (such as farmers, for whom the landscape is important from a revenue point of view and who often also have deep emotional ties with it), "naturalists" (such as bird watchers), "walkers" (people interested in long walks, incl. aesthetics and health aspects), "dog walkers" (habitual users of landscape, who enjoy fresh air and are pragmatic about the landscape they use), "fitness fans" (such as joggers listening to music), "thrill seekers" (people engaged in different forms of extreme sports), "artistic dreamers" (who likes the landscape to provide a romantic setting for their artistic activity), "free range families" (who want their children to be "outdoorsy" and experience landscape in an unstructured way as part of their development). All these types of users will typically have different user patterns with regards to landscape, and perhaps also some differences in preferences.

Looking more closely at demographic groups Swanwick (2009) notes that there is no conclusive evidence of effects on attitudes and references to landscape for certain demographic factors including gender. There is little academic evidence on the influence of socioeconomic group on landscape preference, and that which does exist tends to suggest there is no or little significant influence (Daniel et al. 2012, Swanwick 2009, Kaae 2004). Studies indicate, however, that childhood experiences and value orientation influences attitudes and preferences to landscape. Greater exposure to landscape experience as a child, either due to a rural upbringing or due to planned visits, means a higher likelihood of later adult visits (Kaae 2004, Swanwick 2009). It also seems clear that having more information and knowledge about a landscape increases the experienced value of that landscape (Research Box et al. 2009).

Studies can generally not reveal clear-cut patterns between landscape preferences and socioeconomic groups, but patterns of actual consumption do reflect significant differences in the behaviour of socioeconomic groups. It is for instance well established that ethnic minorities in the UK and the Netherlands are less likely to visit the countryside and less likely to access parks and greenspaces, than other groups in society (Buijs et al. 2009, Swanwick 2009). This is likely to be the case also in the Nordic countries. Swanwick (2009) notes that this is likely to be due as much to the circumstances of the individuals in the different groups as to their underlying preferences if all other things were equal. In the UK, the main explanatory factors for the lower propensity of immigrants to visit the countryside and urban greenspaces are not related to attitude or preference but rather factors such as cost, 
lack of knowledge, lack of culturally appropriate provision (countryside), or poor maintenance, lack of facilities and safety fears (parks and urban greenspaces), or fear of discrimination (both) (Swanwick 2009). In the Netherlands, a study (described below) showed that differences between the local population and immigrants mainly were related to different views on nature.

Environmental value orientation is recognized as a strong determinant of people's attitudes to change in landscapes (Buijs et al. 2009, Kaae 2004, Swanwick 2009), with marked differences between people having an anthropocentric view ("nature exists to be used by man") on environment and those having an ecocentric view ("man is a part of nature, which has value in itself"). A study comparing preferences of the ethnic Dutch population with preferences of the Turkish and Moroccan immigrants in the Netherlands (Buijs et al. 2009) found that it was mainly the "image of nature" held by the different groups - and not factors such as age, gender and education - that influenced their preferences for nature and landscapes. Whereas the ethnic Dutch tended to favour an ecocentric view of nature and prefer wild or natural landscapes, the immigrants tended to favour an anthropocentric view of nature and showed a lower degree of preference for non-urban landscapes and especially wild and unmanaged landscapes. This view was to some extent also shared by the older segment of the ethnic Dutch population.

Studies from the UK indicate that at an overall level there exists an apparent polarization in society (Swanwick 2009): At one extreme are the older, more affluent, better educated, more environmentally aware people, often in the middle class or upper-middle class, who have an ecocentric view on nature and who are actively engaged with experiencing the countryside. At the other extreme are younger age groups, ethnic minorities, semi and unskilled manual workers as well as casual or lowest grade workers, pensioners, and others who depend on the welfare state for their income, who tend to live in cities, are less environmentally aware, and are less exposed to countryside experiences. These groups, and those between the extremes, have quite different values and attitudes. Swanwick (2009) stresses, however, that such a classification must be considered an extreme oversimplification. Even so, there is likely to be a degree of relevance and truth in these characterisations also for the Nordic countries, even though the Nordic societies perhaps generally are more socially homogenous and less class-divided than the UK.

In a recent and very relevant study from the UK based on extensive qualitative research, Research Box et al. (2009) demonstrate complex ways in which individuals interact with landscapes and the ways that 
their attitudes are expressed. It is documented that people have a need to access and enjoy different types of landscapes at different times and for different purposes, and that the everyday landscape experience plays an important role for people even if they are unremarkable. In real life each person will typically have a "portfolio of places", that is particular to each person and where the landscape experience often is closely linked with personal history. This portfolio can be illustrated with a pyramid, distinguishing between the local and frequently used natural or semi-natural landscapes, and the more distant and special landscapes accessed for special purposes (ref. figure 3.1). The "intensity" of the landscape experience increases vertically up the pyramid. This pattern of use (which applies more to urban populations than to rural residents) can be compared with the way that some people shop, using a local corner shop for the small everyday needs, a mainstream supermarket a few times a week for larger supplies, an upscale supermarket shop when nicer products occasionally are sought, and a specialist delicatessen for the rare and special occasions.

\section{Figure 3.1: The portfolio pyramid of landscape experience}

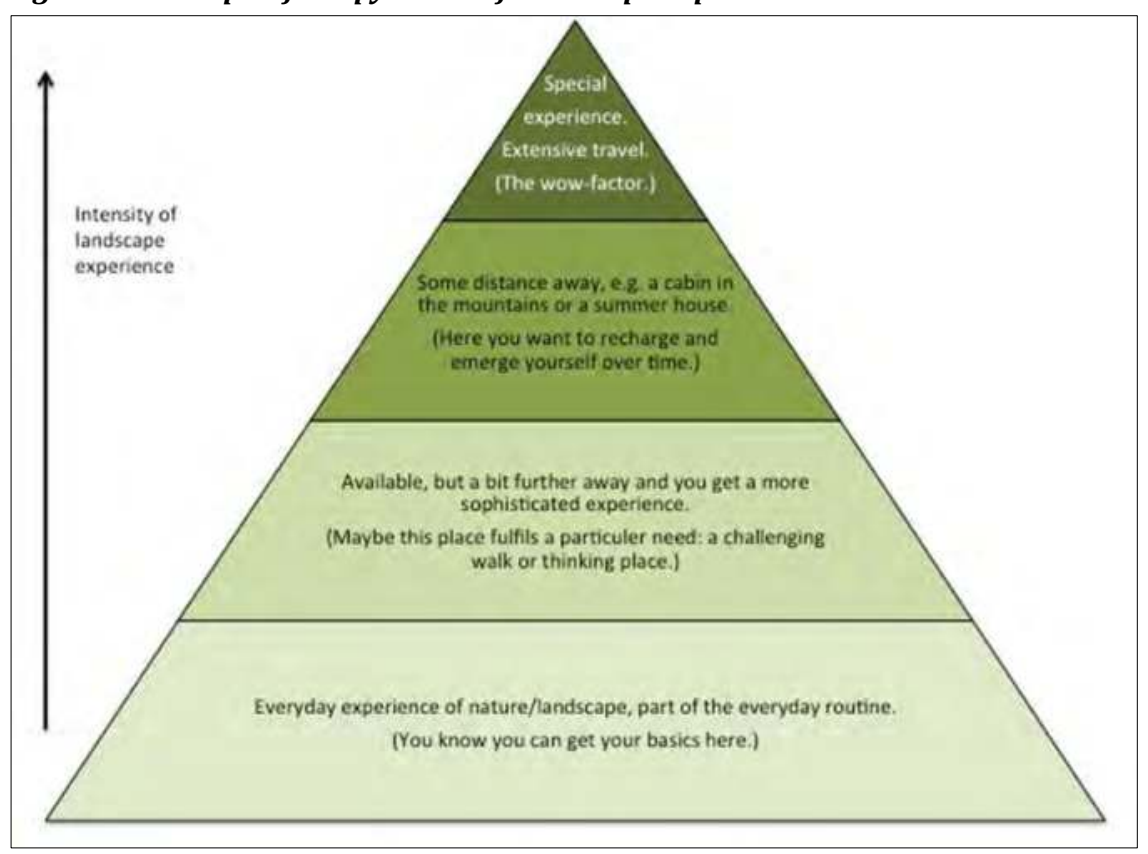

Source: Vista Analyse. Adapted from Research Box et al. (2009). 
Swanwick (2009) notes that if society is to take into account the varied ways in which each individual uses and appreciates different types of landscapes, it is necessary to maintain a range of different landscapes to meet these needs for a diversity of landscape experiences. The portfolio pyramid of landscape experience also implies that although the intensity of landscape experience from the nature experienced in the everyday life compared to the rarer excursions to attractive landscapes may be lower, the volume of the ecosystem service provided is much higher due to much higher exposure.

\subsubsection{Landscape experience - a multifaceted concept}

According to the Landscape Convention, a landscape is a multisensory experience of physical surroundings that forms a whole and which can be constituted by natural (wild), rural, peri-urban or urban elements in various degrees. This is a wide definition.

The brief survey above of how the concepts of "landscape" and "landscape experience" are understood and treated in different scientific disciplines reveals that "landscape experience" is multifaceted and works across different axes. We try to summarize, highlight and elaborate on some of the main facets and axes below, without claiming to be conclusive.

There is, to our knowledge, no defined typology for different types of landscape experience agreed upon in the literature, something which makes "landscape experience" an open-ended concept. In principle, a "landscape experience" occurs any time anyone has a holistic experience of his or her surroundings.

Landscape experience occurs along the axis of scale, ranging from holistic experiences of immediate surroundings (an alley, a path in the forest, a small brook surrounded by trees etc.), larger vistas such as the outlook over a lake, to grand vistas such as the Grand Canyon and the starry sky.

Landscape experience is conditioned by availability, the extent to which landscape is available to people. As pointed out by Olafsson (2013), the spots within a certain area that to a significant extent "provides" landscape experience can be determined geographically. As noted in UK research (Research Box et al. 2009), landscape experience is also sociologically conditioned, occurring most often where individuals move 
about in their everyday lives. In Scandinavia, people's general right to roam means that landscapes both privately and publicly owned may be experienced almost equally well. ${ }^{16}$

Landscape experience occurs with varying degrees of intensity, from the everyday holistic experience of your street or local park (generally with a low degree of intensity) to the rarer and more spectacular experiences of landscape that are often actively sought.

The landscape experience is conditioned by the symbolic meanings users attribute to the landscape. The landscape experience arises in a moment when the physical reality of a certain landscape and the beholder's consciousness with concepts of landscape meet, thereby creating a physical experience charged with value.

Finally, the view we emphasise here is that analysis of landscape experience and the value (economic or socio-cultural) of landscapes and landscape experiences have an important democratic element when based on the preferences of the people who are the "experiencers", rather than primarily on views of experts or planners. This is an important principle of welfare economics, ${ }^{17}$ and the underlying motivation for investigating what the literature more specifically says about people's preferences (see Chapter 4). Before this review, we attempt in the next section to interpret the role of landscapes and landscape experiences with the framework of ES.

\subsection{What do we mean by "cultural ecosystem services"?}

Man benefits in a multitude of ways from ecosystems. Collectively, these benefits are known as ES. The ES concept was popularized by the Millennium Ecosystem Assessment (2005), which grouped ecosystem services into four broad categories:

\footnotetext{
${ }^{16}$ Privately owned land in other countries may of course always be viewed from a public access / view point, even if there is no right to roam. But entering such landscapes for more direct experiences will not generally be as easy as in the Nordic countries.

${ }^{17}$ I.e. sometimes termed "consumer sovereignty". However, as also noted above, when the preferences of people run counter to ecological risks and realities (e.g. risk of ecosystem collapse, irreversible losses of landscape qualities, large loss of biodiversity etc.), these preferences should clearly not be the only information that should count in making decisions. Even so, it is often difficult in practice, and a slippery slope, to decide (how? when? by whom?) under which circumstances the preferences of the general population should be "set aside" due to other concerns (that may also typically be disputed).
} 
- Provisioning, such as the production of food and water.

- Regulating, such as the control of climate and disease.

- Cultural, such as spiritual and recreational benefits.

- Supporting, normally seen as services that are necessary for the production of all other services.

In this set-up, landscape experience is a form in which ecosystems/nature brings benefit to man and would fall within the category "cultural ES". We discuss this category in detail below.

\subsubsection{The technical definition and classification of cultural ecosystem services}

The Common International Classification of Ecosystem Services (CICES) system, develops the MA classification further, and defines four main groups (types) of cultural ES subdivided into eleven classes (CICES 2013). ${ }^{18}$

- A. Physical and experiential interactions:

- Experiential use of plants, animals and land-/seascapes in different environmental settings, such as in-situ whale and bird watching, snorkelling, diving etc.

- Physical use of land-/seascapes in different environmental settings, such as walking, hiking, climbing, boating, leisure fishing (angling) and leisure hunting.

- B. Intellectual and representative interactions:

- Scientific, such as subject matter for research both on location and via other media.

- Educational, such as subject matter for research both on location and via other media.

- Heritage, cultural, such as historic records, cultural heritage e.g. preserved in water bodies and soils.

- Entertainment, such as ex-situ viewing/experience of natural world through different media. 
- Aesthetic, such as sense of place, artistic representations of nature.

- C. Spiritual and/or emblematic:

- Symbolic, such as emblematic plants and animals e.g. national symbols such as American eagle, British rose, Welsh daffodil.

- Sacred and/or religious, such as spiritual, ritual identity e.g. "dream paths" of native Australians, holy places; sacred plants and animals and their parts.

- D. Other cultural outputs: ${ }^{19}$

- Existence, such as enjoyment provided by wild species, wilderness, ecosystems, land-/seascapes.

- Bequest, such as willingness to preserve plants, animals, ecosystems, land-/seascapes for the experience and use of future generations; moral/ethical perspective or belief.

It is clear that landscapes may be important in the production of most of, if not all, of the above cultural service sub-categories. However, note that these services are by definition flowing from the biotic environment (i.e. living organisms/systems). In addition, abiotic factors such as rock formations and mountains are also very important for landscape experiences (and other benefits people derive from natural systems). These are then not formally considered ES. For our purposes here, this distinction is not central, as we aim to assess people's preferences for landscapes and landscape experiences, and separating biotic and abiotic factors in this process is not helpful or even possible.

Finally, note that the ES classification above is a way of structuring the combined benefits humans derive from nature, i.e. an anthropocentric approach. It is not aimed to be a "reductionist" approach, in that other concerns (e.g. the intrinsic value of nature) may also be valid parts of a comprehensive information basis for public decision-making.

The full CICES-mapping of cultural ES is shown in Annex II.

${ }^{19}$ These services are closely related to what economists term "non-use" values (see discussion in chapter 2.2.2 above). 


\subsubsection{Four main cultural service categories - a more concrete typology}

In a much-cited paper, Daniel et al. (2012) attempt to better define and integrate cultural ES into the ES framework. Their attempt can be seen as a more concrete and operational typology than the one by CICES above. They define four main types of cultural services and carry out a review of the literature that explicitly link ecological structures and functions with cultural values and benefits. The four main service categories are: outdoor recreation, aesthetics, cultural heritage and spiritual significance. While these four groups do not cover all aspects of cultural ES, they may be considered main types and we will draw on them as such in the following. ${ }^{20}$

\section{Outdoor recreation}

Many people engage in some form of outdoor recreation and recreational activities such as walking, camping, and nature study, which offers an opportunity for many people to experience the benefits of ES directly. This applies particularly to people living in urban environments, where contact with natural or semi-natural ecosystems often is limited. In the field of conservation biology, recreation and tourism have been recognized mostly as a threat to ecosystems (e.g. via wildlife disturbance and habitat fragmentation), and negative offsite effects are commonly attributed to traffic emissions and infrastructure developments. However, recreation and tourism also provide many important benefits, such as physical exercise, aesthetic experiences, intellectual stimulation, inspiration, and other contributions to physical and psychological well-being.

Daniel et al. (2012: 3-4) note that numerous studies have shown that even short exposure to green spaces can have positive effects on human health and that public green spaces are also important venues for promoting physical activities that improve health. One survey of visitors to urban/sub-urban parks in nine Swedish cities, found that psychological well-being was positively correlated with the species richness and habitat diversity in the park (Grahn and Stigsdottir 2010).

\footnotetext{
${ }^{20}$ In the following, our description of these four categories paraphrases the description provided in Daniel et al. (2012).
} 


\section{Aesthetics}

Aesthetics are consistently included as an example of cultural ES, but more specific operational definitions to guide assessments are rarely provided. The Millennium Ecosystem Assessment refers to the "beauty or aesthetic value in various aspects of ecosystems, as reflected in the support for parks, 'scenic drives', and the selection of housing locations". Conceptualizations often emphasize visual landscape aesthetics, especially scenic beauty.

Daniel et al. (2012) note that in general, landscape aesthetic models best fit the ES concept when the landscape-characteristic variables are selected to provide a bridge to the underlying ecosystem processes and conditions. Studies have, for instance, shown that timber harvest practices affect judgements of beauty for north-western US forest vistas (Ribe 2005); perceived beauty increased as the percentage of green trees in cut areas increased, so long as retained trees were evenly dispersed rather than clumped in small groups.

\section{Cultural heritage}

Natural or semi-natural features of the environment are often associated with the identity of an individual, a community or a society. The provide experiences shared across generations, as well as settings for communal interactions important to cultural ties. Cultural heritage is usually defined as the legacy of biophysical features, physical artefacts, and intangible attributes of a group or society that are inherited from past generations, maintained in the present, and bestowed for the benefit of future generations (cf. also footnote 3). Both tangible and intangible aspects are relevant to cultural heritage as ES, including visible material representations on the landscape (e.g., rice paddies, viticulture terraces) as well as landscapes and individual species that are linked to intangible heritage, including myths, legends, and religious practises that refer to concrete locations and ecosystem features.

Daniel et al. (2012) note that although it is often difficult to measure cultural heritage values in ES assessments, there are many examples of specific cultural landscapes acquiring cultural significance (e.g. the classic pastoral landscapes of England, terraced landscapes in Portugal or the Alps, or heath lands in Northern Europe). In some cases, the cultural landscape, as well as the products derived from it, may represent a whole region and act as an important trademark for touristic offers and product marketing (e.g. the Champagne region in France, Tuscany in Italy, Napa Valley in the United Sates, the Darjeeling region in India). Non-market economic valuation techniques have been successfully applied to cultural heritage objects (Navrud and Ready 2002), but valua- 
tions of aspects such as regional identity or sense of place remain largely elusive. As different cultures may have different heritage associations with the same ecosystem features, understanding cultural heritage as an ES requires simultaneous consideration of both the ecological and cultural contexts.

\section{Spiritual and religious significance}

Spiritual and religious significance of ES is included in the Millennium Ecosystem Assessments, and both nature conservation practitioners and diverse religions groups have tried to strengthen the link between religion and environmental stewardship (see for instance Wild and McCleod 2008). Assigning spiritual or religious significance to certain areas or species occurs in most societies, but how this significance is expressed varies across and within societies. Sacred areas are often marked by religious symbols (e.g. crosses or prayer flags on mountain summits, shrines along pilgrimage routes), their spatial extent may vary from a few trees to a mountain range, and boundaries may not be fixed. Sacred sites may attract tourism, which may coincide or conflict with the religious or spiritual use of these sites, as observed at the heavily visited pilgrimage route to Santiago de Compostela in Spain. In Scandinavia, it is a common for urban populations to link recreational activities along the coast (Denmark) or in the mountains (Norway) with a spiritual dimension of "reconnecting" with nature (Vacher 2011, Ween and Abram 2012).

Daniel et al. (2012) notes that spiritual and religious services do not generalize well across communities, and they are difficult to value in monetary (economic) terms. In chapter 4 we will draw on various methods used to measure values of cultural ES as referred by Daniel et al. (2012), when assessing values related to landscape experience.

\section{Critique of Daniel et al. - can cultural values be linked to physical and biological attributes?}

Note that after the publication by Daniel et al. (2012) Kirchhoff (2012) wrote a letter where he argued that cultural values of nature cannot be integrated into the ES framework, illustrated by the statement that "the sense of a poem results from a meaningful arrangement of words and not from a pattern of ink on the paper". Daniel et al. (2012) disagreed in principle that cultural values where disconnected from ecological and physical structures/attributes and argued that whether there are such links (and how strong they are) is an empirical question. They maintained, and we agree with that view here, "that a landscape's cultural value depends on an area's unique character as understood by relevant 
residents or users is consistent with research on landscape aesthetics and place attachment". But, as also admitted by Daniel et al., we agree that there is still much to learn about such linkages, and that there may be elements of cultural value that cannot easily be captured by mere physical measures of landscape features.

\subsection{Landscape experience as a cultural ecosystem service}

Different studies have tried to relate "landscape experience" or similar concepts to ES. An important question when considering "landscape experience" as an ES is whether to introduce it as a new and distinct cultural ES in its own right or to consider landscape experience as an element (factor) in the "production" of a range of other services.

An example of the first approach is the UK study (Research Box et al. 2009) using focus groups, which identified the following cultural services to be related to landscape experience; leisure and activity (recreation), learning (education), inspiration (stimulus), a sense of place (identity, feeling of home), a sense of history (heritage), calm (relaxation, tranquillity), escapism (getting away from it all), and sense of spirituality (feeling of being part of something greater than man). We here see that the four main types of cultural services highlighted by Daniel et al. (2012) are supplemented with more psychological services (calm, escapism), to constitute a range of benefits under the heading landscape experience.

The second approach focuses on identifying the landscape experience element in the generally accepted list of cultural ES. A good example of this approach is de Groot et al. (2010), which have presented a list of the main cultural ES involving landscape, and also provided indicators for this landscape element (ref. table 3.1 below). De Groot et al. (2010) list six main categories of cultural ES involving landscape:

- Recreational: opportunities for tourism and recreational activities.

- Aesthetic: appreciation of natural scenery (other than through deliberate recreational activities).

- Education and science: opportunities for formal and informal education and training.

- Inspiration for culture, art, design. 
- Cultural heritage and identity: sense of place and belonging.

- Spiritual and religious inspiration.

These cultural ES categories are close to both the typology presented by CICES and by Daniel et al. (2012). Both de Groot et al. (2010) and Daniel et al. (2012) discuss indicators and ways to measure the flows of ES in general and landscape elements in particular. We will follow their approach in Chapter 4.

\subsection{Conclusions and operationalisation of landscape experience as an ecosystem service}

\subsubsection{Scientific traditions - benefits for people emphasized here}

Landscape experience is a complicated concept. It is grounded in a physical reality constituted by one's surroundings, and arises and is conditioned by the human consciousness. There is thus both a physical and a socio-psychological aspect to the landscape experience. As we have seen above, the scientific traditions related to the two different aspects tend to deal with landscape in different ways. The natural science tradition has focused on physical mapping of landscapes, and landscape ecologists and architects have analysed landscapes more from an "expert" assessment of aesthetical beauty or ecological value of landscapes independent of humans. The economic and sociological traditions bring in the anthropocentric view, where the preferences of people, and the myriad of ways different groups experience landscapes, are centre stage. While the natural science perspective is important, the remainder of this report look particularly into the landscape preferences of the general population.

\subsubsection{Narrowing the scope}

The definition of landscape in the Landscape Convention is very wide, as it includes experience of landscape at any scale and in any type of surrounding. As discussed in the introduction (Chapter 2) for practical purposes, we will narrow down and specify the forms of landscape experience we will look at here. Firstly, we will mainly consider natural and semi-natural landscapes and not urban landscapes. This is also justified by the nature of the ES concept; it is about services provided by nature 
and an urban landscape can be totally devoid of natural elements. Secondly, we will not focus on the cultural (built) heritage aspect of landscape experience, as this element is treated in depth in a parallel study to this one financed by the Nordic Council of Ministers.

\subsubsection{Landscape experience as ecosystem service - when is the landscape element important?}

First of all it must be noted that considering landscape experience as a form of ES is not something that replaces other existing methods for valuing landscape. Rather, the ES approach provides an additional perspective and a systematic way to structure the human benefits and values that may not be incorporated by other approaches.

As noted in chapter 3.4, an important question when considering "landscape experience" as ES, is whether to consider landscape experience as an element in the "production" of a range of other services, or whether to introduce it as a new and distinct cultural ES in its own right. We have chosen to stick with the established categories of cultural ES and use "landscape experience" as a concept that serves to highlight the importance of the landscape element across these categories. This makes it easier to draw on experiences and methodological development related to quantification of benefits from such services. (However, a challenge does arise when/if one is to isolate the effect of the landscape element.) Methods are described further in chapter 4.

In table 3.1 below, we have tried to show how "landscape experience" is an element in the different cultural ES and highlight how it typically will tend to be a more important element in some than in others. Of course, the significance of the "landscape experience" in assessment of a certain cultural ES will vary on a case-by-case basis. We consider especially the "aesthetic appreciation" and "cultural heritage and identity" categories as having a very close relation with the underlying landscape qualities, as indicated by the dark green colour in the table. 
Table 3.1: Tentative assessment of the relation between different cultural ecosystem services and landscape experience (list of ES based on de Groot et al. 2010)

\begin{tabular}{|c|c|c|}
\hline $\begin{array}{l}\text { Cultural ecosystem } \\
\text { service }\end{array}$ & Relation to landscape experience & $\begin{array}{l}\text { Degree of } \\
\text { relation/overlap }\end{array}$ \\
\hline $\begin{array}{l}\text { Recreation through } \\
\text { activities in natural } \\
\text { surroundings }\end{array}$ & $\begin{array}{l}\text { This ES partly overlaps with landscape experience, as land- } \\
\text { scape experience is often but not always part of recreational } \\
\text { activities. In hiking, sensory and emotional landscape experi- } \\
\text { ence is an integral part to the activity. In other cases, such as } \\
\text { the jogger listening to music while running in the forest, } \\
\text { sensory and emotional landscape experience is only to a } \\
\text { limited degree integrated in the recreational service. }\end{array}$ & $\begin{array}{l}\text { Large degree of } \\
\text { overlap in some } \\
\text { cases, less in } \\
\text { others. }\end{array}$ \\
\hline $\begin{array}{l}\text { Aesthetic apprecia- } \\
\text { tion of natural } \\
\text { surroundings }\end{array}$ & $\begin{array}{l}\text { This ES largely overlaps with sensory and emotional land- } \\
\text { scape experience (perhaps especially sensory), and historical- } \\
\text { ly the concept of "landscape" is closely associated with } \\
\text { aesthetics. Aesthetic appreciation may, however, also be of } \\
\text { individual ecological elements. }\end{array}$ & $\begin{array}{l}\text { Large degree of } \\
\text { overlap. }\end{array}$ \\
\hline $\begin{array}{l}\text { Education and } \\
\text { science }\end{array}$ & $\begin{array}{l}\text { This ES partly overlaps with landscape experience, as land- } \\
\text { scape experience in many cases provide input for formal and } \\
\text { informal education and training as well as scientific research. } \\
\text { However, ecological processes or elements provide input for } \\
\text { education and science in many ways besides landscape } \\
\text { experience, for instance through education and research } \\
\text { related to biology on species or micro-level. }\end{array}$ & $\begin{array}{l}\text { Large degree of } \\
\text { overlap in some } \\
\text { cases, less in } \\
\text { others. }\end{array}$ \\
\hline $\begin{array}{l}\text { Inspiration for } \\
\text { culture, art, design }\end{array}$ & $\begin{array}{l}\text { This ES partly overlaps with landscape experience, as } \\
\text { landscape experience often serves as inspiration for crea- } \\
\text { tive processes (the most obvious example being painting). } \\
\text { However, ecological processes or elements provide inspira- } \\
\text { tion in many ways besides landscape experience, for } \\
\text { instance through art or design mimicking natural forms on } \\
\text { species level. }\end{array}$ & $\begin{array}{l}\text { Large degree of } \\
\text { overlap in some } \\
\text { cases, less in } \\
\text { others. }\end{array}$ \\
\hline $\begin{array}{l}\text { Cultural heritage and } \\
\text { identity; sense of } \\
\text { place and belonging }\end{array}$ & $\begin{array}{l}\text { This ES largely overlaps with sensory and emotional land- } \\
\text { scape experience (perhaps especially emotional). Landscapes } \\
\text { embody cultural heritage and constitute the physical context } \\
\text { within which people live their everyday lives. }\end{array}$ & $\begin{array}{l}\text { Large degree of } \\
\text { overlap. }\end{array}$ \\
\hline $\begin{array}{l}\text { Spiritual and reli- } \\
\text { gious inspiration }\end{array}$ & $\begin{array}{l}\text { This ES partly overlaps with landscape experience, as land- } \\
\text { scape experience in many cases (but not always) provide } \\
\text { spiritual or religious inspiration. In certain traditions, such as } \\
\text { the Sami culture, certain landscapes carry religious meanings. } \\
\text { In modern, secular society many people also express nature } \\
\text { and certain types of landscape experience as spiritually } \\
\text { rejuvenating. }\end{array}$ & $\begin{array}{l}\text { Large degree of } \\
\text { overlap in some } \\
\text { cases, less in } \\
\text { others. }\end{array}$ \\
\hline
\end{tabular}

\subsubsection{Justification and the role of the ecosystem service perspective}

One could ask whether there is any added value in trying to integrate "landscape experience" in the ES model, or whether it just complicates the analysis without adding any benefit.

As pointed about by de Groot et al. (2010), seeing "landscape experience" as an ES highlights that landscape or nature conservation strategies do not necessarily pose a trade-off between "environment" and 
"development" and that investments in sustainable use of ecosystems can generate substantial ecological, social and economic benefits at the same time. Better understanding of landscape experience as a form of ES, could allow for more optimal land use planning integrating ecological, social and economic benefits. As such, combining landscape elements with the (cultural) ES approach may bring in a more systematic way to analyse the human benefits of better landscape management.

It would seem to us that applying "landscape experience" as a distinct element in the ES model is justified by the importance given to the landscape concept in policy and planning. Using an ES approach opens up for new ways to assess and demonstrate benefits of natural elements related to landscape experience, thereby contributing to a better integration of such benefits in policy development and planning. In a way, the purpose of this study is to investigate the extent to which this is the case.

As we have seen in this chapter there is a certain divide between how the natural science on the one hand and the economic and sociopsychological traditions deal with landscape and landscape experience. In order to fully operationalize the landscape concept as it has been defined in the Convention, these two traditions need to become better integrated so that we use methods that include physical as well as sociopsychological characteristics and values of landscape. The ES perspective is anthropocentric, utility-oriented and uses the language of economics. Applying an ES perspective can possibly contribute to developing a more integrated approach to landscape assessment and management. In the next chapter we will look at how people's landscape preferences can be and have been assessed and valued in research studies from the Nordic countries. 



\section{People's preferences for landscape experiences - methods, values and illustrations}

\subsection{Introduction}

This chapter first discusses ways to measure and illustrate cultural ES and the extent and magnitude of landscape experiences as part of these services, as well as the "toolbox" of methods in different fields of the literature to measure and value landscape experiences.

We then provide a review of important literature that either surveys people's landscape preferences without using monetary measures of value, or derive monetary values of landscape change from revealed or stated preference methods from environmental economics (cf. explanation in chapter 3.2.2). This literature review does not, as noted in chapter 2 , aim to be comprehensive or to cover all countries equally well. We draw on examples of important studies and use illustrations from all the Nordic countries. We then discuss in chapter 4.5 some specific illustrations and examples (using available data and statistics) of the magnitude of important landscape experiences in the Nordics. Chapter 4.6 summarises key points.

Hence, the main objectives of the chapter are to:

- Briefly present indicators and methods that can be used to measure and illustrate people's landscape preferences.

- Present an illustrate some practical studies from the literature on the (monetary and non-monetary) assessment of people's preferences for landscapes and landscape experiences and draw out some lessons of relevance for current practices (Chapter 5).

- Illustrate some of the variety and magnitude of important landscape experiences, within the cultural ES categories we have discussed. 
We acknowledge at the outset that it is difficult to arrive at some overarching theory or unified empirical basis for how people value landscapes that then can be followed more or less directly by decisionmakers. As discussed in chapter 3, this would probably be overambitious, or not even desirable (in cases for example where people underestimate ecological thresholds, biodiversity or other ES with less directly experienced utility, such as carbon sequestration etc.). It is also often difficult to pinpoint the role of landscape characteristics for the cultural ES that people value directly or indirectly. This is both a theoretical challenge and a challenge in measurement.

Our motivation and ambition here is only that, even if it is a challenge, increasing our knowledge of people's landscape preferences and values, can still contribute to better decision-making if it is taken into account. Moreover, applying an ES framework contributes a way to map services and values of landscape experience in a systematic manner.

\subsection{How can we illustrate and measure people's landscape preferences?}

\subsubsection{Indicators of landscape experiences as a cultural ecosystem service}

In order to go from the concept of cultural ES, and the role of landscape elements, indicators to measure the services are required. The ES literature is still a bit immature in this area (see e.g. Hernández-Morcillo et al. 2013), so we have to use what we can find, even rough proxy indicators, that may help us to illustrate the landscape dimension in particular. De Groot et al. (2010), discussed in Chapter 3, outline potential indicators for each of the cultural service categories for determining (sustainable) use of landscape as a provider of ES, as shown in Table 4.1 below. The cultural ES (left column) are associated with functions in the landscape (second column) and indicators of how much of the services are present (third column). The last column provides examples of how much of the service can be used sustainably. For example, the number of tourists along a scenic route can say something about the magnitude of the aesthetic service of the landscape. Number of school classes visiting a particular landscape site may be another example illustrating the educational experience of that landscape. We return to more specific examples in Chapter 4.5 below. 
Table 4.1: Potential indicators for determining (sustainable) use of landscape as cultural ecosystem service

\begin{tabular}{|c|c|c|c|}
\hline $\begin{array}{l}\text { Cultural ecosystem } \\
\text { service }\end{array}$ & $\begin{array}{l}\text { Functions: Ecological } \\
\text { process and/or compo- } \\
\text { nent providing the } \\
\text { service (or influencing its } \\
\text { availability) }\end{array}$ & $\begin{array}{l}\text { State indicator } \\
\text { (how much of the } \\
\text { service is present) }\end{array}$ & $\begin{array}{l}\text { Performance indicator } \\
\text { (how much can be used } \\
\text { /provided in a sustaina- } \\
\text { ble way) }\end{array}$ \\
\hline $\begin{array}{l}\text { Recreational: opportu- } \\
\text { nities for tourism and } \\
\text { recreational activities }\end{array}$ & $\begin{array}{l}\text { Landscape features. } \\
\text { Attractive wildlife. }\end{array}$ & $\begin{array}{l}\text { Number/area of land- } \\
\text { scape and wildlife } \\
\text { features with stated } \\
\text { recreational value }\end{array}$ & $\begin{array}{l}\text { Maximum sustainable } \\
\text { number of people and } \\
\text { facilities. } \\
\text { Actual use. }\end{array}$ \\
\hline $\begin{array}{l}\text { Aesthetic: appreciation } \\
\text { of natural scenery } \\
\text { (other than through } \\
\text { deliberate recreational } \\
\text { activities) }\end{array}$ & $\begin{array}{l}\text { Aesthetic quality of the } \\
\text { landscape, based on e.g. } \\
\text { structural diversity, } \\
\text { "greenness", tranquillity. }\end{array}$ & $\begin{array}{l}\text { Number/area of land- } \\
\text { scape features with } \\
\text { stated appreciation }\end{array}$ & $\begin{array}{l}\text { Expressed aesthetic } \\
\text { value, e.g.: Number of } \\
\text { houses bordering natural } \\
\text { areas, number of users } \\
\text { for scenic routes etc. }\end{array}$ \\
\hline $\begin{array}{l}\text { Education and science: } \\
\text { opportunities for } \\
\text { formal and informal } \\
\text { education and training }\end{array}$ & $\begin{array}{l}\text { Landscape features with } \\
\text { special educational and } \\
\text { scientific value/interest. }\end{array}$ & $\begin{array}{l}\text { Presence of landscape } \\
\text { features with special } \\
\text { educational and scien- } \\
\text { tific value/interest }\end{array}$ & $\begin{array}{l}\text { Number of school classes } \\
\text { visiting. } \\
\text { Number of scientific } \\
\text { studies etc. }\end{array}$ \\
\hline $\begin{array}{l}\text { Inspiration for culture, } \\
\text { art, design }\end{array}$ & $\begin{array}{l}\text { Landscape features or } \\
\text { species with inspirational } \\
\text { value to human arts etc. }\end{array}$ & $\begin{array}{l}\text { Number/area of land- } \\
\text { scape features or } \\
\text { species with inspira- } \\
\text { tional value }\end{array}$ & $\begin{array}{l}\text { Number of books, } \\
\text { paintings, etc. using } \\
\text { ecosystems as inspira- } \\
\text { tion }\end{array}$ \\
\hline $\begin{array}{l}\text { Cultural heritage and } \\
\text { identity: sense of place } \\
\text { and belonging }\end{array}$ & $\begin{array}{l}\text { Culturally important } \\
\text { landscape features or } \\
\text { species }\end{array}$ & $\begin{array}{l}\text { Number/area of cultur- } \\
\text { ally important land- } \\
\text { scape features or } \\
\text { species }\end{array}$ & $\begin{array}{l}\text { Number of people } \\
\text { "using" forests for } \\
\text { cultural heritage and } \\
\text { identity }\end{array}$ \\
\hline $\begin{array}{l}\text { Spiritual and religious } \\
\text { inspiration }\end{array}$ & $\begin{array}{l}\text { Landscape features or } \\
\text { species with spiritual and } \\
\text { religious value. }\end{array}$ & $\begin{array}{l}\text { Presence of landscape } \\
\text { features or species with } \\
\text { spiritual value }\end{array}$ & $\begin{array}{l}\text { Number of people who } \\
\text { attach spiritual or } \\
\text { religious significance to } \\
\text { ecosystems. }\end{array}$ \\
\hline
\end{tabular}

Source: de Groot et al. (2010: 263).

\subsubsection{Methods of measuring landscape preferences and values}

Daniel et al. (2012) discusses different methods that can measure the importance (monetary and non-monetary value) of cultural ES, depending on the relevance of observable physical and biological characteristics of the underlying natural capital (or "ecological structures and functions" which is the particular term they use). This is also relevant for our specific discussion about landscapes here, and we go more into detail based on Figure 4.1 below.

Table 4.1 above presented some general indicators that illustrate the importance of landscape for cultural ES flows. To be more specific, we would ideally like to know more about people's preferences for physical or biological (or biotic and abiotic, as discussed in Chapter 3) 
characteristics of landscapes that are important for their experiences. For some service categories of experiences, such as recreational and aesthetic experiences, these elements are likely to be more directly connected and important for the value of landscape experiences than for other types of experiences (as also alluded to in our reference to Kirchhoff's critique of Daniel et al. in Chapter 3.3). Hence, this may be a useful way to classify experiences, and is the dimension on the vertical axis in Figure 4.1 below.

On the method-spectrum (horizontal axis in Figure 4.1), methods of measuring value of landscape experiences range from direct and indirect monetary valuation, non-monetary quantification and more qualitative description (to the far right in the figure).

Figure 4.1: Methods for assessing importance (value) of cultural ecosystem services and their relation to observable physical and biological characteristics of the landscape

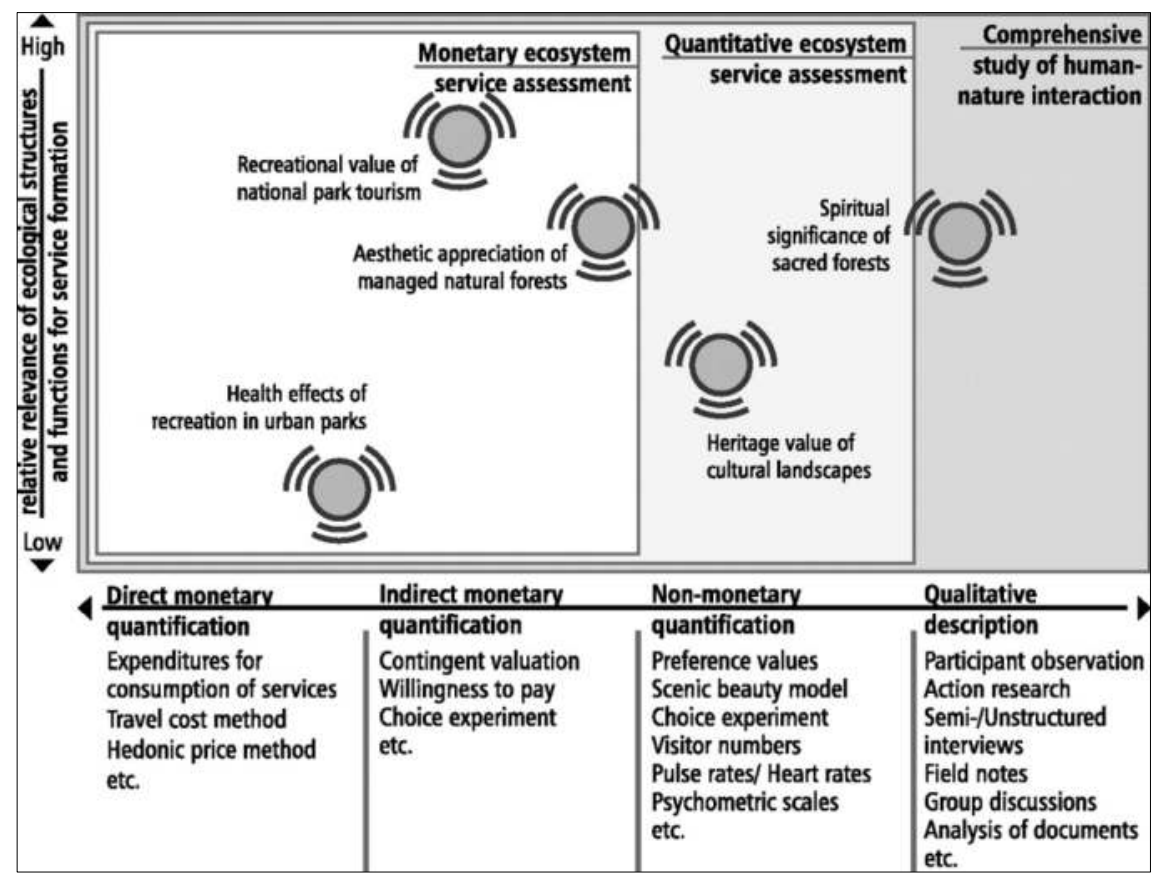

Source: Daniel et al. (2012).

The direct monetary valuation methods include a set of methods that are based on revealed preferences, i.e. how people behave and reveal values in actual markets (as briefly touched upon in Chapter 3.2.2). The travel cost method measures the economic value of recreation in a national park, for example, based on the visitor's incurred costs in time and out- 
lays expended in conducting their activity as a measure of the benefit they get. Hedonic pricing methods derive value of surrounding environmental characteristics (such as views, park features etc.) from the prices of houses and recreational homes. There are also a range of other methods that measures such experiences utilizing market behaviour and prices of products and services that can directly or indirectly be linked with landscape experiences.

The indirect valuation methods utilize surveys where people state their preferences in a hypothetical setting, usually deriving their willingness to pay to achieve a landscape gain or avoid a loss of landscape benefits. This can either be done directly through asking willingness to pay (contingent valuation method - CVM) or indirectly by characterizing the landscape or experience with different quality attributes (e.g. degree of openness, tree or other vegetation cover, views etc.) that could take different values/scores. Including a cost of management to achieve higher scores on one or more attributes and letting respondents choose a series of such choice questions would reveal their marginal trade-off between attributes and costs incurred. A forest landscape could for example consist of more or less trees, deciduous or coniferous species, more or less clearings, light, lakes and constructed facilities such as benches, tracks etc. This type of method is called choice experiment (CE), which together with contingent valuation are the most common indirect monetary valuation methods. While the contingent valuation method typically value landscape (change) as a whole, choice experiments assume that people may be able to value the component parts of a landscape. The former is perhaps closer to how people normally view landscapes, i.e. as a holistic experience (Swanwick et al. 2007). The stated preference methods are the only ones that can capture non-use values, as value measurement is not based on tracing actual behaviour (i.e. use).

In addition to these valuation methods, it is possible to use benefit transfer methods (not mentioned explicitly in Figure 4.1). This approach assumes that values for an environmental asset determined by a valuation study in one place (or from many places, if more studies in the literature are used as basis) can be transferred and used in another place. This "other place" is typically an area called a "policy site", where there is need for benefit information, but no time or resources to carry out a primary valuation study. Whether this approach is advisable or not will among others depend on the decision context and the required precision in the benefit estimate compared for example to the cost in a costbenefit analysis (Lindhjem and Navrud 2008). The method has been 
used for landscape values in the past (Santos 2007), but it may be harder methodologically than for other environmental goods, due to the complexity of landscape values and especially because they tend to be very site specific (Ayala et al. 2014). We will return to the issue of benefit transfer and use in practice below.

The non-monetary valuation methods are a less clearly defined group of methods than the monetary valuation methods that have their origin in different disciplines and subjects including cultural geography, psychology, philosophy, sociology and anthropology, as well as professional areas, notably planning and landscape architecture (Swanwick 2009). Daniel et al. mention a few examples of methods in the figure above. A more thorough review of values and non-monetary methods is provided by Gómez-Baggethun et al. (2014).

One set of methods that are of particular interest to us, and that we review below, are the preference survey methods. These methods are similar to the indirect valuation methods in that they often use surveys, combined with photos (and sometimes 3D visualisations) to reveal people's preferences for different landscape characteristics. However, these studies obtain landscape preferences without investigating monetary values of changes in the landscape. The aim is typically to find out what kind of landscapes people like the most, as basis for ranking and prioritising different landscapes. Some of the current practices we review in Chapter 5 often include types of non-monetary and semi-qualitative valuation methods.

Finally, Daniel et al. (2012) mention a second type of non-monetary valuation method (to the far right of Figure 4.1), which is more based on qualitative description and assessment of the importance of the cultural ES within this category. We interpret this category widely, and use different illustrations of the magnitude and importance of landscape value in chapter 4.5.

In Figure 4.1, Daniel et al. (2012) have placed five examples of their main cultural ES types in relation to the methodological dimension and the relevance of landscape characteristics. They have included two on recreation to illustrate that while health effects of enjoying recreation in an urban park may be fairly independent of the physical characteristics of that park, the value of recreation in a national park may be very closely linked to observable features of the park landscape. Both experiences are depicted in the area of the figure where monetary valuation methods may be used. Heritage and spiritual values are placed more to the right in the figure, (more) suitable for valuation by non-monetary methods. In the literature, there will of course be studies that also use non-monetary 
methods in the areas where monetary valuation would be possible, and perhaps also the other way around.

In the next two subsections we first review important examples of non-monetary (chapter 4.3) and monetary studies (chapter 4.4) of landscape preferences. Chapter 4.5 presents some quantitative and specific illustrations and examples (using available data and statistics) of the magnitude of important landscape experiences in the Nordics. This works as an illustration of people "voting with their feet", seeking specific landscape experiences.

\subsection{Non-monetary surveys of landscape preferences}

This section and the next look in particular at scientific studies that try to measure or assess people's expressed valuation (non-monetary or monetary) of landscapes and landscape experiences.

Research on the measurement of people's preferences for landscapes and landscape experiences has a relatively long history and has fallen in and out of favour in the last decades, as compared to expert judgment and other approaches to landscape analysis (Swanwick 2009). It is, however, still a flourishing research field in many countries. As indicated in section 3.2 above, the literature on people's preferences for landscapes and what characterises landscapes and experiences people enjoy and think are important (valuable), is diverse and includes many fields and professions. We do not aim to reflect the full complexity of this field, but rather try to draw out some points that may be relevant to consider when reviewing the current practices of landscape assessment in Chapter 5. Can we say anything more general than anecdotes and examples about what characterizes landscapes and experiences the majority of people prefer and value? We provide examples of non-monetary studies in this section first, and then go more into detail in chapter 4.4 where we review economic studies, a field that is more recent than the more general landscape preference studies. We through forest and agricultural landscapes first, and then cover some more general studies, for example related to types of landscape impacts. 


\subsubsection{Forest landscapes}

We review a selection of Nordic studies that investigate landscape preferences for different landscape types. We start with forest landscapes.

Many studies in the Nordic countries, especially in Norway, Finland and Sweden, have investigated people's preferences for different types of forest management and their experiences of the forest landscape. Forest cover is high and forests are important in people's view of national landscapes in these three countries (as also shown by the Google images in chapter 5.2). These preference studies show that forest management practices may be highly important for the enjoyment of recreation experiences. This large, non-economic, literature attempts to measure people's preferences for aesthetic aspects of the forests through surveys using pictures and other visualization techniques. This research is relevant for assessing the quality of forest landscape experiences, not just the quantity (magnitude) of such experiences, as discussed in chapter 4.5. It provides an important basis for deciding appropriate forest management practices in areas where the quality of recreation is important. The research demonstrates that people's preferences may be both in conflict and in tune with practices that prioritise forestry vs. for example biodiversity protection. We present some main findings from this literature here. The next subchapter will present some of the economic research in this area.

Frivold and Gundersen (2009) and Gundersen and Frivold (2008) have investigated 55 published, quantitative surveys in Norway, Sweden and Finland about people's preferences for forest attributes, forest landscapes and management. The results are interesting, and can be summed up in the following main points:

1. Natural clearings in the forest, such as lakes, marshland and other treeless areas are experienced as more positive than clearings caused by clear felling.

2. Clearings in the forest related to traditional farming are seen as positive. Traditional cultural landscapes and traces of past (old) uses provide a richer experience for many people.

3. Forests with views are highly preferred.

4. Many recreationists prefer views further into and through the forest (i.e. dense forests are not preferred).

5. Hikers prefer to walk in scattered rather than dense young forests.

6. The general population like the forest more if there are more old trees. 
7. Folk tend to like a forest of diverse age, which creates variety (though this preference may be in conflict with the wish for a view).

8. Elements of deciduous trees in the conifer forest are seen as very positive. There are, however, diverse opinions of preferred tree species. These preferences are influenced by factors such as clearings, age composition, light/views and the tree species that people are used to.

9. Dead trees in the forest are seen as negative by most people (as they contribute to "untidiness" and inaccessibility), at least as long as they don't know about the importance of such trees for biodiversity.

10. Large, recent clear fellings are considered negative by most forest visitors. If trees are left standing (for example for seeds) this gives a less negative impression. This is also the case if the clearing provides wider views.

11. Closed felling of the type that gives a more heterogeneous forest structure than industrial clear felling and other modern practices, usually do not give negative reactions.

12. The majority is against the use of chemicals etc.

13. Management and thinning of young trees increase the view and accessibility and is accepted by the public as long as the visible residue is limited.

14. Most people state that they prefer to walk on paths that are not well prepared, but in practice they typically use the forest roads more often.

15. Highly visible traces and signs of transport of timber in the terrain are seen as negative.

16. People with a forestry background appreciate "textbook" forest management more than other groups.

As can be seen from many of these points, people prefer "sensitive" forest management, rather than "heavy-handed" clear felling and industrial forest management. They have a preference for "naturalness" of the forest landscape, but at the same time also enjoy management that provides them with more light and views, better access and lower amount of dead trees and "untidiness" than a natural, untouched forest would provide. In other words, forest landscapes completely left untouched are unlikely to provide higher value landscape experiences in general (when the whole population is considered) than multifunctional forestry that 
takes people's preferences into account. This is also the case when considering agricultural landscapes that are reclaimed naturally by forests (as is the case in many Nordic countries where agricultural areas are scaled back, see below). It is also clear, that other impacts in the forest landscape, such as power lines, are seen as negative, in the same way as wheel tracks from timber transport and other "high impact" intrusions.

As Gundersen and Frivold (2008) point out, however, it makes sense to interpret the results in light of the forest condition people are used to, i.e. mostly industrial forestry. Hence, preferences are clearly shaped by the physical conditions in the areas people come from. Interestingly, they point out that preferences seem quite stable over time, and they do not point out any differences between preferences of Fins, Norwegians and Swedes. These preferences are likely to be similar. Emmelin et al. $(2005)^{21}$ confirming this result refer to a series of studies in Finland that demonstrate that preferences for forest landscapes are fairly homogenous and that classification of landscapes for users could be based on this in a planning context. ${ }^{22}$

The forest landscapes in Denmark (and Iceland) are different than in Norway, Sweden and Finland. Jensen and Koch (1997) compare results of two nationally representative surveys from 1977/78 and 1993/94 on preferences for how forests are managed and kept. Respondents received 14 randomly selected black and white photos out of 52 photos in $1977 / 78$ and 64 photos in 1993/94 (The same 52 photos from the $1977 / 78$ survey were also included in the 1993/94 survey). Respondents were asked to rank these according to the criteria of which forest environment they would most prefer when visiting a forest. The photos were grouped in two blocks and respondents made the ranking within each block (photos in the two blocks were in differently coloured envelopes). Each block represented one theme and photos in a block were similar except from the theme that was being ranked. The purpose of this was to allow for an internal comparison and keep other aspects constant. In addition to photos, each respondent was also asked to assess seven impacts out of 100 randomly selected verbally described impacts. Combining the ranking of the photos and the verbal impacts,

\footnotetext{
${ }^{21}$ They refer to a study by Sivenän and Karjalainen (1994), but this reference is not included in the reference list of Emmelin et al. (2005).

22 There is also a literature, especially in Finland, which uses non-monetary methods to analyse trade-offs between different goods and services from forest landscapes. The most commonly used method is multi-criteria analysis, see e.g. Myllivita et al. (2011) and Leskinen et al. (2009). We do not go into this literature here, among others because the methodological tradition is not consistent with principles of welfare economics.
} 
Jensen and Koch (1997) find that average preferences in the population for forest landscapes were as follows:

1. A lake and a water course are also very popular landscape elements in forests and more popular than bogs. Bogs in turn are preferred to agricultural land within a forest.

2. A varied forest is considered more positive than a homogenous forest. This is indicated e.g. through a preference for old beach growth with self-seeded trees than an old growth beach forest without self-seedlings, or silver fir with higher birch trees are preferred to only silver fir.

3. Broadleaf forest becomes more popular as it ages. Also, broadleaf forests are more popular than coniferous forests, a trend that has increased between the two surveys. This is similar to the results discussed for Finland, Sweden and Norway above (although it is unlikely that people would prefer all conifers to be replaced by broadleafs).

4. Natural growth forests are not considered as the perfect site for recreation. Also, people prefer to see no veteran trees in beach woods and brushwood lowers the ranking. At least as long as they don't know about the importance for biodiversity. This is the same as noted by Gundersen and Frivold (2008) and Frivold and Gundersen (2009) above.

5. Small parking lots are preferred to large along with natural paths with a minimum of specialisation (for joggers, horse rides and bikes). Infrastructure that is "natural" in a forest (e.g. a bridge over a watercourse, a bench or a shelter) is clearly preferred to nonforest like infrastructures (e.g. playground with swings, a toilet etc.).

6. Information about the reasons why an arrangement has been made increases the probability that it is accepted. This trend increased between the two surveys. In the survey this was indicated by the different rankings of pictures of natural growth forest where pictures that were labelled natural growth forest were higher ranked than pictures without a label. The same was the case with photos of jogger pathways.

7. People prefer signposts to guided tours and exhibitions. Also leaflets containing maps and tours are very popular, even if they need to be paid for. 
8. People dislike mechanisation of the forest along with the use of chemicals.

9. People prefer selective thinnings and thinnings that are made in rows. Also smaller clear fellings after some years are considered positively.

10. "Silence" was ranked the highest among the verbal assessment. People do really not like to encounter large outdoor events, especially when these are foreign to forests or disturbing. Also people dislike disturbances from vehicles in forests, mountain bikers, areas for dogs to roam free, loud music and to encounter tents or a caravan.

Interestingly, despite the quite different physical conditions (and amount) of forests in Denmark compared to Norway, Finland and Sweden, there are elements of preference similarity. The liking for deciduous trees, views and clearings and water, for example, illustrate this. There is also higher acceptability when information is provided about the reasons for a type of management practice or arrangement (e.g. that old, dead trees are important for biodiversity).

\subsubsection{Agricultural landscapes}

Agricultural landscapes are by some thought of as the quintessential landscape, where the natural elements blend with obvious human influence and history. There are quite a few studies surveying what kinds of agricultural landscapes (sometimes mixed in with forest patches and other vegetation) people like the most. We mention a few examples here.

In a much-cited study from Norway, Dramstad et al. (2006) investigates preferences for agricultural landscapes among (non-local) students of environmental subjects and the local population in Østfold and Akershus counties south of Oslo, using a fairly standard methodology from the landscape preference literature. The study therefore represents a typical example from this literature. They used spatial metrics to categorise and map the landscape, and pictures and images to visualize for the respondents, especially different views and degrees of openness in the landscape (se Figure 4.2). Landscape metrics included the total area of what they call "the viewshed", number of different land types present, number of land type patches, total length of patch edges, area of open land types, grain size of the open landscape, landscape heterogeneity and land type diversity measured as Shannon's diversity index. The main photos are shown in Figure 4.2. Photograph (a) received the lowest 
average preference score from the locals group and photograph (b) received the highest average preference score from this group. Photograph (c) received the lowest average preference score from the student group, while photo (d) received the highest average preference score from this group. Photograph (e) is an example of a viewshed containing water, while photograph (f) shows the most open viewshed. Photographs (g) and $(\mathrm{h})$ were those over which there was greatest disagreement between students and locals; (g) was ranked number four for the students (i.e., fourth most preferred) and number 17 for the locals, (h) was ranked number 21 by the students and number 10 by the locals.

Figure 3.2: Photos tested in the study by Dramstad et al. (2006)

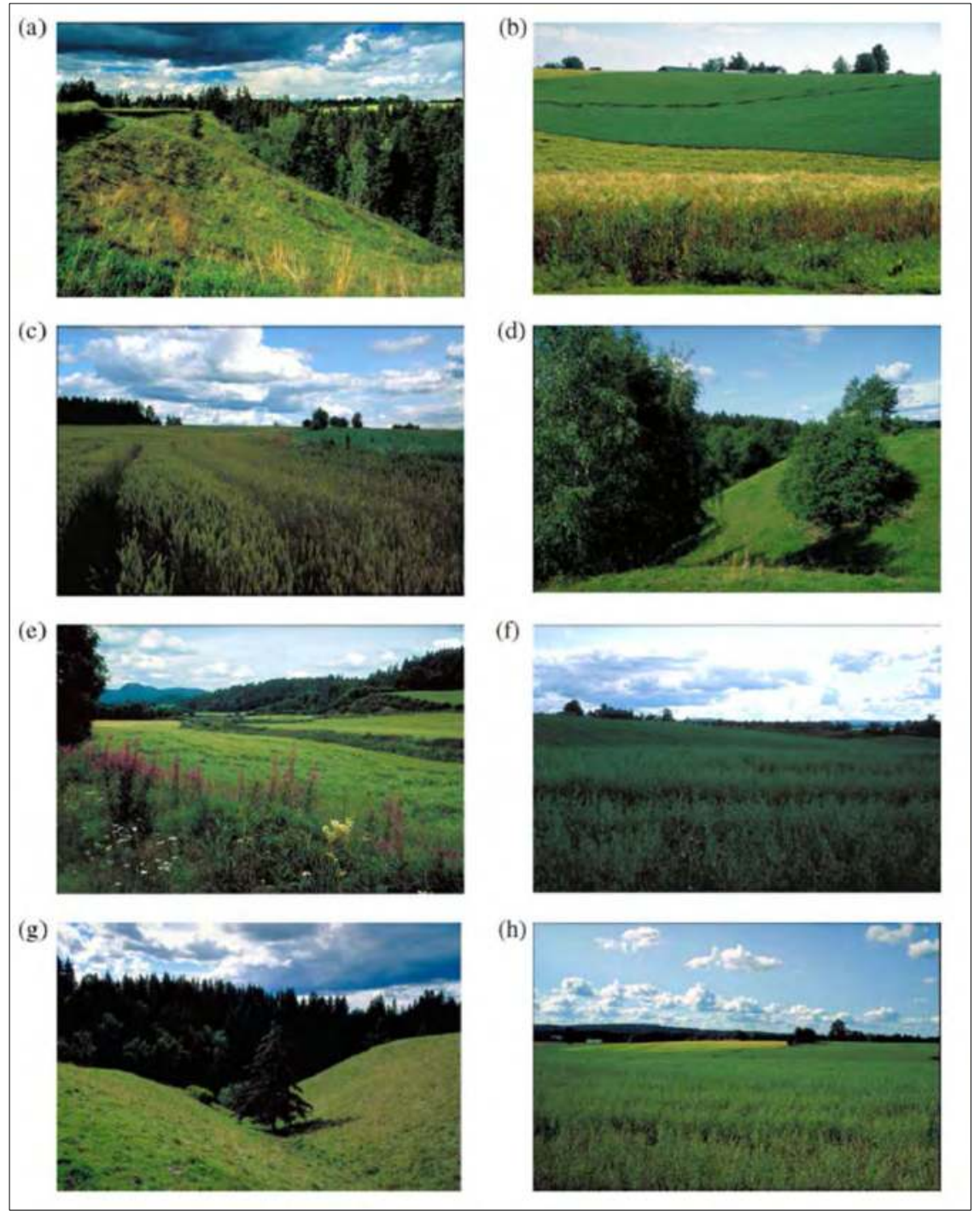


Dramstad et al. (2006) found significant positive correlations between preferences and spatial metrics used for landscape mapping, including number of land types, number of patches and land type diversity. In addition, preference scores were high where water was present within the mapped image area, even if the water itself was not visible in the images. When the dataset was split into the two groups, the authors found no significant correlation between the preference scores of the students and locals, i.e. they were different. Whilst the student group preferred images portraying diverse and heterogeneous landscapes, neither diversity nor heterogeneity was correlated with the preference scores of the locals (see Figure 4.2). ${ }^{23}$ This illustrates that even if there may be common elements of preferences among the general population, there will also be heterogeneity between selected groups, as discussed in chapter 3.2.3.

Interestingly for our study, Dramstad et al. (2006) note that "highly subjective and expert approaches do not seem acceptable to policymakers or the general public and make it difficult to compare landscapes or quantify changes over time. This is particularly important if, as our study suggests, the trained experts (i.e. "the environmental students" 24 ) have different landscape preferences than local people. The present situation that excludes visual aspects of a landscape from consideration due to lack of methods, is not acceptable either. In this respect, we agree with the statement that "... indicators can distort priorities - those things which are being measured and reported are viewed as more important, while things which are less readily measured are omitted and given lower priority" (Detr 2000:6). Landscape aesthetics are among the issues less readily measured." Dramstad et al. (2006) therefore advocate the development of indicators that can be used to measure aesthetics, which then in turn can be used as basis or reflection of people's preferences in policy considerations.

\footnotetext{
23 Tveit (2009) conducts a similar study in 2009, which confirms that there are differences between students and the general public regarding preferences for percentage open land in the view and the size of the "landscape room".

${ }^{24}$ Our addition.
} 
Building on the work by Dramstad et al. (2006) and others a series of studies by Swedish and Norwegian researchers, for example Ode et al. (2008; 2009; 2010), have tested indicators of visual and aesthetic representation of landscapes. They conclude that different data sources complement each other and that applying indicators using various data sources, when available, will enhance the comprehensiveness of visual landscape assessment.

A much-debated topic in Norway is the rapid change of the agricultural landscape due to natural regrowth of former pastures and fields with forests. The reasons for this change is the gradual closing of traditional farms coupled with climate change. People, and especially tourists to Norway, tend to dislike that agricultural landscapes are reclaimed by forests - even if it is a natural process (Bryn et al. 2012). But on the other hand, they also strongly dislike landscapes with elements of modern agricultural practices (Kaltenborn and Bjerke 2002).

A recent application from Sweden illustrates that the cultural dimension may be very important when evaluating agricultural landscape preferences (see Figure 4.3 and Table 4.2) (Kumm pers. comm. 2014). ${ }^{21}$ The study used a web-based survey to the adult Swedish population in the summer of 2014. It asked which landscape the respondent would prefer based on his or her needs in terms of living environment or recreation. The four photos in Figure 4.3 where compared, and Table 4.2 shows the results. Almost half of the sample preferred the third photo where birch trees are planted and cows are grazing. The natural regrowth photo came second. The least preferred was the field without animals. Hence, people prefer both animals and some vegetation, but the vegetation should be "tidy". This is similar to some results from the forest landscape literature, where many people do not like old-growth forests that have a large amount of dead wood on the ground and "messiness". On the other hand, dense planting is not preferred either. So in this case, the scattered birch trees (though planted) seemed pleasing. This ranking order was highly robust to age, gender and the size of the city/village where respondents lived (large, medium, rural/small). 
Figure 4.3: Drawings of four agricultural landscapes in Sweden as basis for preference surveying

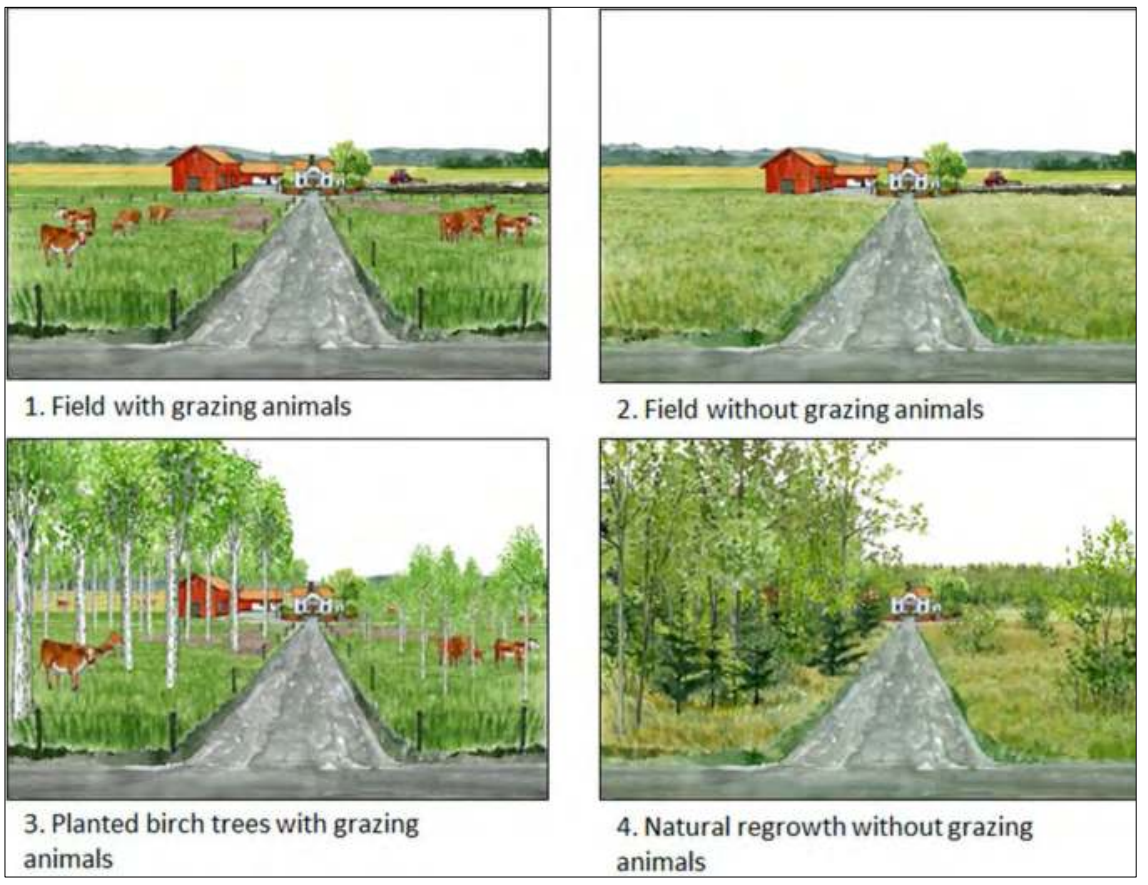

Source: K.I. Kumm pers.comm. ${ }^{25}$

Table 4.2: Preference ranking (1 to 4 ) of four agricultural landscapes in Sweden

\begin{tabular}{lccccc}
\hline Landscape & First best & Second best & Third best & Last & Mean \\
\hline $\begin{array}{l}\text { 3. Planted birch trees } \\
\text { with grazing animals }\end{array}$ & $49 \%$ & $29 \%$ & $16 \%$ & $6 \%$ & 1.8 \\
$\begin{array}{l}\text { 4. Natural regrowth } \\
\text { without grazing animal }\end{array}$ & $23 \%$ & $20 \%$ & $21 \%$ & $37 \%$ & 2.7 \\
$\begin{array}{l}\text { 1.Field with grazing } \\
\text { animals }\end{array}$ & $19 \%$ & $36 \%$ & $30 \%$ & $15 \%$ & 2.4 \\
$\begin{array}{l}\text { 2. Field without grazing } \\
\text { animals }\end{array}$ & $10 \%$ & $15 \%$ & $33 \%$ & $42 \%$ & 3.1 \\
\hline
\end{tabular}

Source: K.I. Kumm pers.comm.

From Denmark, Jensen and Koch (1997) included in their national surveys 1977/78 and 1993/94 of forest landscape preferences (discussed in the section above) some questions relating to agricultural landscapes. Results show that Danish people prefer fields with livestock to corn

${ }^{25}$ See also the following link: http://www.lantbruk.com/debatt/populart-med-nya-hagar-pa-gamla-akrar and an older study at: http://www.vaxteko.nu/html/sll/slu/fakta_ekonomi/FEK95-02/FEK95-02.HTM 
fields. Pasture is as popular as old growth beach wood, which is one the most popular forest landscape types.

While the landscape preference studies often find some heterogeneity of expressed preferences in response to pictures, graphics, drawings etc., as also discussed in the sociological literature in chapter 3.2.3., there also seems to be some commonality among the preferences, such as liking for openness, light/views, variety / diversity, animals and presence of water of various kinds. And in some cases, the cultural aspect and what people are used to (for example from childhood) may be important determinants. Intrusive and technical, non-natural elements are also typically disliked among most people.

\subsubsection{Other Nordic and European studies}

\section{Other Nordic studies - the concept of naturalness or purism}

One concept which is much studied in the landscape preference literatures is "naturalness" or "purism". These concepts aim to capture how close a landscape is to a perceived natural state (Ode et al. 2009) and can be measured with different types of scales (Vistad and Vorkinn 2012). Studies using this construct show that it can be measured and related to people's preferences. It may be useful for separating management strategies according to different user groups. Emmelin et al. (2005), a research update for the Swedish Environmental Protection Agency, for example, note that some users may be happy with a low "purism" score, if they are more used to conditions that are not untouched or have some degree of human impact. Other groups may react very negatively to similar landscapes (who may be the same people who prefer old-growth forests without forestry activities, as discussed above). Hence, and as also noted by Emmelin et al. 2005, the "average recreationist" may not be a useful concept in some situations, as some degree of diversification of management strategies according to user groups will give higher total value of landscape experiences (i.e. and welfare in economic terms) than aiming to please the average recreationist.

\section{Survey of preferences for agrarian landscapes from many European countries}

We mention one interesting international study that also includes some studies from the Nordics. A recent meta-analysis of surveys of stated preferences for agrarian landscapes across Europe (van Zanten et al. 2014) examine whether there are generic landscape preferences across Europe for particular types of landscape attributes. Taking 51 studies 
covering 345 cases in 14 countries, including Norway, Sweden and Finland among the Nordic countries, they compared preferences for particular landscape attributes. By using relative preferences, the authors aimed to better reflect the relative importance and value of a particular type of landscape attributes in a particular landscape context. An initial categorisation of attributes was as follows: One group of cases referred to direct anthropogenic influences in agrarian landscapes such as irrigation, farm stewardship, field margins and livestock; a second group covered attributes that describe landscape structure (predominantly agricultural landscape, mosaic landscape, dominance of nature areas or forests), a third group was related to land cover composition (green and grey linear elements, historic buildings and point elements), while a fourth group gathered biophysical features (presence of water and hills or mountains).

The meta-analysis found cross-case generic preferences for attributes that describe historic buildings in the landscape, mosaic land cover and the presence of livestock in the landscape. Mosaic landscapes and to a lesser extent landscapes with a dominance of nature or forest obtained higher preference scores than landscapes dominated by agriculture.

Interestingly, the study reveals that in peri-urban areas with a relatively dense population, people express higher preferences for landscapes associated with forest and natural land cover. The opposite is found in areas with a relatively small share of agricultural land cover, where preferences are higher for agricultural land cover. This is probably explained by the fact that marginal agricultural land cover in remote regions is appreciated for economic reasons and aesthetics (van Zanten et al. 2014).

The literature on landscape preferences gives us some general knowledge about what characterizes landscapes people prefer and that give them the most valuable landscape experiences. The economic studies go one step further and try to quantify the value of landscape changes (or attributes) in monetary terms. Some of these studies are carried out in forest and agricultural landscapes (or less commonly other landscapes such as mountains and seascapes) or focus particularly on visual intrusions such as wind farms, roads and power lines in different types of landscapes. We turn to this literature next. 


\subsection{Monetary valuation of landscape and landscape experiences}

The landscape preference literature usually compares different types of landscapes, where important attributes are measured by spatial metrics or other indicators, and visualised to respondents to elicit their preferences in a quantitative survey. The landscape economics literature, on the other hand, is not concerned with the "total value" or "preferences" for landscape types in general, but rather on the value people attach to changes in landscapes, due to some project or policy intervention. It is the economic value of this change compared to a baseline situation that economists attempt to measure through revealed and stated preference methods, and that typically could be used in cost-benefit analysis. Hence, if it is possible to derive economic values of landscape changes, these values are easier to utilize directly in decision-making contexts than the more diverse and rich information from non-monetary preference studies.

The monetary valuation studies also rely on measuring landscape qualities through different indicators (e.g. openness, number of old trees, presence of rivers and lakes etc.), but the use of such indicators differs depending on the economic valuation method. As noted in chapter 4.2 , the contingent valuation method attempts to value the total change in a landscape as perceived by respondents, rather than breaking the landscape qualities down into its separate components or attributes and measure the trade-offs between such individual components. The latter is commonly done through the choice experiment method. For the stated preference methods, it is usually assumed that people value the benefits (or loss of such) they think they can derive from a change in the landscape, rather than the physical landscape elements per se. Hence, it is the flow of ecosystem services that the respondents care most about and that are impacted the most by a landscape change that these studies value. However, most studies do not use the ES terminology in the description of landscape change, as this is a more recent concept. Note that, as discussed in chapter 3.2.2, a broad interpretation of "landscape experience" would include not just use value, but non-use value.

For the revealed preference methods (travel cost and hedonic pricing methods) it is also important to pin down the landscape amenity variables that determine people's demand and valuation of such qualities. For example, what kind of views and landscape qualities will yield higher prices in markets for houses and recreational homes located in such areas? Which qualities at a recreational site encourage people to travel 
further and incur higher expenses to experience the landscape? These travel costs are an expression of their (implicit) value of such qualities compared to more ordinary landscapes and landscape experiences. It is the experienced (rather than hypothetical) benefit of landscape elements (or changes in these) that is valued by the revealed preference methods. And the value consists of use value only.

People's willingness to pay for an improvement in landscape qualities (or avoid a negative change) represent their welfare gain, and in turn demonstrates the value they place on landscapes and the cultural ES they associate with the landscape change. If such values are high, it is an indication of the importance of such landscape experiences. And it is this benefit (or loss) that should be compared with the cost (or benefit) of a landscape change, to guide policy decisions (see further discussion in chapter 5).

We first present some national level estimates of economic value and then present examples of individual studies of forest and agricultural landscapes, and specific landscape impacts (such as roads, power lines, wind mills etc.). There are not many studies that attempt to assess the value of landscape change or impacts directly, ${ }^{26}$ but some studies use attributes of forest management, agricultural practices etc. to at least indirectly assess elements of importance for landscape experiences.

\subsubsection{National level valuation studies of recreation}

The most recent study in Denmark on the monetary valuation of recreation in different landscapes is a national study on visits to nature areas and large urban parks of 2,500 adults (Bjørner et al. 2014). This is the first time that large urban parks have been included in a national recreation valuation survey, likely due to the recognition that recreation patterns over the past 40 years increasingly show more visits in the vicinity to where people live. The survey applied the travel cost method using a so-called random utility framework with spatially explicit representation of recreation sites. The analysis includes more than 2,400 recreation sites of which 52 are urban parks; all in all representing some $17 \%$ of the total area in Denmark.

\footnotetext{
${ }^{26}$ See also the following link: http://www.lantbruk.com/debatt/populart-med-nya-hagar-pa-gamla-akrar and an older study at: http://www.vaxteko.nu/html/sll/slu/fakta_ekonomi/FEK95-02/FEK95-02.HTM
} 
The results of the valuation are shown in Figure 4.4 below as value of access to these sites per year and per hectare. The map shows a clear geographic pattern with the highest quartile of recreation values towards the east of Denmark and lower quartile towards the west of Denmark. This coincides with population density (i.e. accessibility). Also availability of substitution sites, site and population characteristics play important roles in value creation. The estimation of site preferences show a positive relationship with a number of site characteristics: size (at a marginal declining rate), the amount of pathways per hectare, proximity to the sea and coast, freshwater body at least covering $25 \%$ of the site and share of area that is part of the Natura 2000 network. Negative relationships between preferences and site characteristics include share of forest area that is privately owned and share of forest representing less than $25 \%$ of the site.

Among the highest quartile values, sites with a per hectare recreational value higher than 6,700 EUR (ca. 5\% of sites in this group) are almost all in vicinity to the larger cities and Copenhagen.

The average value of accessing a site and enjoying the recreational benefits of the site looking at both urban parks and sites in the countryside is at about 237,000 EUR (2013 prices). Taking the 52 urban parks alone, the average value is far higher: 2.3 million EUR and nature sites somewhat lower: 192,000 EUR. Taking these values and the model estimations of national visit numbers, Bjørner et al. (2014) arrive at a recreational value of 3.4 EUR/visit. This is low, but in the range of other recreation valuation studies. 


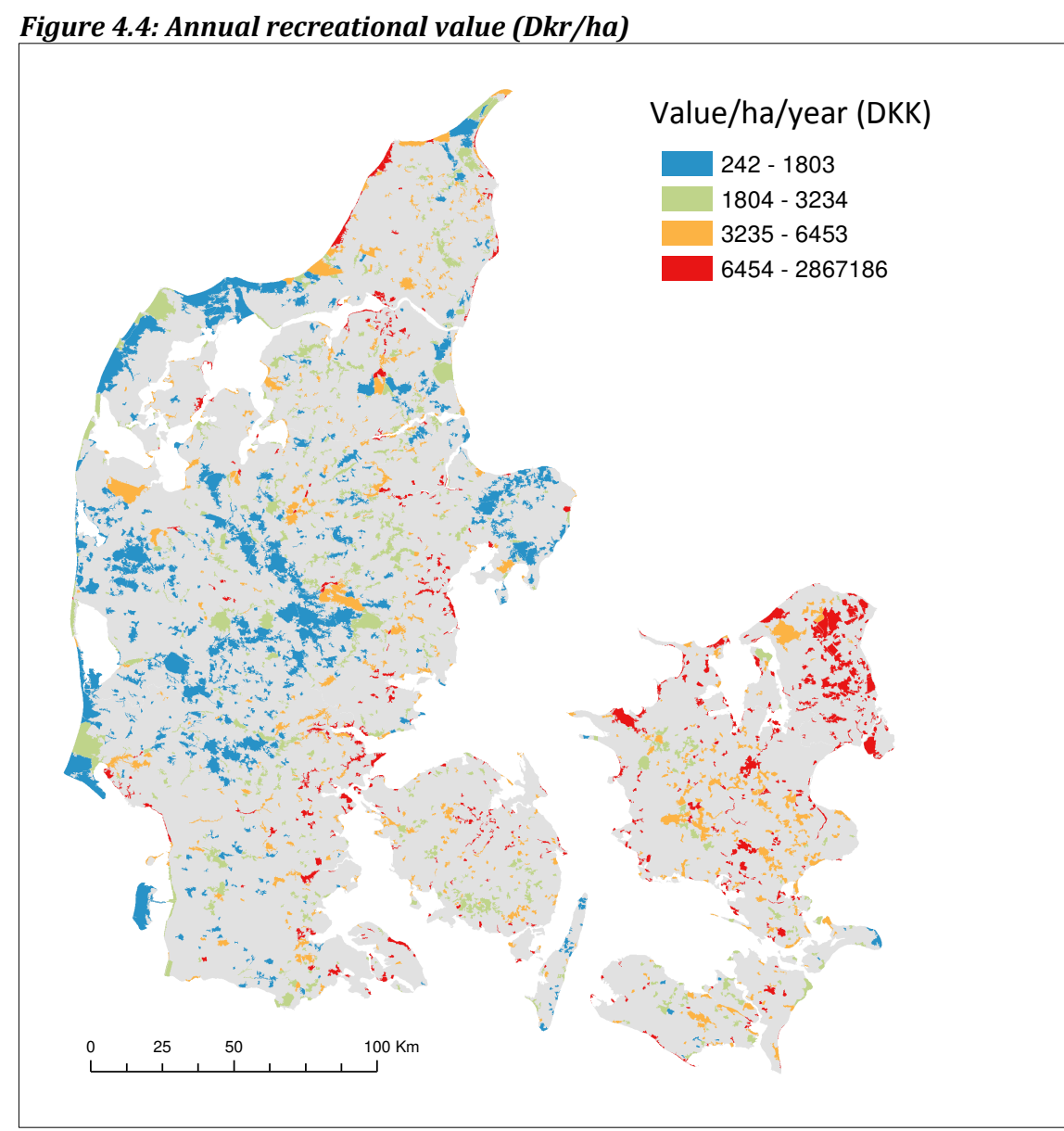

Note: Areas are divided into four equally large groups based on the value per hectare of each site. Source: Bjørner et al. (2014).

Fredman et al. (2008) estimates the economic value of recreation in Sweden for a number of main activities and landscapes, using a diverse set of methods. They estimate for example the experienced value of general recreation in forests at 200 SEK per day and person. Recreation in mountains is valued much higher at 1,760-3,500 SEK per visit per person, while recreation in agricultural landscapes is valued lower than forest recreation. In total, this amounts to more than 1 billion SEK per year in general recreation vales. Hunting and fishing, also important cultural ES, are valued at around 1-3 billion SEK per year. These estimates are consumer surpluses (benefit above costs incurred to conduct the activity) and give a rough indication of the magnitude of recreation in various landscapes in Sweden. The authors note that the knowledge basis for their calculations is thin because of few studies. 
In a study from Norway, Lindhjem and Magnussen (2012) estimate the economic value of forest recreation at NOK 10-20 billion per year, not considering recreational hunting and fishing. To our knowledge, there are no similar studies in Norway documenting the value of other landscape experiences, e.g. recreation in mountains or in agricultural landscapes.

These studies clearly show the potential magnitude and importance of landscape experiences for people's welfare, especially associated with recreation activities. Hence, changes in the landscape qualities that often are the basis for the attractiveness of these recreation activities, will have potentially large welfare impacts across a national population.

\subsubsection{Forest landscapes}

Similarly to the landscape preference literature, the economic landscape valuation literature in the Nordic countries seems to be dominated by studies of forestry practices that alter the forest landscape for users (and sometimes non-users). This is typical in Norway, Sweden and Finland, and can be explained by the relative importance of forestry in these three countries. In Denmark and Iceland forestry is much less important, though the emphasis of many Danish forest valuation studies is on reforestation and management for recreational use, primarily (the latter mentioned in the subchapter above). We summarise some of the forestry studies here. Lindhjem (2007) conducted a meta-analysis of Fennoscandian studies using primarily the contingent valuation method to assess people's willingness to pay (WTP) for forest and biodiversity protection and for multiple use forestry (i.e. different forest landscape preferences depending on the forestry practices). In table 4.3 we reproduce those of the studies that surveyed preferences for various types of multiple use forestry practices, as these include recreational benefits specifically. The table shows a fair number of studies from all three countries. The right column displays the range of the WTP to obtain a positive change in the forest landscape (or to avoid a negative change). WTP per household or individual is generally high, with some variation (depending on many factors that we do not go into here). 
Table 4.3: Stated preference valuation surveys of Fennoscandian forests, 1985-2005

\begin{tabular}{|c|c|c|c|c|c|c|}
\hline Main references & $\begin{array}{l}\text { Year of } \\
\text { survey }\end{array}$ & Good $^{a}$ & Gain/ loss ${ }^{b}$ & Survey mode & Scope ${ }^{c}$ & WTP (USD) ${ }^{d}$ \\
\hline \multicolumn{7}{|l|}{ Finland } \\
\hline Pouta $(2003,2004,2005)$ & 1998 & M & G & Mail & $\mathrm{N}$ & 287-299 \\
\hline Rekola \& Pouta (2005) & 1995 & M & G & Mail & L & 20 \\
\hline Horne et al. (2005)* & 1998 & $P, M$ & $\mathrm{G} / \mathrm{L}$ & Interv. & $\mathrm{L}$ & -16 \\
\hline \multicolumn{7}{|l|}{ Norway } \\
\hline Simensen \& Wind (1990) & 1989 & $P, M$ & G & Interv. & L & 21-159 \\
\hline Hoen \& Winther (1993) & 1990 & $P, M$ & G & Interv. & $\mathrm{N}$ & $14-65$ \\
\hline Sandsbråten (1997) & 1997 & $\mathrm{M}$ & L/G & Interv. & $\mathrm{L}$ & $43-45$ \\
\hline Skagestad (1996) & 1996 & $P, M$ & G & Interv. & $\mathrm{L}$ & 15 \\
\hline Hoen \& Veisten (1994) & 1992 & M & G & Interv. & L & 50 \\
\hline Hoen \& Veisten (1994) & 1993 & M & G & Interv. & $\mathrm{L}$ & 48 \\
\hline \multicolumn{7}{|l|}{ Sweden } \\
\hline Bostedt \& Mattson (1991) & 1991 & $\mathrm{M}, \mathrm{O}$ & $\mathrm{L}$ & Mail & $\mathrm{L}$ & 385 \\
\hline Mattson \& Li (1993) & 1991 & $\mathrm{M}, \mathrm{O}$ & $\mathrm{L}$ & Mail & $\mathrm{R}$ & 469-907 \\
\hline Mattson \& Li (1994) & 1992 & $\mathrm{M}, \mathrm{O}$ & L/G & Mail & $\mathrm{R}$ & $440-1280$ \\
\hline Bostedt \& Mattson (1995) & 1992 & $\mathrm{M}, \mathrm{O}$ & G & Mail & $\mathrm{L}$ & $78-84$ \\
\hline Fredman \& Emmelin (2001) & 1998 & $\mathrm{M}, \mathrm{O}$ & G & Mail & $\mathrm{R}$ & 92 \\
\hline
\end{tabular}

Notes:

$a=$ Good type: $\mathrm{P}=$ Forest protection, $\mathrm{M}=$ Multiple use forestry (MUF), $\mathrm{O}=$ Other (e.g. tourism WTP attributed to forests in an area)

$b=$ WTP for proposed improvement (gain) or to avoid a proposed negative change (loss)

$c=$ Geographical scope: National $(\mathrm{N})$, regional $(\mathrm{R})$, local $(\mathrm{L})$ forest good

$d=$ WTP estimates converted from NOK used in the meta-regression analysis to USD 2005 using

OECD Purchase Power Parity (PPP) and Norwegian Consumer Price Index (CPI). The WTP formats are given as reported (i.e. lump sum, per month, per household or individual, long-term annual etc), and are therefore not directly comparable.

* = This study, which uses a CE approach that is not directly comparable to CV, was judged too different from the other studies and taken out of the final meta-regression analysis. The WTP is negative here since people preferred open scenery (and less biodiversity) to a more closed forest (with more biodiversity).

A relatively old study from Norway in the meta-analysis, for example, Simensen and Wind (1990) investigate people's WTP to go from a forest landscape with moderate industrial forestry (Figure 4.5A) to a situation where the forest is under full protection (Figure 4.5B). This was one scenario, and the mean WTP in the study varied from USD 21 to 159 per household or individual for this change. 
Figure 4.5A: Moderate modern forestry

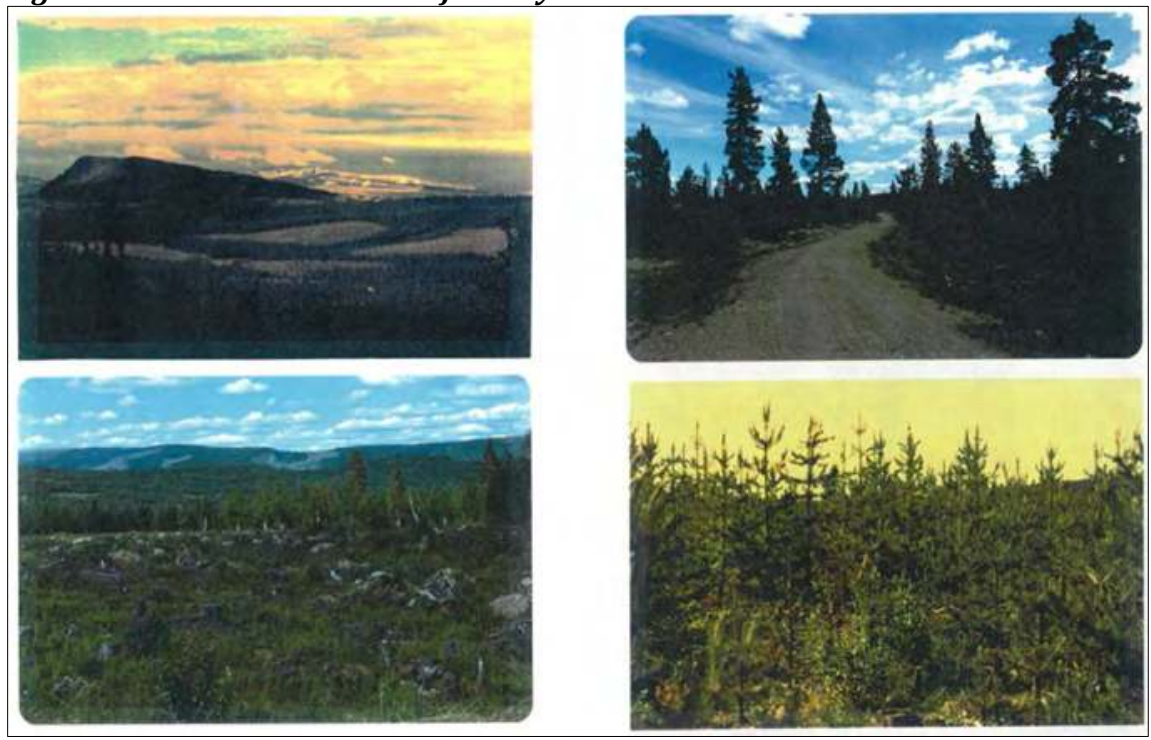

Source: Simensen and Wind (1990).

Figure 4.5B: Full protection of old growth forest

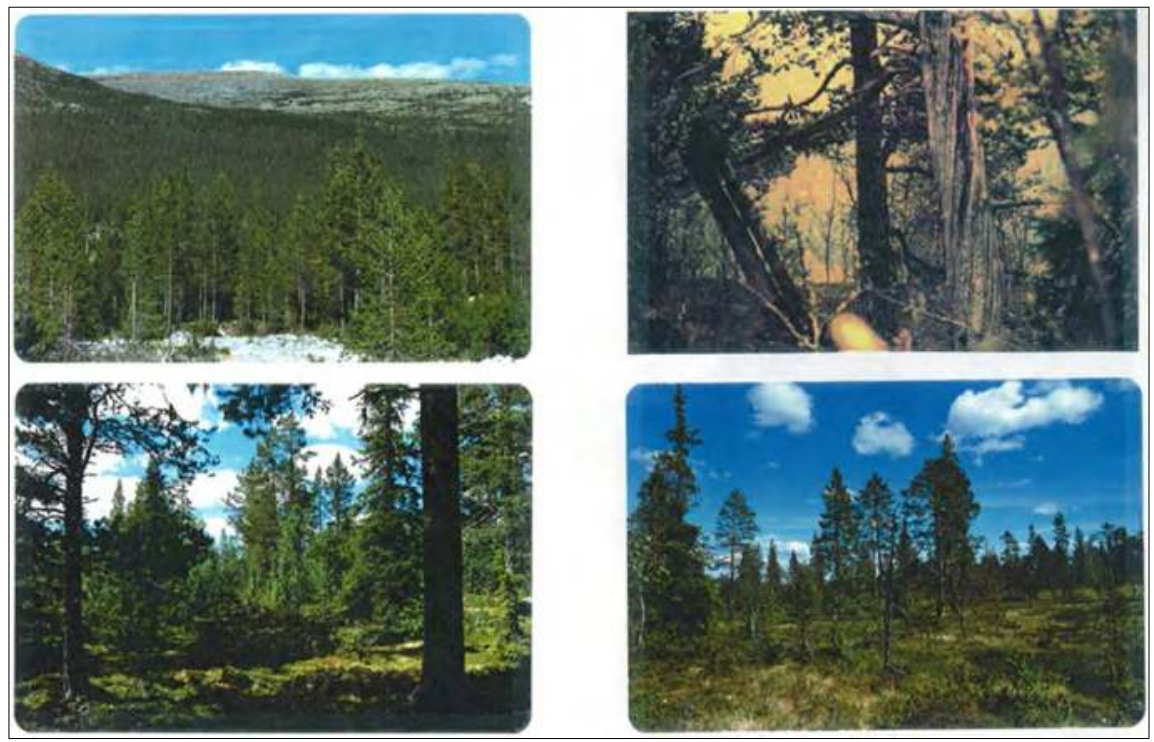

Source: Simensen and Wind (1990). 
Figure 4.6: Example of visual material from Swedish forest valuation study, where more landscape sensitive forestry practices are emphasized

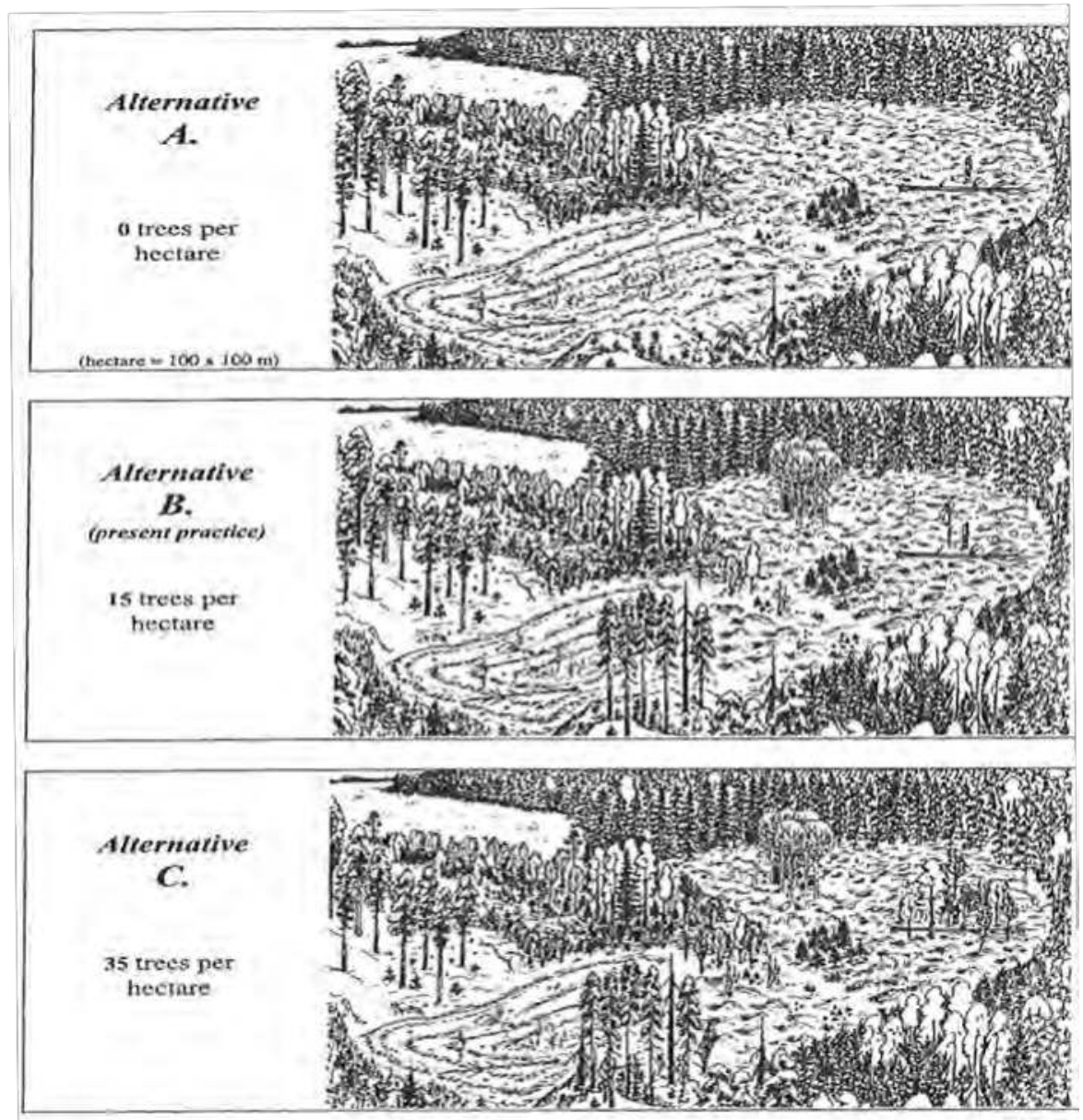

Source: Bostedt (1997). 


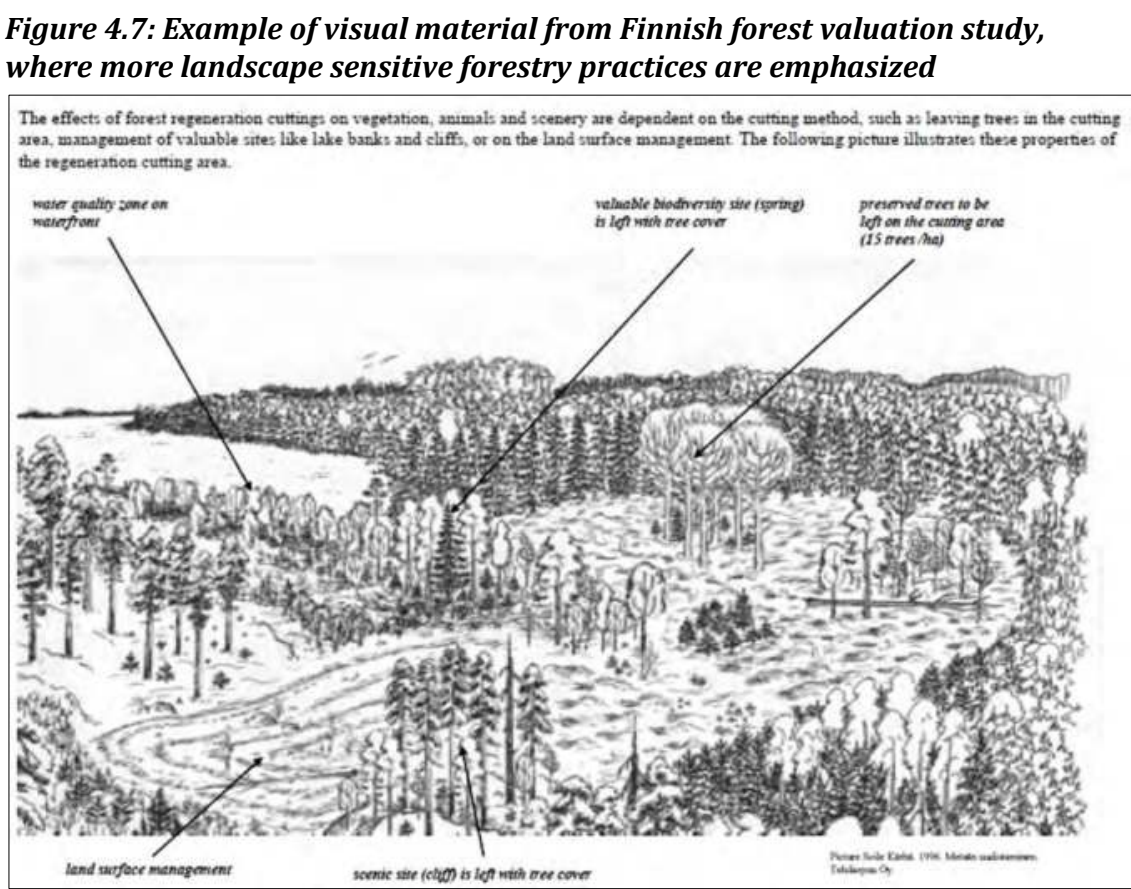

Source: Pouta (2003).

Figures 4.6 and 4.7 show examples of visual material from two other studies in the same vain, one from Finland and one from Sweden. There are also more recent studies, e.g. Normann et al. (2011) and Boman et al. (2008) from Sweden.

In Denmark, Termansen et al. (2013) model forest recreation values in a national study of a choice experiment and economic valuation based on the travel cost method. They model the value of access to woodlands larger than 10 ha under three different policy options: i) increasing the area of all existing forests by 10 ha; ii) increasing the proportion of broadleaved areas by 5\%; and iii) altering land uses adjacent to forested areas, increasing the boundaries with semi-natural vegetation by $5 \%$. Results show that parking facilities is an important attribute, which increases the likelihood of a site to be chosen. Larger forest sites have a higher probability of selection but with a declining marginal effect (i.e. the value to visitors of increasing the size of a relatively small site is larger than increasing a relatively large site by the same amount, which makes sense).

Sites close to the coast are found to be more popular than inland sites. Distance to marked nature trails was found to decrease the selection probability. Recreationists were found to prefer sites, which were adjacent to other semi-natural areas and undulating topography was also preferred 
to topographically flat areas. On average broadleaved areas are preferred to coniferous woodland, as also noted in chapter 4.3.1 above, however, a large variation of intensity exists for this preference parameter. The results suggest that $40 \%$ of the population do not favour broadleaves. The mean value of accessing a forest is estimated to be $3.76 \mathrm{EUR} /$ trip while increasing forest area by 10 ha per site would induce an increased value per trip of $0.48 \mathrm{EUR}$; increasing broadleaved area by $5 \%$ would increase welfare by $0.07 \mathrm{EUR} /$ trip and increasing the natural area around forests by $5 \%$ would mean a higher welfare of 0.60 EUR/trip. Hence, small adjustments in management practices that acknowledge the average preferences of recreationists yield a welfare gain.

The aim of this brief review is first to point out that there are several studies and tried and tested methods to evaluate the benefits for people of making landscape changes (positive or negative). Second, the value of avoiding negative changes or obtaining positive changes in forest landscapes in this case, for example for recreation, is often found to be relatively high. This indicates (again) that leaving such values out of decision-making, if that is the case, will severely bias forest management decisions.

\subsubsection{Agricultural landscapes}

The economic valuation literature is scarcer for agricultural landscapes, than for forest landscapes. In a pioneering study in a Nordic context Drake (1992) estimates the economic value of the agricultural landscape in Sweden. Using the contingent valuation method he estimated the Swedes' willingness to pay to preserve the agricultural landscape at about $541 \mathrm{SEK} /$ person and year or $975 \mathrm{SEK} /$ hectare and year. It was shown that WTP was significantly correlated with income, age (negatively), level of education and with positive attitudes towards preservation of the agricultural landscape. WTP per hectare differed due to land use and regional location.

Drake (1999), in a more recent context, explains that the main motivation for wishing to preserve the agricultural landscape was found in the survey to be nature conservation, followed by aesthetic, recreational and cultural-historic reasons. Landscape characteristics are without doubt welfare relevant in this study. The most important underlying factors for the WTP include water, biological and scenic variety, openness and, at least for rural areas also, type of activities. Under present conditions in the Swedish agricultural landscape, these underlying factors can all be seen, according to the author, as reflecting the demand for 
increased variability. Some open water in a terrestrial landscape increases variability just as well as an island does in a sea. Openness is less common than closeness in forest-dominated Sweden. Also, due to very low population density in rural Sweden and high labor productivity, various activities in the landscape are not very common but rather quite rare. This study lends support for the general economic result of diminishing marginal values of landscape experiences and activities.

In a more recent study from Sweden, Hasund et al. (2011) investigates preferences for agricultural land using the choice experiment method. They estimate WTP for 28 levels of 12 attributes (characteristics). Two survey versions concerned permanent grassland and two concerned field elements of cultivated land. A sample of 8,000 randomly selected Swedish inhabitants was used. The estimated values were found to vary significantly between linear field elements and grassland types, where stone walls and oak-wooded pastures, respectively, were found to have the highest marginal WTP. Highly valued environmental qualities are biodiversity, visibility and absence of brushwood.

The only Norwegian study that aims to value preservation of agricultural landscapes is, to our knowledge, Bergland (1998). In a national personal interview survey he used the contingent valuation method to assess people's WTP for changes in landscape elements. Only certain elements (such as streams, ravines, forest patches, etc.) of the landscape were manipulated into computer-generated photos. The results showed clearly that the most highly valued landscape elements were vegetation along the edges of the fields alone or in combination with streams. Other elements were less important. The WTP for vegetation on the edges was NOK 225 per household, for streams NOK 175. For the two in combination, the WTP was NOK 625. Fences along the paths were viewed negatively, at NOK 100 per household if removed.

We are not aware of specific Danish (or Icelandic) studies that value preferences for agricultural landscapes (but some that value negative impacts, see next section). From Finland, Grammatikopoulou et al. (2012) use a choice experiment approach to assess the value of certain attributes of the Finnish agricultural landscape. The data from a municipality-level case study in southern Finland revealed that the most valued attributes were the renovation of production buildings and the presence of grazing animals (similar to the example from Sweden referred in chapter 4.3.2). A statistical model indicated the existence of heterogeneous preferences regarding the landscape attributes, with attitude variables being significant determinants of heterogeneity. One in five of the respondents even perceived disutility from changing the level of land- 
scape attributes (i.e. which supports the status quo bias that many people when considering changes). Our findings have implications for integrating landscape planning in agri-environmental measures, such as supporting organic animal husbandry which guarantees the presence of animals outside in the agricultural landscape. This finding supports some of the studies we reviewed in chapter 4.3, where animals and active agriculture are important elements for landscape experiences. See Box 3.1 for details about this study.

\section{Box 3.1. Value of agricultural landscape management in Finland}

In planning landscape-related policy, such as agri-environmental measures, the European Landscape Convention emphasizes the need to account for the benefits that the population and various stakeholder groups obtain from the landscape. In this study, a choice experiment was employed to evaluate a program that provides certain landscape attributes in a typical agricultural area. The attributes of a local landscape program were the share of uncultivated fields, number of plant species in cultivation, existence of grazing animals in landscape, management of water protection zones and the condition of production buildings.

The study also tested the feasibility of a local landscape value trade scheme as a policy tool so as to provide landscape ecosystem services. The program was described as a local voluntary trade for landscape management in the NummenpääLepsämä river valley area (the area of the survey). Respondents were told that the residents would pay for the landscape services provided by the landowners contributing this way to increase landscape value and prevent landscape deterioration. Landowners, on the other hand, would provide landscape management if they perceived the compensation for their landscape services to be sufficient.

The case study area for conducting the survey was selected from Nurmijärvi Southern Finland such that the typical southern Finnish agricultural landscape was represented. The data were collected via a questionnaire survey in March 2008 which yielded 630 responses from both landowners and residents without land ownership.

The results showed that most valued attributes were the renovation of production buildings and the presence of grazing animals. Results on the importance of landscape characteristics revealed that in the agricultural landscape, the separate visible landscape elements such as grazing horses and cattle and the condition of production buildings were of particularly important. The average willingness to pay ranged from EUR 147.57 to EUR 227.52 for various levels of the landscape program directed to these attributes. Allowing heterogeneity of respondents' preferences provided a versatile picture of the landscape values. The four identified resident segments differed considerably from each other, but 
only one segment opposed landscape improvements while the remaining three segments attached a positive value to any change from the current state of the landscape. Although the segment of $21.07 \%$ opposing the management policies existed, the actual landscape changes would not cause compensation needs if participation in the policy was voluntary, as suggested in this study. However, the heterogeneity of preferences would still complicate the formulation of the content of the management policy, even on the local level.

The results demonstrated that the challenge for landscape value trade was mainly on the sellers' side. $43 \%$ of landowners (sellers) were negative towards participating in the landscape value trade. Those who were positive or indecisive towards the trade scheme particularly appreciated the idea of improving the landscape through a higher proportion of cultivated land, an attribute that was less important for local citizens, i.e. buyers. Landowners demanded compensation that exceeded the anticipated expenses, especially for attributes demanded by residents such as the renovation of production buildings and presence of grazing animals. The requirement for compensation exceeding the expenses of landscape improvements reveals the low personal benefits from such landscape measures.

The results do not encourage revision of the intensification of crop production as such. The results indicated high benefit-cost ratio for producing simple positive focal points such as the presence of animals as a landscape attraction and the avoidance of landscape damage due to ramshackle production buildings. Although the present study was a local case, its findings may apply in a broader context, in that it provided empirical results regarding preferences for the agricultural landscape attributes of a typical agricultural production landscape in Northeastern Europe. It demonstrated that the landscape is not a simple onedimensional public good, but the perceptions of this ecosystem service can vary greatly among population groups.

Source: Textbox reproduced from Kosenius et al. (2013). Source studies are Grammatikopoulou and Pouta (2013) and Grammatikopoulou et al. (2012).

\subsubsection{Studies on negative landscape impacts, such as power lines, roads and wind turbines}

One of the reasons why economists became interested in studying landscapes, as noted in chapter 3.2.2 was the increased degradation of them, especially from constructions such as power lines, roads, wind power facilities etc. We provide some examples of Nordic studies of such landscape impacts in the following. 
Navrud et al. (2008) compare the benefits of avoiding the negative aesthetic impacts of overhead power transmission lines as compared with underground cables in Norway. They use the contingent valuation method to estimate the external costs from these aesthetic impacts, and find that the social benefits of avoiding the negative impacts on the landscape exceed the costs of burying the lines as underground cables. Their best estimate of the aesthetic benefits from burying the power lines was three times as large as the cost. These conclusions were based only on an assessment of the aesthetic impacts. Impacts of overhead power lines on wildlife and human health would likely make burial of power lines even more attractive, according to the authors. These results were obtained in an urban setting; hence additional studies are needed to assess the costs associated with aesthetic impacts in rural and pristine natural areas. The study shows that power lines are viewed as a "visual intrusion" in the landscape, in a similar way as wheel tracks and other substantial marks of industrial forestry in the forest landscapes reviewed in chapter 4.3.1 above.

In another Norwegian study, Alsvik (2013) assesses the economic value (cost) of landscape impacts from road projects in a municipality in Norway (Nittedal). The study looks into three alternative road routings which have varying degree of negative landscape impacts. Using a web based contingent valuation survey she finds that WTP among potentially affected households is significantly positive for reducing the impacts. In this particular case, the inclusion of the landscape values did not change the ranking of the alternatives in terms of net present value. However, inclusion of such values adds to the completeness of cost and benefit assessment for making a good decision.

In a Danish study, Olsen (2009) investigates the public's willingness to pay in a choice experiment to avoid negative impacts on different types of landscapes by motorway construction. Three different landscape types of interest were identified and chosen as main attributes in the choice experiment design. The three attributes were "forest", "wetland", and "heath/pastoral area". The base case levels of the attributes were assigned on the basis of the area distribution of these landscape types in Denmark in general. Thus, the status quo alternative in the choice sets entailed $10 \mathrm{~km}$ of new motorway located through forest areas, $5 \mathrm{~km}$ through wetland areas, and $5 \mathrm{~km}$ through heath/pastoral area. The study showed significantly positive WTP to avoid landscape encroachment, with some degree of heterogeneity of preferences in relation to the landscape types. 
In addition to power lines and roads, other landscape impacts include the construction of wind farms, deeply unpopular, at least locally, in many countries. Typically, the "not in my back yard" (NIMBY) principle plays an important role, as people's objections are all the stronger if landscape intrusions are placed where they live. Off-shore wind farms when placed in the coastal zone may have negative effects on the seascape, particularly in the case where these wind farms are located close to areas with recreational activities in the coastal zone. In a study from Denmark, Ladenburg and Dubgaard (2007) look into the opportunity of placing wind farms offshore to reduce visual disamenities. They used the choice experiment method with a valuation scenario comprising the location of 720 offshore wind turbines (equivalent to $3600 \mathrm{MW}$ ) in farms at distances equal to: 12,18 or $50 \mathrm{~km}$ from the shore, relative to an $8 \mathrm{~km}$ baseline. Willingness to pay amounts were estimated as: 46, 96 and $122 \mathrm{EUR} /$ household/year for having the wind farms located at 12, 18 and $50 \mathrm{~km}$ from the coast as opposed to $8 \mathrm{~km}$. The results also reveal that WTP deviates significantly depending on the age of respondents and their experiences with offshore wind farms. Hence, visual impacts of wind farms are substantial if left along the coast where people can easily see (and hear) them.

In another paper from Denmark, Ladenburg and Dubgaard (2009) find that people who can see off-shore wind farms from their residence, anglers and recreational boaters significantly perceive the visual impacts to be more negative compared to people who do not use the coastal areas for those specific purposes. The same pattern is found for frequent beach visitors compared to less frequent beach visitors. Results indicate that specific users and frequent visitors of the coastal zone are willing to pay approximately twice as much to have future offshore wind farms moved further away from the coast, when compared to less frequent users and visitors.

A hedonic house pricing study, also from Denmark, by Termansen et al. (2012) find evidence of declining house prices with increasing proximity to on-land wind turbines. Results show welfare estimates to increase by between 200 DKK to 900 DKK per year per household when increasing the distance to wind turbines by 100 meters, depending on the distance to the wind turbine. Similar results are found in Jensen et al. (2014)

Although few if any comprehensive studies we are aware of from the other Nordic countries have valued visual disamenities from wind farms, the popular resistance towards these in the media and in public hearings, reflect that the economic values of reducing such effects likely are high also in the other Nordics. This is also the case for large power lines 
and other infrastructure projects that make substantial landscape impacts such as roads and power lines.

\subsubsection{Results from some international studies}

The literature that we have briefly reviewed on valuation of landscape preferences seems relatively limited in the Nordic countries compared to the US and some other European countries. We finalise chapter 4.4 by summarising some results from a few international studies.

In a survey of the North American literature on farmland valuation research, Bergstrom an Ready (2009) find relatively strong evidence that preferences and values are positively related to farmland acreage (i.e. size), regional farmland scarcity, alternative development intensity, public accessibility, and productivity (e.g., soil quality). They also found some evidence that preferences and values are positively related to human food plants, active farming, and negatively related to intensive (i.e. industrial) agriculture. With respect to socio-demographic variables, there is evidence that preferences and values are positively related to income, age, education, visiting open or green space in the past, and experiences with farms and farming. They also investigate and discuss whether people living in urban areas prefer agricultural land nearby or not, and to what extent farmland in some situations provide disamenities (smell, odour) and in other situations amenities that are valued (open and green space benefits). They do not conclude firmly on these points. They conclude that although much has been learned about farmland amenity values since the first farmland protection and amenity valuation studies in the 1980s, more qualitative and quantitative research is needed to understand better the effects of specific farmland attributes on preferences and values for farmland protection and amenities. Hence, the specific landscape attributes that matter are still not fully understood.

Santos (2007) reviews the international agricultural landscape valuation literature conducting a so-called meta-analysis for use in benefit transfer. By that time he identified 19 relevant studies, many from the $U K^{27}$ (also including some of the Nordic studies we reviewed above). The main aim of the study was to investigate precision in transferring esti-

${ }^{27}$ In the UK, monetary valuation of landscape impacts has been an interest of policy makers for some time, see for example the website noting some important, recent studies: http://archive.defra.gov.uk/corporate/policy/ guidance/env-impact/area/landscape/monetisation.htm 
mates from the literature to a relevant policy site. He generally finds fairly large transfer errors, indicating (as we also touched upon in chapter 4.2 ) that landscape values may be very site specific, so in some case conducting a primary study (if possible) may in many cases be the only option to get reliable estimates of values of landscape change.

Ayala et al. (2014) in a recent conference paper investigates the international literature for landscape values, more broadly than just agricultural landscapes. They identify studies covering landscape protection, views, impacts, aesthetics, rural, diversity, access, etc. While the studies they review are interesting and document the importance of landscape attributes for valuation, they conclude that it is difficult to use the literature for benefit transfer, probably much due to the site specificity of many of the landscape (attribute) values they document. However, this will depend on the level of precision required for the decision-making context the transferred value will be used in.

Campbell et al. (2009) use a choice experiment in Ireland to estimate economic benefits from policy measures which improve the rural landscape under an agri-environment scheme. They find spatial differences and use a model to transfer WTP estimates to the whole Republic of Ireland. In cases such as this where it is possible to identify which local factors influence WTP for landscape attributes and how much, it may actually be possible and meaningful to transfer such values to policy sites in need of estimates of value, for example in cost benefit analysis of new measures.

In a review Waltert and Schläpfer (2010) the aim is to investigate the relationship between landscape amenities and local development based on two major strands of empirical research, migration and regional economic models, and hedonic pricing models. Following common amenity definitions they identify 71 relevant peer-reviewed studies internationally and systematically assess the reported effects of the landscape amenity variables. The migration and regional economic studies suggest that migrants are attracted by amenities nearly as often as by low taxes. The hedonic studies suggest that nature reserves and land cover diversity have mostly, open space and forest often, and agricultural land rarely, positive effects on housing prices. They find that studies at larger geographic scales and studies involving urban areas were more likely to identify significant amenity effects. They also highlight some limitations of the existing studies and emphasise the need for complementary information from the analysis of political preferences for land-use management. 
We have not singled out international studies in particular that investigate preferences to avoid negative landscape impacts, such as power lines, roads and wind turbines. Some of these studies are included in the reviews mentioned above. One recent and interesting study that specifically review the literature on the burdens associated with power transmission, is Doukas et al. (2011). A large number of studies quantify and monetize whether or not negative public perception is translated into lower property values or longer marketing periods in the proximity of high-voltage transmission lines. ${ }^{28}$ In countries where transaction data are available, research Doukas et al. (2011) review suggest the presence of distribution equipment may have a detrimental burden on the value of proximate residential property. The results, however, are very mixed going from no real effects to significant value diminution. Studies reporting a negative market reaction tend to suggest that it was not the health and safety issues that influenced the market but other factors such as unsightliness, visual, and aural pollution, in other words typical negative landscape attributes. Valuation studies using a robust methodology tend to indicate a general reduction in mean house values of between 2 and $10 \%$. A pylon (tower) appears to have an even greater negative burden of up to $27 \%$, according to this review. Hence, landscape intrusions such as power lines have a direct, measurable expense for many people's houses, in addition to other user and non-users of such areas.

None of the international landscape valuation studies, that we are aware of, use the ecosystem service approach. One exception is the very recent study by van Berkel and Verburg (2014) that value the cultural ES of the Dutch landscape. Their survey collected data on landscape preferences for individual landscape features, and the structure and composition of the landscape as a whole among tourists in a specific region. This was linked to respondent appreciation of the landscape functions of recreation, aesthetic beauty, cultural heritage, spirituality and inspiration. To give a monetary estimate of the value of these services a willingness to pay (WTP) exercise was conducted using photo manipulations depicting likely landscape changes. Increased residential infill, the removal of landscape elements for improved agricultural production and rewilding due to agricultural abandonment were simulated. Complementary to this estimate, a travel cost estimate

\footnotetext{
${ }^{28}$ It is difficult to say how much of the effect is due to perceived health risks associated with power lines compared to the visual landscape impact.
} 
of the value of landscape service was done based on respondents' travel time to reach the region. The monetary value of the cultural services is placed between EUR 86 (WTP) and EUR 23 (travel cost) per tourist/year. According to the authors, the achieved understanding of the spatial heterogeneity of service provision in the region, as well as, the monetary valuation of the assets delivered by the landscape may help in prioritizing areas, and landscape features and structure for maintenance/restoration, while demonstrating the importance of conserving cultural service delivery. Hence, more such studies, using the ES approach, are desirable, if the ES approach is to take hold in management of landscapes.

\subsection{Examples and illustrations of the variety and magnitude of landscape experiences}

Above, we have reviewed the academic literature on both monetary and non-monetary valuation of landscapes and their attributes. Some of those studies are based on hypothetical landscapes and scenarios for landscape change. Others are, as we saw, based on the actual behaviour of people in markets, either as reflected in the distance and the costs people incur to travel to landscapes they like or effects on property prices from landscape attributes. This section finalises chapter 4 by giving further illustrations of actual behaviour from statistics and other information that illustrate how people "vote with their feet" for landscapes they prefer and how important cultural ES are associated with landscapes. Hence, this section provides more qualitative and quantitative examples and illustrations of the magnitude of different landscape experiences in the Nordic countries. As discussed in Chapters 3 and 4.2, we utilize a varied and broad set of indicators of such experiences, as for example suggested by de Groot et al. (2010).

In table 4.4 below, we provide examples of landscape experiences in Denmark, Norway and Sweden. In the text below, we elaborate on some of these examples with data, statistics and other information. Refer back to table 4.1 in chapter 4.2 .1 for the generic version of table 4.4. 
Table 4.4: Examples of landscape experience as cultural ecosystem services in Denmark, Norway and Sweden

\begin{tabular}{|c|c|c|c|}
\hline $\begin{array}{l}\text { Landscape as cultural } \\
\text { ecosystem service }\end{array}$ & Denmark & Norway & Sweden \\
\hline $\begin{array}{l}\text { Recreational: opportuni- } \\
\text { ties for tourism and } \\
\text { recreational activities }\end{array}$ & $\begin{array}{l}\text { Popular landscapes for } \\
\text { recreation, such as } \\
\text { Himmelbjerget in } \\
\text { Jutland or Dyrehaven } \\
\text { north of Copenhagen }\end{array}$ & $\begin{array}{l}\text { Popular landscapes for } \\
\text { recreation, such as } \\
\text { Besseggen in Jotunhei- } \\
\text { men or Marka around } \\
\text { Oslo. }\end{array}$ & $\begin{array}{l}\text { Popular areas for } \\
\text { recreation, such as the } \\
\text { Stockholm archipelago, } \\
\text { skiing at Sälen) }\end{array}$ \\
\hline $\begin{array}{l}\text { Aesthetic: } \\
\text { appreciation of natural } \\
\text { scenery (other than } \\
\text { through deliberate } \\
\text { recreational activities) }\end{array}$ & $\begin{array}{l}\text { Popular vistas, such as } \\
\text { those provided by } \\
\text { viewpoints or scenic } \\
\text { routes (such as Mar- } \\
\text { gueritruten). } \\
\text { Landscapes portrayed in } \\
\text { art as typically Danish } \\
\text { (e.g. open beech forests, } \\
\text { Danish coast) }\end{array}$ & $\begin{array}{l}\text { Popular vistas, such as } \\
\text { those provided by } \\
\text { viewpoints or scenic } \\
\text { routes (such as Atlan- } \\
\text { terhavsveien). } \\
\text { Landscapes portrayed in } \\
\text { art as typically Norwe- } \\
\text { gian (e.g. mountain and } \\
\text { fjord landscapes) }\end{array}$ & $\begin{array}{l}\text { Popular vistas, such as } \\
\text { those provided by } \\
\text { viewpoints or scenic } \\
\text { routes (such as Blågröna } \\
\text { Vägen in Bohuslän } \\
\text { county). } \\
\text { Landscapes portrayed in } \\
\text { art as typically Swedish } \\
\text { (e.g. Dalarna-landscape, } \\
\text { coastal archipelagos) }\end{array}$ \\
\hline $\begin{array}{l}\text { Education and science: } \\
\text { opportunities for formal } \\
\text { and informal education } \\
\text { and training }\end{array}$ & $\begin{array}{l}\text { Landscapes that are } \\
\text { practically available for } \\
\text { education and science, } \\
\text { such as Amager Fælled } \\
\text { outside of Copenhagen } \\
\text { constituting an im- } \\
\text { portant bird area. }\end{array}$ & $\begin{array}{l}\text { Landscapes that are } \\
\text { practically available for } \\
\text { education and science, } \\
\text { such as the islands of } \\
\text { the Oslo Fjord with a } \\
\text { unique flora. }\end{array}$ & $\begin{array}{l}\text { Landscapes that are } \\
\text { practically available for } \\
\text { education and science, } \\
\text { such as urban forests } \\
\text { like Nacka south of } \\
\text { Stockholm. }\end{array}$ \\
\hline $\begin{array}{l}\text { Inspiration for culture, } \\
\text { art, design }\end{array}$ & $\begin{array}{l}\text { Landscape elements that } \\
\text { inspire culture, art, } \\
\text { design, such as the } \\
\text { integrated use of flint } \\
\text { stones for functional and } \\
\text { decorative purposes. }\end{array}$ & $\begin{array}{l}\text { Landscape elements } \\
\text { that inspire culture, art, } \\
\text { design, such as the } \\
\text { glacial forms of the } \\
\text { Opera in Oslo. }\end{array}$ & $\begin{array}{l}\text { Landscape elements } \\
\text { that inspire culture, art, } \\
\text { design, such as the } \\
\text { creation of play- } \\
\text { grounds/-scapes formed } \\
\text { as traditional rural } \\
\text { landscapes (e.g. } \\
\text { Småland at IKEA). }\end{array}$ \\
\hline $\begin{array}{l}\text { Cultural heritage and } \\
\text { identity: sense of place } \\
\text { and belonging }\end{array}$ & $\begin{array}{l}\text { Characteristic historic } \\
\text { landscapes being } \\
\text { recognised in local and } \\
\text { national culture, such as } \\
\text { traditional agricultural } \\
\text { landscape (e.g. her- } \\
\text { regårdslandskab), the } \\
\text { Ox Rute (hærvejen), } \\
\text { Møns Klint and Skagen. }\end{array}$ & $\begin{array}{l}\text { Characteristic historic } \\
\text { landscapes being } \\
\text { recognised in local and } \\
\text { national culture, such as } \\
\text { traditional agricultural } \\
\text { landscape (e.g. sæter- } \\
\text { landskap), fjord land- } \\
\text { scapes (the apple } \\
\text { blossoms in Geiranger) } \\
\text { and coastal landscapes } \\
\text { (Lofoten). }\end{array}$ & $\begin{array}{l}\text { Characteristic historic } \\
\text { landscapes recognised } \\
\text { in local and national } \\
\text { culture, such as the } \\
\text { island Birka in Mälaren. }\end{array}$ \\
\hline $\begin{array}{l}\text { Spiritual and religious } \\
\text { inspiration }\end{array}$ & $\begin{array}{l}\text { Landscapes with spiritu- } \\
\text { al and/or religious } \\
\text { significance, such as } \\
\text { coastal landscapes and } \\
\text { pilgrimage routes } \\
\text { (hærvejen). }\end{array}$ & $\begin{array}{l}\text { Landscapes with spiritu- } \\
\text { al and/or religious } \\
\text { significance, such as } \\
\text { mountain landscapes } \\
\text { and pilgrimage routes } \\
\text { (Olavsleden). }\end{array}$ & $\begin{array}{l}\text { Landscapes with spiritu- } \\
\text { al and/or religious } \\
\text { significance, such as } \\
\text { pilgrimage routes } \\
\text { (Olavsleden) or land- } \\
\text { scapes with spiritual } \\
\text { significance to the Sami. }\end{array}$ \\
\hline
\end{tabular}


Many types of recreation activities carried out outdoors is of course an important landscape experience (first row of the table). The other examples illustrate other aspects of cultural ES, including the aesthetic, education and science and inspiration for art and design, religion and so on.

We start by presenting illustrations for the magnitude of recreation and aesthetical landscape experiences. We then move to a series of shorter examples.

\subsubsection{Recreation and aesthetic appreciation}

Outdoor recreation in landscapes is traditionally widely practiced in Denmark. A national study from 2007-2008 finds that 91\% of Danes are out in nature at least once a year and total numbers of nature visits per year are estimated at approximately 108 million (Jensen, 2014). The most popular landscape elements comprise forest, beach/coast, fields, lakes and meadows. Least visited elements include moor, ancient monuments and marshlands.

Forests receive an estimated 70 million visits per year while beaches and coastlines receive some 43 million visits per year. Figure 4.8 shows the range of yearly visits by adult people living in Denmark in 2008 by nature type. An identical survey was carried out in 1994-1995 showing a similar trend with the exception of visit numbers to beach/coast and the sea. ${ }^{29}$

29 The difference is due to the differences in weather during the summer of 1994-1995 and 2007-2008 where an exceptionally warm and sunny summer in 1994 visibly made more people visit beach/coast and the sea than in $2007 / 2008$, which were average summers. 
Figure 4.8: Yearly number of visits to different landscape elements of the adult Danish population in 2008

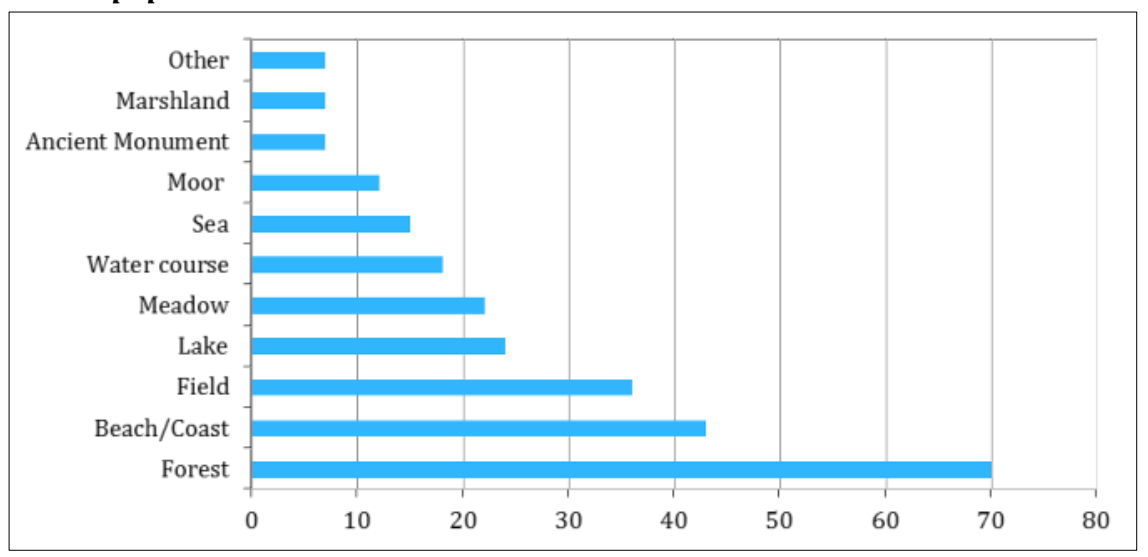

Compared to recreation in the 1970s, a major shift has happened in the population towards more frequent visits closer to home with a shorter duration of visit. In addition, there has been a markedly shift in transport mode towards more visitors using bikes or walking (Jensen and Koch, 2004).

The national on-site survey of 592 forests and other nature areas show the most visited nature sites in Denmark (Jensen, 2003). This is the latest national on-site survey made in Denmark (see table 4.4).

Table 4.4: Most popular rural sites for recreation

\begin{tabular}{lr}
\hline Site & Yearly number of visits \\
\hline Jægersborg Dyrehave og Hegn m.v. & $7,501,000$ \\
Røm $\varnothing$ Strand & $1,900,000$ \\
Gornbæk Plantage & $1,017,000$ \\
Løkken Strand & 866,000 \\
Hareskovene, Jonstrup Vand og Bøndernes Hegn & 848,000 \\
\hline
\end{tabular}

Source: Jensen (2003).

In Norway, a survey from 2011 showed that $66 \%$ of the population carried out the activity "trips in forests" at least once a week (Breivik and Rafoss 2012). This is a high number illustrating the importance of forest landscapes, especially relatively close to where most people live. Other trips with percentages included that are directly associated with landscapes from the survey: Skiing trips in mountains and forests (41\%) and trips in mountains or high plains (33\%). There were also other activities such as running for training and cross-country skiing and downhill skiing etc., which also depend on well-managed landscapes. Similar numbers could be shown for Finland, Sweden and Iceland. The discussion of national-level monetary welfare estimates 
reported in chapter 4.4.1 also indicate the large number of trips underlying the total welfare impact of this cultural ES.

In the following, we go through other cultural ES for which landscapes are important, and where hard indicators and numbers are typically somewhat harder to produce.

\subsubsection{Education and science}

The London Wetland Centre, a relatively small site of wetland in Barnes, west London, provides an example of the magnitude of the ecosystem service "education and science". The centre registered visits of more than 20000 children during organized school visits in 2009 (Mourato et al. 2010: 43). ${ }^{30}$

A survey of 132 schoolteachers in natural science in Norway mapped the frequency with which classes (level 1-10) would go on educational excursions into nature (Jensen, no year). The survey showed that on average $10 \%$ of classes would go on such excursions once a month or more often, $31 \%$ once every semester, and $28 \%$ once a year. $8 \%$ of classes reportedly never went on excursions and for $9 \%$ of the classes the teacher was not able to say how often they went on educational excursions into nature. The survey was carried out with a limited number of teachers who were all educated at the same higher institution of learning in Oslo, and cannot be considered a representative estimate of the scale with which educational excursions into nature are taking place in Norway. Still, it may serve as a reference point for indicating the scale of the ecosystem service "education and science". By January 2014, ${ }^{31}$ there were a total of 618,117 children in Norway in the age group 6-15 (equal to the level 1-10 in the Norwegian school system). The survey thus suggests that every year in Norway about 425,000 children in the age group 6-15 benefit from educational excursions into nature at least once a year.

Of course, the ES "education and science" related to landscape experience comprises many other types of experiences and sections of the population than the examples provided here of one type of experience and one segment of the population.

\footnotetext{
${ }^{30} \mathrm{~A}$ background study for the recent UK National Ecosystem Assessment.

${ }^{31} \mathrm{http}: / /$ www.ssb.no/befolkning/statistikker/folkemengde
} 


\subsubsection{Cultural heritage and identity}

The interest in and use of the ancient Hærvej in Denmark is an example of a landscape experience constituting an ecosystem service providing cultural heritage and identity. The Hærvej is a name for the ancient transport route running North to South in Jutland along the main watershed, connecting Jutland with Germany and continental Europe. The route, which consisted of a dirt track(s) in the landscape, has been used for transport and trade since time immemorial. A 450 kilometres long bike- and pedestrian route called "Hærvejsruten" was established in 1993, running from Skiveren in northern Jutland to Padborg on the Danish-German border. Hærvejsruten is considered a national bike route in the Danish system. Today, the Hærvej is a popular tourist destination being marketed as "a journey through the history of Denmark" (Haervej.dk). ${ }^{32}$ The website marketing the Hærvej to tourists lists 616 hotels or hostels along the route, indicating the large scale to which the Hærvej as a tourist phenomenon involving landscape experience affects the economy.

Bicycle tourism is a form of tourism that in Denmark is closely related to nature and landscape experience (Petersen 2013). An indication of the magnitude of such landscape experience is given by the number of bicycle tourists on the Danish island of Bornholm and the Swedish island Gotland, which are well known for their cultural heritage and historic landscapes. Annual bicycle tourists in Bornholm has been reported to be 150,000 and for Gotland 70,000 (Kågeson 2007).

\subsubsection{Spiritual and religious inspiration}

Landscape also contributes to the ecosystem service "spiritual and religious inspiration" in the Nordics. In recent years, the traditional catholic pilgrimage to the Nidaros cathedral in Trondheim (Olavsleden), Norway, has been reopened. The Nidaros cathedral, with the shrine of St. Olav, in the Middle Ages constituted the northernmost point in the catholic pilgrimage universe. Today, the traditional pilgrimage routes have been marked through Denmark, Sweden and Norway to the cathedral, highlighting historic and characteristic landscapes. The route from Selånger, outside Sundsvall on the Bothnian Sea in Sweden, follows in the footsteps of the king Olav Haraldsson himself, who landed

32 http://www.haervej.com/ln-int/haervej/haervej 
here when returning from exile to claim the Norwegian throne as a Christian king. In the booklet describing the route (SÖT 2013), landscape is frequently mentioned. We first learn about the Selånger valley, "a rural landscape with traces of Iron Age civilization" and later the route goes through Sami areas and "reindeer landscape" in Årefjällen mountains. After crossing the border to Norway, one arrives at Stiklestad where Olav Haraldsson was killed in battle and became a Christian martyr. Stiklestad lies in a traditional agricultural landscape and is described as "a green peaceful spot where you can feel the wings of history. Here modern-day pilgrims can reflect on their inner and outer journey and exchange thoughts". The Danish bishop Kjeld Holm has commented on the modern understanding of pilgrimage (Hansen 2012). Bishop Holm notes that while pilgrimage traditionally was about moving away from this world and towards the holy as something transcendent, pilgrimage is today about reconnecting with the physical world, experience the beauty of engaging with nature, and understanding the sanctity of creation. Today, pilgrimage involves making nature/landscape holy as you traverse through it, notes the bishop.

According to the National Pilgrim Center in Trondheim, 1,300 pilgrims registered at the centre during the summer of 2014 (MarchSeptember). ${ }^{33} 59 \%$ were Norwegians, $23 \%$ were Germans and the remaining were groups and individuals from all parts of the world, including a significant number of people from the other Nordic countries. These numbers of course only encompass a fraction of the total number of people who receive spiritual or religious inspiration from traversing parts of the Olavsled in Norway, Sweden or Denmark every year. The Olavsled facilitates landscape experience providing spiritual and religious inspiration on a large geographic scale, for a significant number of people in Scandinavia and beyond, and also has economic implications. One may also note that the revival of the Olavsled in representations of Nordic nature and landscape (brochures, websites, blogs etc.) also creates a virtual landscape experience contributing to identity and sense of place. For instance, by reading the richly illustrated folder about the Olavsled from Selånger to Trondheim, mental landscape experiences are evoked and create emotional responses in the reader - who may or may not actually embark on such a pilgrimage.

${ }^{33}$ Source: Phone interview 13.10. 2014. 
We may finally note a few examples of landscape and nature being considered holy in a more traditional sense. The lake Vesletjern in Lillomarka, in Oslo, Norway, has been consecrated as holy by TamilNorwegian Hindus and is the scene of annual ritual ablutions during the tirthotsav festival (Jacobsen 2008). On the main day, thousands of Norwegian and other Hindus participate in festivities at the lake (Holøien 2013). Another example is the Russian-Orthodox congregation in Oslo, which uses the lake Steinbruvann in the Oslo forest (Marka) for baptizing and as part of their Theofania-celebration around New Year. The congregation uses the sanctified Steinbruvann water for sacraments throughout the following year. ${ }^{34}$ The Russian-orthodox congregation in Norway has about 3,000 members. These examples illustrate that minority groups may have other and distinct uses of Nordic landscape and nature compared with the majority. We also noted this in chapter 3.2.3, where we described Sami concepts of nature, landscape and the holy.

\subsection{Summary and some key points}

It is perhaps overly ambitious to come up with a unifying theory backed up by empirical data - of preferences for landscapes that may be readily used by policy-makers as basis for making priorities on behalf of those who are affected by landscape change. This is also what academic studies conclude (e.g. Swanwick 2009). Having said that, a number of indicators and methods have been developed to quantify and value landscape change and landscape attributes (in monetary or non-monetary terms), as discussed in Chapter 4.2. These methods contribute to our understanding of preferences and the welfare impacts of landscape change.

We provided examples of Nordic and some international studies within the literature that investigate in particular people's preferences for landscapes - i.e. what characterize landscapes people prefer for viewing and for a range of activities thy are engaged in? We surveyed forest and agricultural landscapes and looked specifically for economic studies that quantify negative landscape intrusions caused by roads, transmission lines and wind turbines etc.

${ }^{34}$ http://no.wikipedia.org/wiki/Steinbruvannet 
The review of the non-economic literature shows that even though there is some heterogeneity in how people in the Nordic countries (and elsewhere) view landscapes and what they prefer, there are also many common attributes that can be physically measured in the landscape that clearly link with landscapes, and ecosystem services derived from these attributes, that people like. Hence, it is clear that cultural ES from landscapes are not completely detached from the physical or biological attributes of landscapes, and related only to aspects purely in the domains of culture and identity etc. Some of the common preference elements are for example the liking for openness in the landscape, natural elements (but also signs of "traditional" agricultural or forest practices, including presence of animals), views and water, and the disliking of industrial production (agriculture or forestry) and for the intrusion of power lines, high impact roads, wind turbines etc. The literature is quite clear on these points.

Even if there are common elements that people prefer, there is also heterogeneity (as with preferences for most things in life). As discussed in the chapter, it may give higher welfare impacts for a higher number of people if landscape management to some extent is diversified rather than based on the "average person". For example in the case of recreation, there may be scope to diversify practices depending for example on whether people are used to or prefer areas of high degree of naturalness or are used to landscapes with higher visible human impacts.

The economic valuation literature, though not large in the area of landscape valuation in the Nordic countries, demonstrates both that the methods are useful for demonstrating welfare impacts of landscape change, and that the economic significance of landscapes for people's welfare is potentially large. We investigated national-level estimates of the welfare effect of recreation and outdoor activities in several of the Nordic countries. The "everyday landscapes" people use for their daily and weekly activities are clearly important, as are special landscapes such as national parks and mountain areas, where people have more highly valued, but rarer experiences during holidays and weekends (ref. figure 3.1). For both types of activities, quality of landscapes is important both for the activity levels in the countries and the value experienced from each trip/activity. Further, several studies demonstrate people's willingness to pay (both actually in markets and hypothetically stated in surveys) is high to avoid power lines and other intrusions, and for improvements in forest and agricultural practices that bring the best and most preferred elements out of the landscapes. 
Finally, we provided examples, some short and some more detailed, of the types and range of cultural ecosystem services associated with landscapes in the Nordic countries. While the importance of recreation activities has been well-documented in the previous sections, we also provide more unusual examples related to the spiritual, identity, educational and other aspects of importance for cultural ecosystem services. In this area, literature is immature and examples hard to come by. In some cases, specific types of such cultural ecosystem services are shared by relatively small groups and may involve specific sites (e.g. the 3,000 member strong orthodox congregation in Oslo and the holy lake), and in other cases specific types of cultural ecosystem services are shared by large groups of the population (e.g. school children on educational outings) and may involve landscape on a large scale (e.g. pilgrimage routes in traditional landscapes). Landscape experience as cultural ecosystem service thus comes in various forms, shapes and scales, and it provides an additional layer to the more "physical" assessments of landscape value. It may be noted that landscape experience as cultural ecosystem service could be of special importance in economies with increasing focus on value creation related to consumption of (unique) experiences.

Now, the next steps to consider how landscape experiences and the undoubtedly large economic welfare effects of such experiences currently are treated in decision-making situations that may impact landscapes. 


\section{How are values of landscape experiences currently treated in assessments \& decision- making?}

\subsection{Introduction}

Chapter 3 aimed to clarify and provide a better understanding of how landscapes, landscape experiences and cultural ecosystem services are related, and also how natural science, economics and sociology have viewed landscapes and the value of landscapes. Chapter 4 first discussed some of the indicators and methods used to measure monetary and nonmonetary values of various cultural ecosystem services derived from landscapes. Several studies from the Nordics and some international (review) studies were then presented and discussed. Finally, the magnitude and importance of a number of landscape experiences based on data/statistics from the Nordic countries were illustrated.

This chapter aims to investigate through primarily document review (but also selected interviews) some current guidelines, practices and examples of how landscape impacts are incorporated into selected policy assessments and decision-making contexts in the Nordic countries. We emphasize particularly spatial planning, cost-benefit analysis, impact assessments, and the role of landscape analysis and experiences in these contexts. We take a particular look at energy installations and infrastructure, as these are large landscape changers in all the Nordic countries.

This review is not comprehensive in its coverage of all practices in all Nordic countries, and we do not aim to cover the same decision-making contexts equally well in all countries, as Phase 2 of this project will go more into how values of landscape experiences can be better integrated in current guidelines and decision-making. We emphasize in particular examples and illustrations from Denmark and Norway here, and provide shorter reviews of selected topics from Sweden, Iceland and Finland. 
We provide a sufficient basis to identify some areas where impacts on landscapes and the experiences derived from landscapes, may currently be insufficiently incorporated and considered. We have conducted the review with a focus on actual landscape analysis in the contexts above, and have not, for example, reviewed the legal basis or preconditions to include (or not) landscapes in various decision-contexts.

We utilize our discussion and definition of the relationship between cultural ES and landscapes from chapter 3 and the review of people's preferences and values of landscape experiences from chapter 4, in identifying gaps in current guidelines and practices.

Before investigating how values of landscape experiences are currently treated in decision-making, it is worth noting that the Nordic countries are different in geography and likely to some extent also in people's preferences (although, as we saw in chapter 4, there are likely also similarities). This means that landscape analysis and assessment will have to reflect physical and other important differences. In the next section, before reviewing current guideline and practices, we provide a visual representation of some of the differences and commonalities for all five of the Nordics.

\subsection{Common notions of landscape in the Nordic countries - a look at landscape images on Google}

A qualitative and rough illustration of the physical differences and likely differences in landscape preferences can be derived from analysis of common images of Nordic landscapes. An example of this is provided in the following.

We conducted a small survey in order to tentatively identify the most common concept or visual representation of landscape in the Nordic countries. For each of the countries, we googled the word "landscape" and the name of the country, both in the local language and selected the "images" function (for methodology and selection, see appendix III). This gave us a series of images of what presumably may be considered national landscapes in each country, with the images most often being referred to in such a context occurring at the top. We then took the top-18 images for each country and identified how often different main landscape types occurred in the photos. The results are shown in table 5.1, 
and then some typical or "representative" photos for each country are displayed in turn. ${ }^{35}$

\begin{tabular}{|c|c|c|c|c|c|}
\hline & Denmark & Finland & Iceland & Norway & Sweden \\
\hline Coast & $28 \%$ & $89 \% *$ & $33 \%$ & $11 \%$ & $6 \%$ \\
\hline Fjord & - & & - & $67 \%$ & - \\
\hline Agriculture/rural & $100 \%$ & $6 \%$ & $6 \%$ & $22 \%$ & $50 \%$ \\
\hline Lake(s) & $11 \%$ & $89 \% *$ & $17 \%$ & $6 \%$ & $22 \%$ \\
\hline River & $6 \%$ & $6 \%$ & $6 \%$ & $6 \%$ & $22 \%$ \\
\hline Forest & $33 \%$ & $50 \%$ & - & - & $39 \%$ \\
\hline Valley & - & - & $6 \%$ & $11 \%$ & - \\
\hline Mountain(s) & - & $6 \%$ & $94 \%$ & $100 \%$ & $33 \%$ \\
\hline
\end{tabular}

* Double count (not possible to distinguish between coast and lakes).

The survey indicates quite clear differences between the Nordic countries in what is generally considered national landscapes. We can briefly summarize these as follows:

- The typical Danish landscape appears to be agricultural (often rolling fields) without presence of human infrastructure, in many cases framed with forest patches and/or coastline.

- The typical Finnish landscape appears to consist of lakes/coastline, often framed with forest.

- The typical Icelandic landscape appears to consist of a mountain, often in combination with water (a lake or coast).

- The typical Norwegian landscape appears to consist of (often rugged) mountain(s), frequently combined with fjords and occasionally with rural elements.

- The most typical Swedish landscape appears to be rural, often with some elements of forest. (A second main type is with mountain/hill, often with lake/river; Northern Sweden).

\footnotetext{
${ }^{35}$ We initially put together collages of all the 18 photos from Google for each country, but due to unclear property rights, we instead selected 1-2 photos/images representing typical features of the landscapes in each country.
}

${ }^{36}$ Searches were conducted 8.10.2014 at 14.00-16.00. 
We may note that while Denmark, Finland, Iceland and Norway here appear to have very distinct landscape profiles, the Swedish landscape images are more diverse. The 18 Icelandic and Swedish pictures to some extent include humans and infrastructure, while this is practically absent in the landscape pictures from the other countries. We may also note that the searches generated differences in the numbers of hits in the different countries that cannot be explained by differences in population size alone. Our small survey showed that especially Iceland and Norway had a high number of "landscape hits" per capita, while especially Finland and Sweden had significantly fewer hits per capita. ${ }^{37}$ Below in Figures 5.1-5.5 we provide examples of "representative" landscape images.

\section{Figure 5.1: Example of "typical" Danish landscape}

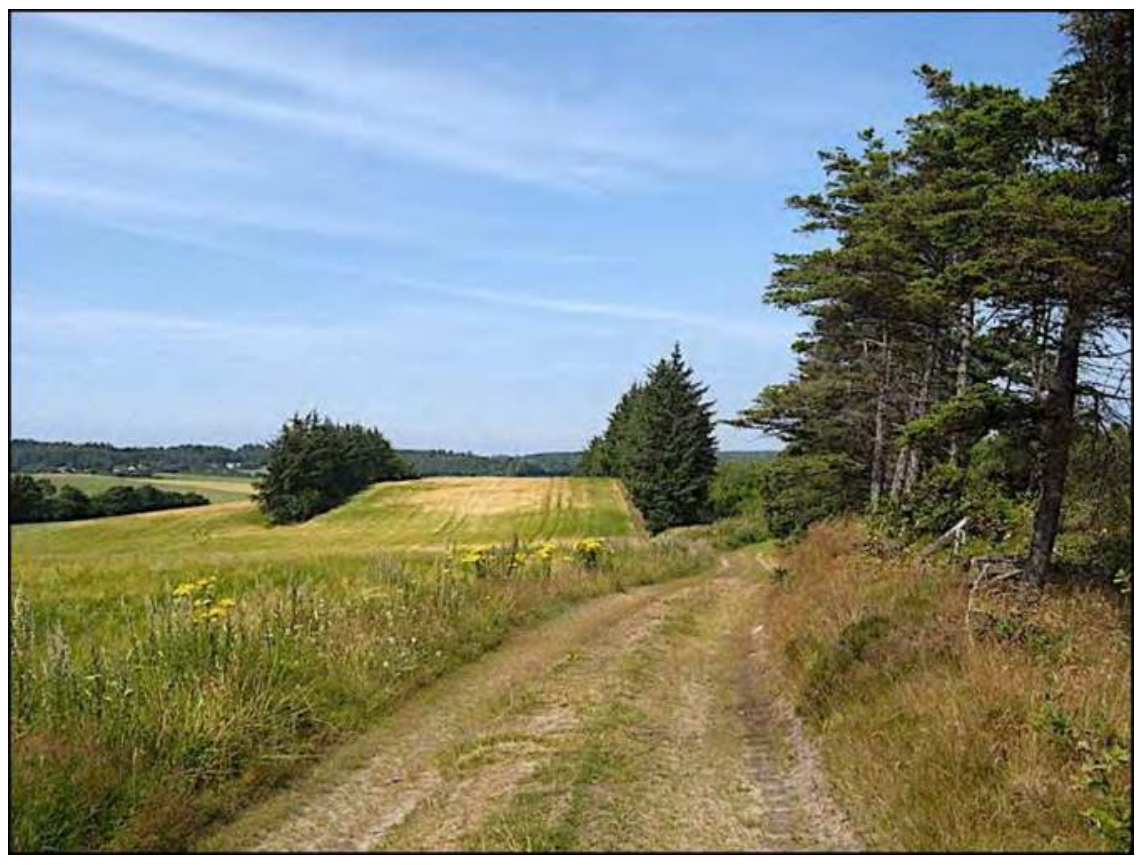

Source: Wikimedia Commons/Tomasz Sienicki. "Danish landscape between Brovst and Fjerritslev".

${ }^{37}$ At www.google.dk, the search “Danmark landskab" Denmark generated 277,000 hits (ca. one hit per 20 inhabitants). At www.google.no, the search "Norge landskap" generated 439,000 hits (ca. one hit per 11 inhabitants). At www.google.is, the search "ísland landslag" generated 77,300 hits (ca. one hit per 4 inhabitants). At www.google.se, the search "Sverige landskap" generated 302,000 hits (ca. one hit per 31 inhabitants). At www.google.fi, the search "Suomi maisema" generated 196,000 hits (ca. one hit per 27 inhabitants). 
Figure 5.2: Two examples of a "typical" Norwegian landscape

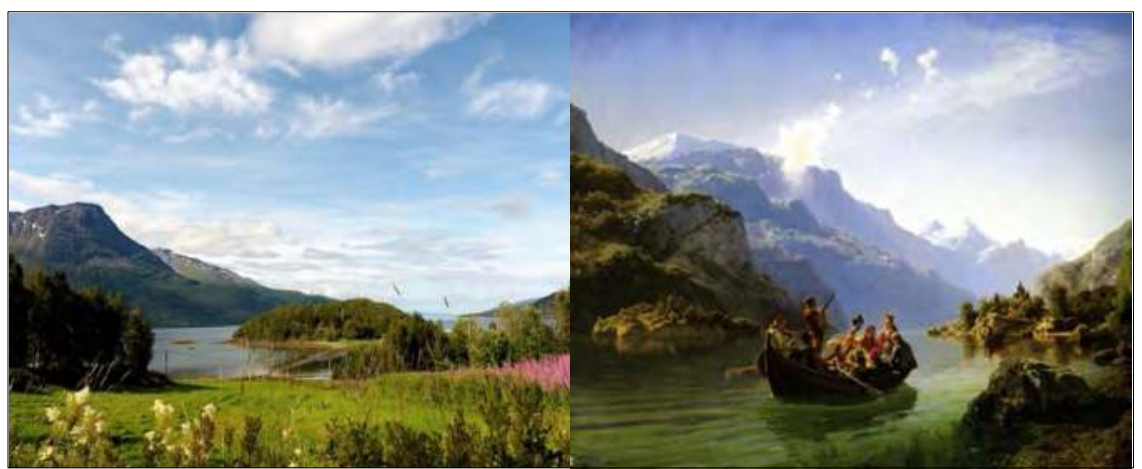

Sources: Left - Wikimedia Commons/Johannes Jansson, norden.org. "Landscape near Narvik". Right - Wikimedia Commons/Tidemand \& Gude. "The bridal procession in Hardanger" (1848).

The landscape painting above, Tidemand and Gude's "The bridal procession in Hardanger" (1848), depicts main characteristic traits in the 18 Norwegian landscape pictures identified in the google-search quite well. We have included it here also to show how the landscape panting tradition (especially in the national romanticist firm) conditions Nordic perceptions of "landscape" even today.

Figure 5.3: Example of a "typical" Icelandic landscape

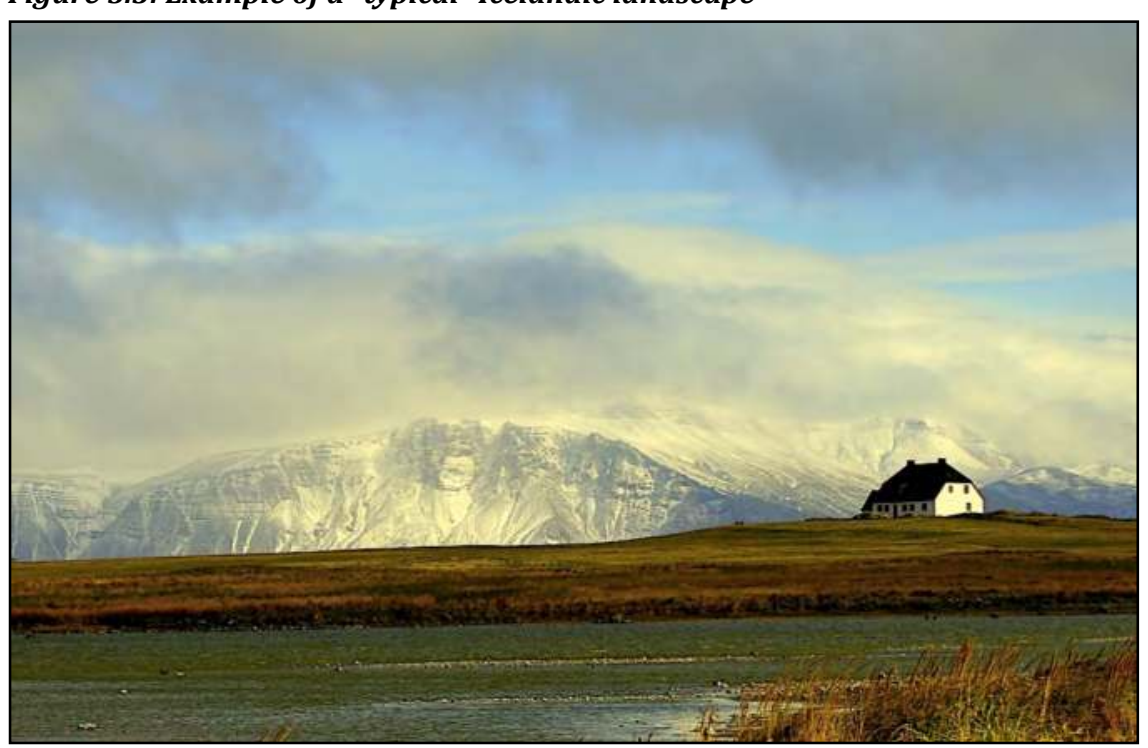

Source: Wikimedia Commons/Lydur Skulason. "The mountain Esja seen from Lambastadir (Reykjavik)”. 


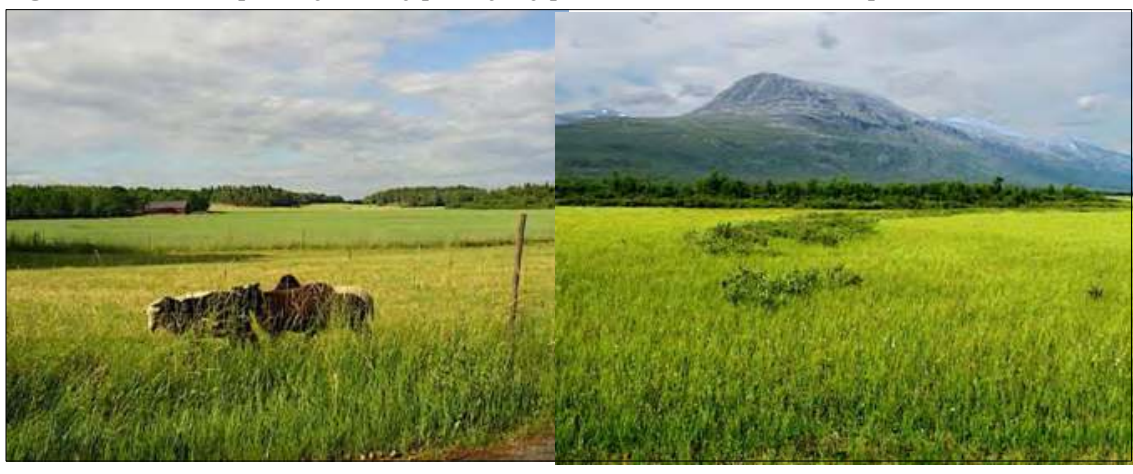

Sources: Left - Wikimedia Commons/Per Ola Wiberg. "Photo taken by a small road between Skå and Svartsjö." Right - Wikimedia Commons/Olof Senestam. "Landscape near Kebnekaise".

Figure 5.5: Example of a "typical" Finnish landscape

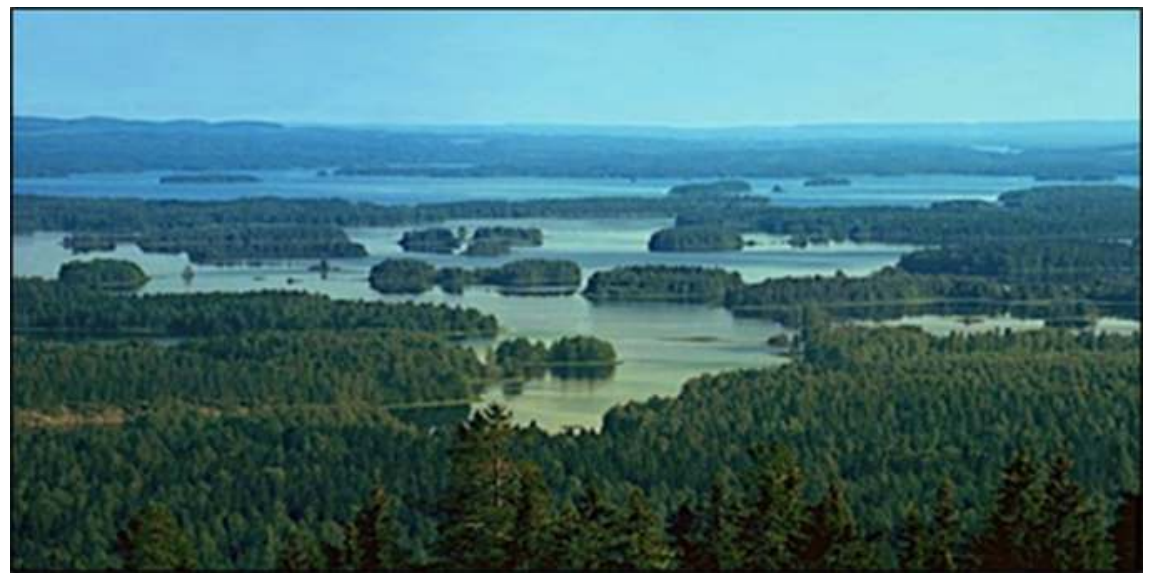

Source: Wikimedia Commons/Paul Lenz. "The lake Syväri in Nilsiä, Finland".

The landscape characteristics described in table 5.1 and exemplified in the pictures above, reflect obvious differences between the countries in terms of geography and physical characteristics. However, this probably does not tell the full story. Landscape experience is conditioned by culture and the cultural conceptions related to landscape; not only the physical realities differ in the different Nordic countries. For instance, while Norway in reality has a high forest cover, the images do not reflect that. The survey indicates that in Norway the forest to a lesser extent than in Finland and Sweden is considered a typical part of the "national landscape".

In addition to differences in geography and cultural valuation of certain landscape types, other factors will also influence which images of landscape appear in a Google-search. For instance will images that are 
used for marketing and tourism purposes on the Internet likely score highly, but may not accurately reflect the main national concepts of landscape in the population as such. As an indication of differences in the conception of national landscapes in the Nordic countries, we still find the survey to provide interesting information. These differences should also be kept in mind when considering how and to what extent landscape experiences are treated in the various guidelines and decision-making contexts.

\subsubsection{Public decision-making contexts where landscape experiences may be relevant}

There are a number of "decision-making contexts" where the value of landscape experiences may be important. These can be both private and public, and involve different stakeholders (see Box 5.1). Since we in this report are primarily interested in public decisions, or in the regulation of decisions made by private actors that may have landscape impacts of a public good nature, we put the emphasis on what the government can do. ${ }^{38}$ Some areas are protected for their landscape qualities (landskapsvernområder) where limited activities are allowed (such as grazing animals etc.). There is always a discussion about whether the current level of protection is high enough or whether it should be increased, if the value of landscape experiences is given higher importance. We do not consider this question here, but are in this report more interested in how landscape impacts may be better included in decision-making contexts that are about areas not currently assigned as protected. ${ }^{39}$

\footnotetext{
38 There are private property rights in the Nordic countries and individuals or companies that own land are free to carry out certain activities on their land that have limited (or in some cases more moderate) landscape impacts. It is the larger potential landscape impacts of relevance for the general public or affected local residents that are our main concern here.

${ }^{39} \mathrm{~A}$ relevant question could of course be whether current criteria for asssigning protected area status (of various categories) take value of landscape experiences sufficiently into account. We have not looked at that question here.
} 


\section{Box 5.1 Stakeholders involved in policy and development with impact on}

landscape

We may distinguish between three main types of stakeholders involved in policy and development with impact on landscape:

\section{Government:}

- Environmental authorities at the central level, responsible for overall mapping and methodologies, overall planning, and monitoring.

- Ministries who plan and facilitate development that potentially has significant effect on landscapes; typically sectors such as agriculture, energy and transport.

- Regional/local authorities, responsible for spatial planning locally.

\section{Business:}

- Private companies, typically consultants and engineering companies, who are engaged in planning or building infrastructure projects that potentially has significant effect on landscapes.

\section{Non-profit:}

- Non-profit organizations who are engaged in work to preserve natural/landscape values.

In this report, we are particularly interested in the government's conduct when entering planning and policy processes which may have impacts on landscapes.

We provide a crude overview of governance structures and general decision-making contexts of relevance in the Nordic countries. Government institutions under the Ministry of Environment are typically responsible for mapping, classification and designation of areas of national importance. This is usually the case for many of the Nordic countries, although the degree to which such mapping work has been carried out and to which level of detail, vary. Landscape areas of particular national importance are in many cases legally protected against modifications including (traditional) activities necessary to uphold landscape characteristics (this usually depends on the degree of protected area strictness)

Regional/local authorities are typically responsible for spatial planning locally, balancing development needs with environmental and other concerns. Local planning is determined by Municipal Plans, in which landscape values are often to be taken into account when designating areas for various uses. In many cases, there are national priorities (e.g. 
related to important infrastructure investments etc.) that will have bearings on how the landscape assessment and other impact considerations will be carried out.

Infrastructure projects such as industrial facilities, wind energy facilities, roads and railroads and transmission lines require an Environmental Impact Assessment (EIA), in which effects on landscape are also to be assessed. In Denmark and Norway, for example, the responsibility to carry out the EIA lies with the authority that has the mandate to approve or reject the project (it may for example be the central government or the municipality).

Plans and programs that are under development may be subject to a so-called Strategic Environmental Assessment (SEA). The SEA shall be carried out in an early stage of the preparation of plans/programs, so that likely environmental impacts can be taken into account when developing the plan/program further. The SEA usually includes an environmental impacts assessment of the plan/program, in which environmental impacts (including landscape impacts), including cumulative impacts, shall be assessed. The responsibility for assessing whether an SEA should be carried out, and for carrying out the SEA if it is deemed necessary, lies with the authority in charge of the planning of the plan/program.

A project, at least if it is of a certain size in terms of investment and other costs for government, is often subject to a Cost-Benefit Analysis (CBA), an analysis tool from economics. This is for example the case in Norway. CBA is a systematic process in which all benefits and costs related to different options for realizing a public project, program or policy are mapped, quantified and to the extent possible assessed in monetary terms. Monetary landscape values are also to be included in CBAs when relevant (while they often are left "un-priced", as discussed in chapter 5.5.5 below). There are national standards for how to perform CBAs, which often are carried out by consultants or in some cases in-house at the relevant directorate/government institution. How and the degree to which non-monetary values (such as most cultural ecosystem services) are assessed in CBAs may vary. CBA is the most adequate tool in which to more systematically integrate economic (monetary) values of landscape impacts.

There are also other tools and methods that are used to a varying degree in assessing impacts of different projects. One example, with a certain tradition especially in Finland, is so-called multi criteria decision analysis (MCDA). This method provides procedures by which concerns about multiple conflicting criteria can be formally incorporated into 
analysis of a decision. In practice, many of the CBAs and to some extent EIAs are "implicit" MCDA analyses, since impacts that have been quantified and to a varying degree valued (in monetary or non-monetary terms) are weighed together in one way or another (see e.g. CatrinuRenström et al. 2013 for an assessment of the use of MCDA in hydropower projects in Norway). However, MCDA does not have a welfare economic foundation and many economists are sceptical to MCDA for that reason.

Above we have discussed the main decision-making contexts, and associated tools to assess and value and incorporate value of landscape impacts, considered here. There may be differences between the Nordic countries in the laws, regulations, guidelines and practices. For example, Sweden has less strict requirements to carry out CBA (only transport infrastructure, otherwise EIA) than Norway has. We do not aim to cover all decision-making contexts and tools in full depth for all the Nordics, but provide interesting examples and illustrations that can help identify current problems and potential ways forward.

We start with more comprehensive reviews for Denmark and Norway. For Denmark, we cover how landscape is interpreted in governance and defined and incorporated in the legal and planning systems. We then look at how the landscape character method is used in Denmark and landscape in EIA and CBA. For Norway, we look more specifically at various guidelines for how landscapes should be characterised and valued in EIA, CBA and spatial plans for various types of infrastructure investments (e.g. roads, energy installations).

\subsection{Denmark: Landscape experiences in physical planning and other decision-making contexts}

We start by going through important aspects of how landscape experiences are treated in Denmark, especially the physical planning process on different levels and different methodologies or tools to include landscape experiences in assessments.

\subsubsection{Landscape in governance in Denmark}

In Denmark one traditionally distinguishes between urban areas and so-called "open land" (det åbne land) in physical planning. There is also a tradition of distinguishing between forests and landscape, as reflected in the tradition of using "Forest \& Landscape" (Skov og Landskab) in 
the names of education and research institutes dealing with nature management. This reflects that there have traditionally been two distinct professions related to nature management: foresters and landscape architects.

The traditional and common view in Denmark is that landscapes are something you find in the "open land", in the form of vistas encompassing mainly agricultural areas and, possibly, some forest elements and the occasional lake (see Box 5.2).40 This reflects that the countryside in Denmark is dominated by agriculture and that there are few, and usually minor, forest areas left. Denmark is, moreover, a relatively flat country devoid of large rivers and almost all streams have been regulated as part of agricultural production.

\section{Box 5.2 Open land as dominant landscape feature in Denmark}

The so-called "open land" is clearly a defining characteristic of landscapes in Denmark. Agriculture represents the dominant landscape character covering 60\% of the area in addition to hedgerows, field roads and ditches. Forests cover 14\%; heaths and dunes take up $10 \%$ and lakes, streams and wetlands another $3 \%$.

Denmark is the country in the EU with the highest proportion of cropland and is among the five EU Member states with the smallest share of forest cover. Compared to the other Nordic countries agriculture covers $8 \%$ of the area of Finland, $7.5 \%$ in Sweden, $4 \%$ in Norway and 1-2\% in Iceland.

Especially the open and undisturbed heath and dune landscapes along the coastline are considered unique in a European context.

Sources: Danish Ministry of the Environment (2013a); Eurostat (2011); Nordic Council of Ministers (2003).

Traditionally, landscape values have been considered important in nature conservation policy, especially in relation to developments in the "open land", in Danish forests and in coastal areas (with efforts to preserve remaining untouched coastal areas) (Nordic Council of Ministers 2003). Denmark also has a significant cultural heritage related to landscapes, especially in the form of castles or estates with historical landscape surroundings. Preservation of such cultural heritage and the landscapes associated with it has been part of modern government policy for

${ }^{40}$ As noted by one of our interviewees, a professor at the Department of Geosciences and Natural Resource Management, University of Copenhagen: "For most people, 'landscape' is the view you have over the agricultural countryside." 
nature management from early on and is also considered important in recent decades - where the tourist industry has become an advocate. A central "point" in physical planning of landscapes in Denmark is the clear physical division between towns and the countryside, where only activities and installations essential for society are allowed in the latter such that the open land landscape values are preserved and enhanced and there is a clear experience of the difference between countryside and towns.

In recent decades, an increasing focus on the ecological aspects of landscapes has developed along with an increased drive to preserve or even recreate or restore "wild" landscapes (Nordic Council of Ministers, 2003). This is reflected for instance in projects to give more room to regulated streams and bring back natural dynamics, flora and fauna constituting a so-called "stream-valley" (ådal) landscape. The largest such project has been the recreation of Skjern $\AA$ in western Jutland, with a price tag of 283 million DKK (DKK-2003). ${ }^{41}$

Recent decades have also seen an increased awareness of the need for recreation in natural environments in an increasingly urban population, leading to many projects aiming at facilitating nature and landscape experiences in or close to urban areas. One example is Vestskoven, a new forest with recreational infrastructure developed since 1967 in the western fringe area in greater Copenhagen. The area includes a 67 meters high artificial hill (mostly made of construction and demolition waste), providing vistas over the natural landscape. On the top of the hill, there is a map providing the direction and names of different natural elements and historical buildings. Over a 20-year period from 1977 to 1997, Vestskoven developed from being one of the least popular forest sites in the region to one of the most popular destinations for daytrips. In monetary terms, the non-market visitor value of the Vestskoven increased 70 times (Zandersen et al. 2007).

The National forestation policy (Danish Ministry of the Environment 2002) aims at doubling the forest cover over a generation (some 80 years) through voluntary purchases of agricultural land by the State and municipalities or on private land. Often, publicly owned forests are planned in vicinity to urban areas to facilitate recreation and on locations of special drinking water interests or on water extraction locations.

${ }^{41}$ http://www.skjernaa.info/om-skjern-a-info/skjern-as-historie/skjern-a-genskabes 
Denmark was active in the development of the European Landscape Convention through the 1990s and it was signed in 2000 and ratified in 2004 by Denmark (Danish Nature Agency 2011). A clearly formulated aim of the Convention by the Government is the recognition that landscape experiences represent an important part of life quality for people wherever they live. This includes in cities, in the countryside; in deteriorated areas as well as in areas of high quality; in areas recognised for their unique beauty as well as in ordinary areas (Danish Ministry of the Environment 2013b).

\subsubsection{Landscape definitions, legal status and the planning system}

Physical planning of landscapes in Denmark have since the 1970s been carried out in a decentralised manner.

\section{State level}

The State defines general guidelines and visions for physical planning through the National Planning Report (Landsplanredegørelse), as well as an overview of state interests that necessitate physical planning.

State interests originate from political decisions such as legislation, action plans, sectoral plans or agreements between authorities that require a physical planning process (Danish Ministry of the Environment 2014). This can for instance be the need to find suitable locations in the open land for large projects such as biogas plants, windmills and large animal husbandry farms. The publications of State interests occur every four years, typically two years prior to the revision of the municipality plans that take place every two years.

The National Planning Report (2013a) is the political announcement of the Government concerning the future physical and functional development of Denmark and is traditionally published after each new election by the Minister of the Environment. The latest National Planning Report from 2013 contains one chapter on landscape (See Box 5.3). 


\section{Box 5.3 Landscape aspects in the 2013 National Planning Report}

The National Planning Report lays out a number of challenges and visions for the development of the Danish landscape. Generally the policy is to ensure both space for i) protection of unique values of landscape, of nature, of water and of cultural heritage and ii) active use of the landscape where dwelling, recreation and development in the agrarian sector are supported.

Agriculture - changes in the Agricultural Act from 2010 allows for much larger animal husbandry farms of industrial character, including large animal husbandry farms with no land attached. This may affect the surroundings and hence the landscape character far more than previously.

Biogas plants - Improved support mechanisms for biogas in the Danish energy policy are planned to lead to a series of large biogas plants in primarily Jutland and Funen. The Ministry of the Environment together with RealDania carried out a development project about biogas plants, architecture and landscape. The project devised concrete solutions as to how best to introduce a new type of architecture into the open landscape and found that biogas plants can develop into an attractive element in the landscape if different architectural and landscape challenges and potentials are included in the planning phase as early as possible (Danish Ministry of the Environment and RealDania 2011).

Particularly valuable landscapes - municipalities hold a particular responsibility for avoiding developments that do not support the landscape characteristics in areas with particularly valuable landscapes (see 4.4 .3 below). These must therefore be designated in the municipality plans. Only in special cases are such developments allowed when there are no other alternatives and it is deemed necessary for society. In such cases buildings and plants can only be carried out on the condition that special landscape enhancing measures are incorporated. This may include possibilities to enhance nature quality, recreation and tourism.

Municipalities are expected to plan for a more varied landscape consisting of connected nature areas allowing for plants and animals to spread, e.g. through the creation of corridors between lakes, streams, forests, meadows and bogs or by creating larger continuous nature areas. This would benefit biodiversity and contribute to making nature more resilient towards the effects of climate change.

Coastal areas - are characterised by large variations and many coastal areas offer important nature and landscape values with potential for recreation and tourism. Especially open coastline landscapes form a whole. The unique Danish dune and heath landscapes are of special national interest and they need to be protected and access need to be ensured for locals and tourists. The Ministry of the Environment plans a collaborative project with stakeholders to further develop coastal zone landscape and nature potentials focusing on developing a richer nature, improved access to nature and landscape areas and create the basis for tourism. 
Recreation and access - a national recreation policy is underway based on extended collaboration with stakeholders. The Government works for an increased focus on ensuring and creating access to nature- and landscape areas. For instance, public access is now ensured on buffer strips along lakes and open streams in the countryside once these have developed into nature [as opposed to farmed land].

Binding instructions and direct interventions in the planning process are also allowed by the State under the Danish Planning Act as a means to influencing and steering physical planning locally.

\section{Local level}

The local level government is required to take into account state interests and to translate State visions, requirements and guidelines in the physical planning in municipality plans and local plans. Prior to the local government reform in 2007, 14 counties were responsible i.a. for regional and environmental planning including physical planning of the open land outside urban zones. Physical planning, environmental impact assessments and permissions of projects in the open land were also the responsibility of counties. Municipalities were responsible for physical planning of urban zones. During the period of the counties, regional designations and guidelines for the open land were quite heterogeneous.

After the 2007 reform, physical planning and permissions in the open land were transferred to 98 municipalities, who had been consolidated into larger units, while five new regions were delegated with the role to develop regional strategic plans containing guidelines that municipalities need to respect in their planning, but containing no concrete maps and designations.

The physical planning of the open land is closely linked to managing landscape interests. For the first revision of the Municipality Plans in 2009 after the Local Government Reform in 2007, the State recommended municipalities to apply the Landscape Character Method (Danish Ministry of the Environment 2007; see next subchapter below). The mappings of landscape characters at municipality level are intended to be the basis for municipal landscape plans and guidelines that ensure the quality of area characteristics and distinctive possibilities for experiences in planning and granting of permissions in the open land (Danish Ministry of the Environment 2009 and 2013a).

Not all municipalities managed to apply the new method in the first revision of the municipality plans after the reform. The Danish Nature 
Agency does not presently have an overview of how many municipalities have applied the landscape character method (Anette Ginsbak, personal communication). The long term aim is to create a nationwide map based on landscape character assessments made in all municipalities.

The latest municipality plans (2013) needed to contain guidelines that preserve values and locations in landscapes that are worth preserving (see chapter 5.4 .3 below). As a rule, valuable landscapes are not allowed to deteriorate. Also, municipality plans needed to designate large continuous landscapes on maps and work to ensure and safeguard e.g. undisturbed landscapes from placements of new large technical plants within or in vicinity to these areas. Also, municipalities should develop guidelines and frameworks to ensure that new urban areas and new installations do not deteriorate existing landscapes, e.g. through building heights, placement in the terrain and illumination.

\subsubsection{Use of the landscape character method in Denmark}

The Danish Ministry of the Environment took initiative in the period 2003-05 to develop a national Landscape Character Method (LCM) together with two regions and the University of Copenhagen, inspired by the UK Landscape Character Network and adapted to Danish context and traditions (Caspersen and Nellemann 2005; Danish Ministry of the Environment 2007). The LCM is a technical planning tool made by and for planners and geographers to allow for a consistent and systematic mapping and description of rural landscapes across municipalities and places worthy of preservation. Traditionally, regional authorities and later municipalities had applied individual approaches to describing and mapping landscapes.

The LCM divides landscape into character areas. Within each area, planners designate places that are the most characteristic and rich in experience potentials as well as places in need of improvement. In this way it provides a coherent overview and shows which areas need preserving and which landscape characteristics can be further developed.

Results of the LCM can be applied in the processing of planning cases such as urban development in peri-urban areas, permissions in rural zones (e.g. roads, technical installations, afforestation) and in management plans to ensure that valuable landscapes are preserved, including large scale landscapes across municipalities.

Landscape mapping in the LCM is based on three strands: i) the landscape physical basis (terrain, soil type etc.); ii) the cultural basis (e.g. built environment, forests, agriculture) and iii) the spatial and visual 
appearance. Based on these three strands, the landscape is first divided into landscape character areas and secondly assessed by professionals with regard to the strength of the landscape character, special possibilities for visual experiences and the state and vulnerability of the landscape character. This assessment is subsequently the basis for making strategic goals and action plans for the landscape before reaching implementation in municipality plans, which necessarily involves balancing other local, regional and national interests. Strategic goals are developed for each landscape character area, where the evaluation of the strength and the state of the landscape character method are combined. This can be illustrated by the following matrix (Danish Ministry of the Environment 2007):

\begin{tabular}{lllll}
\hline & \multicolumn{3}{c}{ Strength } \\
\cline { 2 - 4 } State & $\begin{array}{l}\text { Particularly } \\
\text { characteristic }\end{array}$ & Characteristic & $\begin{array}{l}\text { Weak } \\
\text { characteristic }\end{array}$ & Contrasting \\
Good & Protect & Maintain & $\begin{array}{l}\text { Change } \\
\text { Change }\end{array}$ & Subject to individ- \\
Average & Protect & Maintain & Change & ual assessment \\
Bad & Protect and improve & Maintain and & Chang & \\
& & improve & & \\
\hline
\end{tabular}

In addition to the national guidance on the LCM, efforts have been made to lift the application of this method from often very local sites to larger continuous landscapes, that may cross one or more administrative borders (Danish Ministry of the Environment 2012). Guidance has also been developed on the use of the LCM and urban development (Danish Ministry of the Environment 2008a).

The LCM was developed primarily for professionals to better value and manage landscapes in a systematic way and is kept in a technical language. However, most people have a close relationship to and experience of landscapes they pass through, live in or visit occasionally and people therefore have a stake in the management and preservation of these landscapes. If their preferences are not included, landscape changes may not be optimal in a welfare economic sense. In order to make the LCM more available to everyone, a Landscape Atlas for the Island of Langeland has recently been published that both makes the application of the LCM more approachable and engaged local residents in the assessment (See Box 5.4). This is a good example of attempting to involve the affected people and take local preferences into account in landscape assessment. 


\section{Box 5.4 Landscape Atlas}

The Island of Langeland is quite representative of Danish landscapes with open agricultural areas, settlements, coastal areas and forests. At the same time, as it is an island, landscapes are contained and distances are not great.

The Municipality of Langeland already applied the Landscape Character Method when it decided together with the Danish EPA to develop a Landscape Atlas.

The intended output was to present and illustrate landscape mapping in a language and layout that would be easier to understand and apply for nonlandscape experts. The intended outcome was to increase the interest and understanding of landscapes for local people who move through "their" landscape on a daily basis and not least to assist local politicians who need to make decisions about planning and management of the landscapes. The Atlas can thereby help strengthen municipal planning. The atlas also contains a number of suggestions of where it is particularly important to take care of the landscape and where changes would be warranted.

In addition to applying the Landscape Character Method in a visual and nontechnical language to Langeland, the process also involved a local inspiration group of 30 residents who contributed with valuable information and views during workshops, thematic meetings and trips through landscapes.

The Landscape Atlas exists in a printed and on-line version and a catalogue of ideas was also made that gather ideas from the process as to how Langeland Municipality and other municipalities may disseminate, experience, develop and strengthen landscapes in other ways than through a printed Atlas.

Source: Danish Ministry of the Environment (2014).

\subsubsection{The role of landscape in EIAs and CBAs in Denmark}

Projects that significantly impact the environment require at least an EIA screening by municipalities (EIA Regulation Appendix 2) and in special cases by the State (e.g. off shore projects or large infrastructure projects). The EIA regulation is incorporated in the Danish Planning Act and translates the EU EIA Directive into Danish Law.

Recognising the increasing pressure on the Danish landscape, the Danish Ministry of Environment initiated a process to develop a systematic and coherent assessment using the framework of landscape characters (See chapter 5.4.3). During the same time, the Ministry took initiative to develop a guidebook on how to incorporate landscape considerations in the different phases of EIAs (Danish Ministry of the Environment 2008b). The guidebook describes and exemplifies how to assess landscape impacts under the three EIA phases: Screening (whether an EIA is 
needed or not), Scoping (the scale and content of the EIA) and the EIA. The three main elements in the analyses of landscape impacts in the three EIA phases consist of:

- The project characteristics and possible impacts on landscape and cultural heritage - Projects can be characterised as points (e.g. a large windmill or a building), lines (e.g. a road or train track) or surface (e.g. urban development or afforestation) and the type of impact is described in four main types: physical impacts, functional impacts, visual impacts including other impacts on experience potentials and barrier impacts that can have physical, functional and visual characteristics.

- Landscape and cultural heritage qualities, value and vulnerabilitySpecial characteristics of the impacted landscape and cultural heritage are described along with the dominating qualities of the landscape (small- or large scale; undulating or flat; open or closed etc.). Criteria for assessing the values associated with landscape and cultural heritage can be based on i) designations of various kinds and/or ii) a specific valuation in the concrete case with engagement of stakeholders and relevant professional input. Vulnerability is the interplay between on the one hand landscape and cultural heritage qualities and on the other hand the impacts that may arise due to the project.

- Significance of the impacts - the seriousness of the impacts depends on the vulnerability of the landscape and the character of the impacts. The EIA screening seeks to identify impacts that have such significant consequences that they warrant an EIA. The scoping subsequently assesses whether the impacts necessitates an investigation of alternative solutions or alleviating measures. The EIA looks at consequences and alternatives that ought to be preferred with respect to landscape.

While certain projects require EIAs, not all types of projects also carry out CBAs. In the area of transport, CBA is an integrated part of the impact assessment process of roads, rail and other large infrastructure projects. The most recent guideline by the Ministry of Transport from 2003 (Trafikministeriet 2003) sets out the theoretical basis and approach to carrying out a CBA. In addition, a catalogue of unit prices is regularly updated (DTU Transport and COWI 2014) for aiding in the pricing of impacts. Landscape, however, is one of the aspects along with recreation, groundwater, nature and wildlife, and regional distributional 
impacts that should explicitly not be quantified in the CBA. Depending on the scale and impact, the Manual instead recommends a qualitative assessment of landscape using a 5-point scale ranging from large positive to large negative effect and stresses the need in the CBA to communicate that the CBA quantitative results do not tell the full story.

Recognising that excluding impacts on nature and landscapes may potentially lead to false conclusions, Olsen et al. (2005) carried out a project that aimed to widen the scope of welfare economic assessments of motorway projects. They showed how to include monetary valuation of two different placements of a motorway around the town of Silkeborg using stated preference techniques. One option would be to have the motorway go through a magnificent river valley landscape and another option through a recreation forest at the outskirts of Silkeborg. The project found that people on average preferred the option that would go through the river valley, i.e. avoiding the motorway through the recreational forest.

In the area of energy projects, the Danish Energy Agency published a guideline on the use of CBA in energy (Energistyrelsen 2007). Similar to the CBA guideline on transport, landscape and nature is explicitly excluded from needing a quantitative monetary assessment with the reference to lack of recognized and generalizable monetary values.

\subsubsection{Assessment of how landscape experiences are taken into account in Denmark}

With the development and application of the Landscape Character Method, there is an emerging recognition that a landscape forms a whole as opposed to an area made of separate functions. Municipalities are starting to make the connections between service, place of living, production and landscape in their planning based on the descriptions and analyses made through the Landscape Character Method (Primdahl, University of Copenhagen, personal communication). This is for instance seen through the increasing interest and also (surprisingly) lack of conflicts locally to create public access through traditional production landscapes (e.g. traces in the landscape). ${ }^{42}$

Despite a clear division between towns and the countryside in the physical planning, the Danish rural landscape is de facto in a process of

${ }^{42}$ Spor i landskabet (www.spor.dk) 
urbanisation, especially close to urban areas: Since the 1990s, nonagricultural enterprises are allowed to establish themselves in existing farm buildings and to expand these and part time farming is on the rise. Both tend to plant, change and cover previously open vistas. This development can make it more difficult to "read" and understand a landscape. An example of the scale of this phenomenon is the rural area around the village Sengeløse close to Copenhagen, where more than $50 \%$ of agricultural buildings are not used for agriculture but for industrial purposes. These trends towards an increasing urbanisation of the rural landscape and how the visual character changes cannot be regulated through Local Plans as these are excluded in the open land according to the Planning Act (Primdahl, University of Copenhagen, personal communication).

Current tools available in assessing landscape impacts do not apply the concept of ecosystem services. Cultural ecosystem services could be mapped and assessed consistently within an ES framework, building on the understanding of the link between ecosystems and human wellbeing. Of the cultural ecosystem services, recreation is one category that is fairly straight forward to assess in monetary or quantitative terms. Despite the availability of methods to do so in environmental economics, there is an evident lack of inclusion of such values in landscape assessments and in Environmental Impact Assessments.

In addition, there is presently a lack of specific studies investigating how visitors perceive landscapes, changes in landscapes and the importance of landscape characters for recreation quality in Denmark.

Finally, landscape impacts are not integrated in a quantitative way in cost-benefit analyses in Denmark, with CBA guidelines in the area of transport and energy explicitly excluding landscape and nature from valuation.

\subsection{Norway: Landscape experiences in physical planning and other decision-making contexts}

In the Norwegian case, we briefly go through landscape mapping and governance in Norway, before taking a closer look at to recent guidelines for assessing landscape character and value issued by the Norwegian Environment Agency. These guidelines are pointing the way towards implementing some of the Landscape Convention's intentions in EIA and spatial planning, but seem to be less in use for landscape assessment in practice than the combined guideline on CBA and EIA by the Public Roads Administration, which we also review 
here. We also look at how landscape impacts are assessed for some energy installation projects.

\subsubsection{Landscape in governance in Norway}

The Norwegian Environment Agency has a responsibility to implement the goals set for the management of landscapes in the Nature Diversity Act, Planning and Building Act and the European Landscape Convention. The Environment Agency mainly concentrates on the natural elements of the landscape, since there is a separate directorate with the responsibility for built and other cultural heritage (Directorate for Cultural Heritage). In the following, we focus mainly on the natural elements of the landscape, and potential infrastructure impacts.

Almost 90 percent of Norway's area is managed by the municipalities through the Planning and Building Act. ${ }^{43}$ Around 14.3 percent of mainland Norway is protected, of which $8.3 \%$ is national parks, $1.3 \%$ is nature reserves and $4.7 \%$ otherwise protected. ${ }^{44}$ As noted in chapter 5.3 some of these protected areas are protected for their landscape qualities (landskapsvernområder) where limited activities are allowed (such as grazing animals etc.). We do not consider the issue of area protection here.

For unprotected forests and agricultural land, there is forestry and agricultural legislation that may have impacts on landscapes (as seen in chapter 4), managed by other directorates. Forestry, for example, operates under the forest law, where there are some general provisions for taking multiple uses into account to some extent, including in principles values of recreation benefits carried out in forest landscapes. In certain areas (such as the Nordmarka forest north of Oslo) there are special laws (e.g. "Markaloven") to promote recreation, nature experiences, and sports and to "protect a rich and varied landscape".

In the area of physical planning in general, the procedures are roughly similar in Norway and Denmark (as described in chapter 5.4. above), in terms of the fundamental laws, the roles of state and municipal (local) levels, and the requirements of SEA and EIA for projects or policies that may have significant environmental (landscape) impacts. One difference compared to some of the other Nordic countries in

${ }^{43}$ https://www.regjeringen.no/nb/sub/stedsutvikling/ny-emner-og-eksempler/landskapskonvensjonen/ id535766/

${ }^{44}$ http://en.wikipedia.org/wiki/Protected_areas_of_Norway 
terms of laws is the Norwegian Nature Diversity Act from 2009. This not only an act for the protection of biodiversity more traditionally understood, but it is stated clearly in the act that one of the objectives is to promote also "landscape diversity" (landskapsmessig mangfold). By this is meant the diversity of landscape types, i.e. landscapes with certain (unique) characteristics. The law is primarily for the promotion of nature quality of the landscapes, but may also be relevant for "nature-like" areas in and around cities.

The landscape convention distinguishes between landscape mapping and analysis of landscapes. The Environment Agency has embarked on a substantial effort, as discussed in chapter 3.2.1, mapping the complete landscapes of the whole country (the so-called NIN-landskap), as also carried out in Denmark (as discussed above)Currently, to our knowledge, only Nordland county has been fully mapped using this method. The landscape mapping may have many potential uses, some of which are listed in the method booklet following this mapping exercise (Norwegian Environment Directorate, undated):

- Knowledge basis for development of the landscape as a resource for value creation and business development.

- Identification of important landscape values.

- Identification of important nature values and ecosystem services.

- Monitoring of land use and landscape changes.

- Knowledge basis for management of national parks and large protected areas.

- Assessment of the different landscape types' vulnerability for different landscape changes and projects/impacts.

- Knowledge basis for impact assessments for landscapes.

- Knowledge basis for the suitability of different land uses.

- Knowledge basis for assessment of the level of technical intrusions in the landscape and mapping of recreation activities.

- Knowledge basis for strategic spatial planning and regional planning.

Many of these objectives are potentially directly and indirectly important for better assessment and inclusions of the values of landscape experiences in decisions that impact landscapes in Norway. Note, for example, that the identification of ecosystem services is included as one of the objectives. And to manage the landscapes well, it is important to classify and map the different types of landscapes. However, the method 
booklet does not explain how the landscape mapping, once more complete, can be used to achieve these objectives more specifically, and what the roles of experts vs. people in general will be in the process. We return to this issue briefly below in chapter 5.5.5.

In addition to the management of the Nature Diversity Act (as noted also concerning landscape diversity) and the systematic mapping of landscapes in Norway, the Nature Agency also provides various guidance material of relevance for landscape management and the inclusion of landscape experiences in decisions. This material includes the assessment of landscape character and value (similar to the Danish method discussed above), landscape impacts and wind power development (currently under revision; Trond Simensen, pers. comm.) and methods for landscape analysis in municipal spatial plans. We will briefly present and discuss these first, before moving to the inclusion of landscapes in impact assessments and cost-benefit analysis, with a specific look at road and transmission line projects.

\subsubsection{Approach for assessment of landscape character and value}

The Environment Agency (in cooperation with the Directorate for Cultural Heritage) has developed a guideline or approach to carry out an assessment of landscape character and landscape values (Norwegian Environment Agency 2010). The need for guidance in the area of landscape analysis is related to the new requirement to conduct environmental impact assessment for area plans in the municipalities, but likely also due to insufficient current practices/guidelines. The guideline argues that nature-geographic and cultural-historic elements of the landscape to date have not been well enough included in landscape analyses in Norwegian EIAs. Another motivation is that there is a need for a more comprehensive and consistent methods for assessing landscape impacts from large infrastructure projects, particularly wind power projects. Hence, the guidelines are particularly for municipal level planning (see more details in the next subchapter) and large scale infrastructure projects. The aims of the guideline are partly overlapping with the potential uses of the landscape mapping discussed above. Although not explicitly mentioned, emphasising the benefit and value of landscapes for humans in landscape assessment is a common theme.

The guideline goes into detailed steps for landscape assessment where description, interpretation and assessment of value are clearly separated. In addition, local consultation and involvement is considered 
important. The landscape analysis includes identification of areas, description and interpretation of these, and the setting of landscape character. Connections between areas should be identified. Following this, the landscape analysis consists of (non-monetary) valuation. The general steps of the landscape assessment for EIA and municipal spatial planning are then defined in five phases:

1. Preparation: Setting goals and scope.

2. Description: Initial source studies of the content and qualities of the landscape. Site visits. Synthesize knowledge.

3. Interpretation: Setting landscape character for sub-areas. Interpret connections and completeness in the area under influence.

4. Assessment: Assess the value of the landscape in the area.

5. Planning: Planning process and EIA.

The themes that are listed for further analysis for a defined landscape (delineation of which is discussed in the guideline) include:

- Landforms and water.

- Vegetation cover and structure.

- Land uses and settlements/population.

- Cultural history in the landscape.

- Cultural references.

- Spatial - aesthetic issues.

As can be seen from this list the guideline does not try to make a distinction between cultural heritage and more natural parts or characteristics of the landscape. The guideline then discusses methods for involving local stakeholders to get a better picture of the themes above. We do not go into details here, but draw out some issues of importance for the incorporation (or not) of values of landscape experience. In phase three of the approach the information and descriptions will lead to a characterisation of the landscape which will be impacted, on a physical map. Different elements of the landscape, processes that changes the landscape, elements of connectedness, and specific or unique elements, are then 
assessed in terms of its importance for the overall character of the landscape ("small, medium, large"). In phase four the value of the landscape is assessed in non-monetary terms. ${ }^{45}$ By "value" is meant the "value given to the landscape character we have set for a landscape". The criteria to assess value are given in table 5.2, with stars representing increasing value and a column where the basis for the value "mark" is explained.

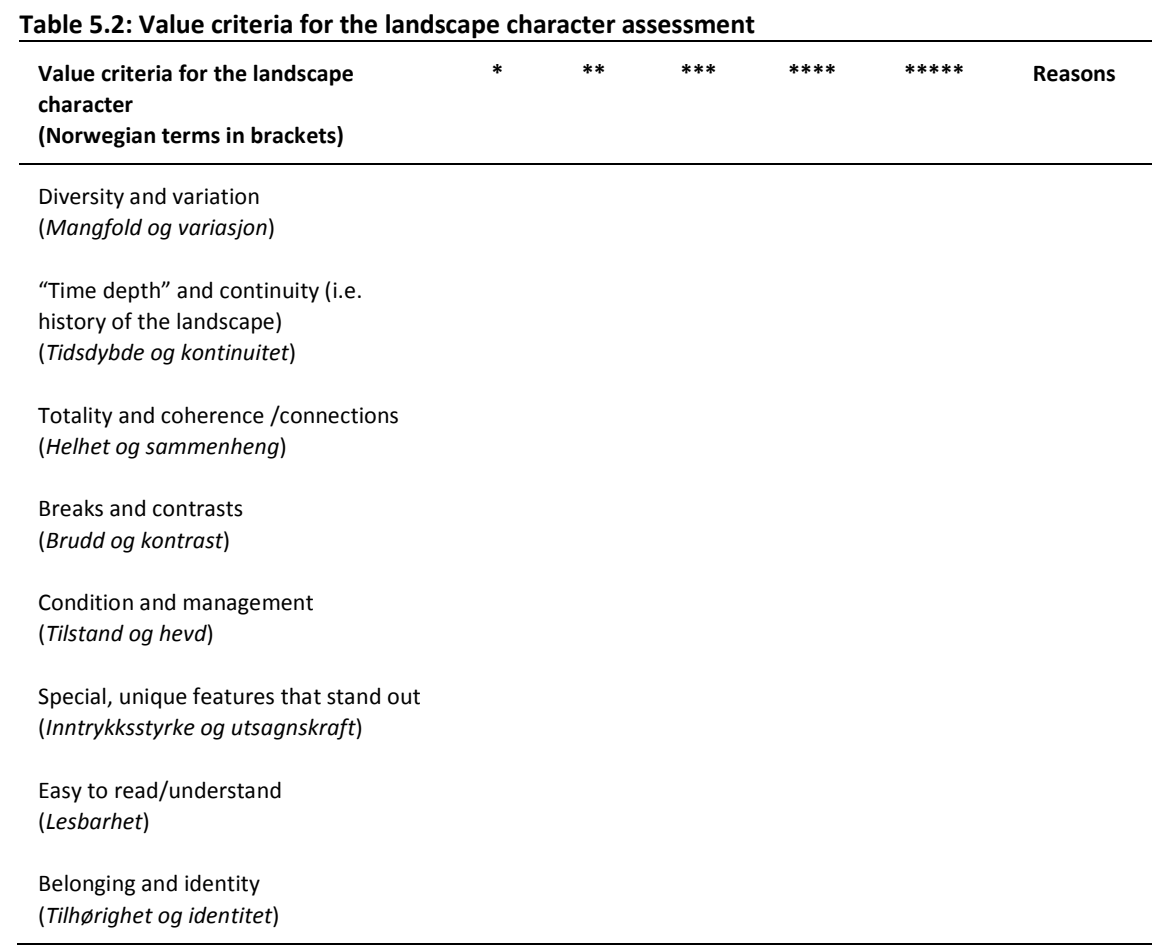

Source: Norwegian Environment Agency (2010).

The overall value of the area is then based on a weighting of the values for each of these criteria, based on the assessors own judgment. There is not much guidance on how this weighting should be done. We do not go into the details of each of the value criteria, but will make a few observations.

First, many of the valuation criteria are similar to many of the dimensions that are considered important for cultural ecosystem services (as discussed in chapter 3), even though this term is not used. For example, many of the criteria has to do with aesthetics and physical characteris-

\footnotetext{
45 This methodology is under gradual revision, and the valuation part is not currently in much use (Moen, pers comm). We still present the steps for completeness.
} 
tics of the landscape (diversity, variation, special features, contrasts etc.) and some have to do with cultural and historic aspects (identity, belonging, time and continuity). The aim of the landscape character assessment and valuation is not clearly stated to be the welfare of humans, though this is implicitly one goal. Preservation of landscape for its own sake seems also to be a motivation. In any case, the objective of the landscape character and valuation exercise (by whom, for whom, what for?) seem a bit unclear. Hence, its influence on actual decisions about projects that may change the landscape is also unclear.

Further, it seems more like an expert-driven process where the expert assesses landscape values based on certain criteria that are not directly derived from people's preferences for specific landscape elements, than starting out with people's preferences and welfare in mind. This is of course partly in the tradition of EIA, which comes from natural sciences and planning, rather than welfare or environmental economics. Shifting the weight perhaps somewhat from the experts to the preferences of people is what we have emphasised in this report. The consultation process that the guideline describes seems to be more to help the expert with information to fill in the gaps and complete the assessment than to systematically gather information about people's preferences for changes of a particular landscape for that to be the basis for setting character and value. That would be more suitable for a complete costbenefit analysis.

The method described in the guideline has potential to be more directly linked to cultural ecosystem services from a particular landscape, with the aim of both better and more systematically analysing how landscape experiences are influenced and how these values should be included in spatial planning and EIAs. The guideline does, however, not go into how the valuations (and the total value) derived from the landscape assessment should be used in practice in the final assessment of the landscape impact or in the process of spatial planning and EIA. It is also unclear how the assessment should be used to inform mitigation efforts, for example. It is not clear to us what the status is for this guideline, in terms of current actual use. It is likely that the guideline from the Public Roads Administration, originally from 2006 and now recently revised (see chapter 5.5.5), is still the more frequently followed, not just for road projects.

In the next sections, we go more into detail about EIA and treatment of impacts related to specific infrastructure projects. 


\subsubsection{Impact assessment and spatial planning on the municipal level ${ }^{46}$}

In this section we briefly review and discuss a more detailed guideline issued by the Environment Agency on landscape assessment in spatial planning and environmental impact assessment (EIA) on the municipal level (following on from the overall guideline on landscape character and valuation above) (Norwegian Environment Agency 2011). A brief review of some of the aspects of landscape mapping, analysis and valuation on the municipal level specifically is given in Nordic Council of Ministers (2013).

The guideline on "Methods for landscape analysis in municipal planning" builds on the more general guideline reviewed above, and is developed further and is more specific about how local government should treat landscape in spatial planning (Norwegian Environment Agency 2011). The law states that the spatial part of the municipality plan should be subject to EIA. We therefore treat the two together here. What is said about landscape analysis is also relevant for EIAs not specifically related to the spatial planning for local government.

The purpose of the landscape assessment is to provide a basis for the municipality's work with area plans, management of landscape resources, assignment of special zones and conditions for land uses and to assess impacts of proposed land use changes (i.e. the EIA requirement). Summarized the landscape analysis proposed in the guideline has the following aims:

- Provide an overview of the municipality's landscape resources generally.

- Provide knowledge about the landscape as a resource for business development and value creation.

- Provide knowledge for the agricultural sector and agricultural management.

- Provide knowledge for the spatial planning in the municipality.

- Communicate special features of the municipality and identity related to landscape, strengthen identity and belonging.

\footnotetext{
${ }^{46}$ It has been decided that this guideline will be revised, yet the time frame has not been decided (Moen, pers. comm.)
} 
- Be a resource for experiences and uses for local inhabitants and the tourism sector.

- Provide knowledge for the long term management of the landscape.

Note that landscape experiences are mentioned as a purpose (although not on the top of the list). Some of the aims are related to the cultural service category, as we have discussed.

The guideline seems to follow quite closely the general guideline for landscape character and valuation in the division of the process into five steps or phases and the content of each phase. The only difference seems to be that the scale in this case is more local and the steps are more closely linked with the steps of municipal planning. The landscape character setting is based on the same criteria as the valuation procedure in general (as described in Table 5.2 above). There is some more elaboration for the overall weighting of a "total" value of the assessed landscape. A five-point scale is introduced from "Very high value" (national significance or values "above average" regionally) to "insignificant value" (degraded landscape, but also landscapes with some potential for restoration).

There are more specific examples of carrying out the different steps of the analysis in this guideline so in this sense it is easier to follow. However, the examples also illustrate the difficulty of setting values for each of the criteria and to assign an overall value. Another difference from the general guideline is that there is more guidance of how to use the analysis for impact assessment. For this an impact table is used which combines the level of impact (large negative, medium negative, small negative, positive) with the value dimensions above (very high to insignificant). The impact of the project would then be put in a cell according to these two dimensions. This procedure is in effect a type of non-monetary valuation methods, typically carried out by an EIA expert or municipality planner. Even though EIA has requirements for consultations, the preferences of those affected are not necessarily centre stage, as discussed above. We will return to this procedure below in the context of EIA and CBA of road projects (and other infrastructure projects), but first we will look at energy installations. 


\subsubsection{Energy installations}

In this section we briefly review how landscape experiences and impacts are assessed for wind and hydro power and for transmission lines.

\section{Wind power installations}

Wind power development is probably the most controversial landscape changer in Norway, together with large transmission line projects. The "not in my back yard" (NIMBY) effect is seen clearly in the public debate, but it also clear that people not directly affected are sceptical towards large scale wind power development along the Norwegian coast especially.

The planning (concession) process in Norway starts by the project developer sending in a note to the Norwegian Water Resources and Energy Directorate (NVE) together with a suggested program for analysis ("utredning") of potential impacts. Based on this, comments from a public hearing and NVE's own assessment, NVE suggests a final program for impact and other assessments, including analysis of landscape changes. Following this, NVE checks if the requirements to the program for assessments have been satisfied and if not, require further assessments. The Environment Agency and the Directorate for Cultural Heritage have recently completed a guideline for how consultants and others should carry out the landscape part of the analysis of impacts. ${ }^{47}$ This guideline follows the general guideline for landscape character assessment and valuation discussed above. The overall impact assessment follows the same non-monetary valuation procedure as described for EIA and local spatial planning, i.e. combining seriousness of the effect for the landscape character (5-scale) with the value of the effect (5-scale), yielding an overall impact (consequence). This is carried out for each defined landscape area (delområde). Each of the consequences is then summed in a table for each of the landscape areas. In contrast to the other guidelines, there is a section on specific mitigation efforts that could reduce the overall impact of the wind power installation. Wind power projects are, to our knowledge, rarely brought through a full cost-benefit analysis. This is more common for example for transport projects (see below). EIA is therefore the most commonly used impact assessment tool.

This is the assessment of the landscape impacts of the individual wind power project. The NVE is also coordinating a thematic conflict

${ }^{47}$ See: http://publikasjoner.nve.no/veileder/2015/veileder2015_01.pdf 
assessment on a more strategic level. Respective authorities assess the potential conflict of proposed wind farm projects with defense issues, reindeer management issues and environmental issues. The Norwegian Environment Agency and the Cultural Heritage Directorate collaborate on the environment issue, "landscape" being one of three main issues. Potential conflicts are ranged on a scale from A (no conflicts) to E (high potential conflict). This result of the conflict assessment is an input into the licensing process.

There is also a guideline on "planning and locating wind power installations" issued in 2007 by the Norwegian Ministres of Environment and of Oil and Energy (2007), providing the directions for how these more strategic considerations and trade-offs are to be done.

The values of landscape experiences and cultural ecosystem services are indirectly and implicitly included in the planning process from the overall level in the treatment of concessions to the local level EIAs. However, as landscape is not explicitly part of the strategic level assessment and the local level EIA level landscape assessment in our opinion is a bit decoupled from underlying preferences of people, there is potential to bring in the value of affected landscape experiences more explicitly into the process. ${ }^{48}$

\section{Hydro power}

Hydro power has changed the landscape in Norway enormously in the past. Currently, there is little support for more of the larger scale hydro power developments. Instead, upgrades of existing hydro power installations are more feasible, with potentially more limited landscape impacts as a result. However, in addition there is a drive to develop smallscale hydro power, which each in itself may have limited landscape impacts, but cumulatively landscape impacts may become large. Each of the power stations typically need access roads etc. that make the overall landscape impact much larger. There have been several hundred applications for concessions the last few years at NVE, though the actual development on the ground very much depends on the electricity prices, which recently have been relatively low. To our knowledge, there are guidelines at the county level for planning and locating small scale hydro

\footnotetext{
48 For completeness of this review: There are also two guidelines on the visualisation of impacts of wind power projects, see http://www.miljodirektoratet.no/Global/dokumenter/tema/arter_og_naturtyper/ Sumvirkninger\%20p\%C3\%A5\%20landskapet.pdf and http://www.nve.no/Global/Konsesjoner/Vindkraft/ Rapporter\%20og\%20veiledere/NVE_Veileder_5_2007.pdf
} 
stations, but whether individual or probably more crucially cumulative landscape impacts are properly assessed is unclear to us from the information at the websites of the Environment Agency or NVE. Some of the upgrades and extensions of current large-scale hydro power installations do require EIA. However, it is likely that the cumulative impacts and impacts from small-scale are currently better assessed in practice in the area of wind power development than for hydro power projects.

\section{Transmission lines}

Statnett is the system operator in the Norwegian energy system. This means operating about $11,000 \mathrm{~km}$ of high-voltage power lines and 150 stations all over Norway. New transmission lines, especially those which go through nature areas and areas connecting east to west through mountains and across fjords have been highly controversial in recent years. The reason seems primarily to be related to the visual impacts of the lines in the landscape. One high profile case was the new proposed line between Sima and Samnanger across an arm of the Hardanger fiord in 2011. Several government commissions looked into this project and the potential impacts. In the end, the perceived benefit for society at large was deemed higher than the negative landscape impacts, and the project accepted. There was no good basis to make this judgment, as no studies were carried out about the welfare loss experienced locally and by the general population and tourists. The welfare loss per person would not need to be very high for the net benefit of the project to be negative, assuming that more people than just the local population would feel a loss from the landscape degradation.

More recently, Statnet has developed its own guideline on CBA (Statnett 2014), with the aim of using this tool more frequently in its project assessments. There is no provision in this guideline to better or more thoroughly assess landscape impacts, for example in monetary terms, compared to the standard, general guidelines on CBA. Hence, it is "status quo" on this compared to previous practices (see discussion in chapter 5.5.5). In some recent CBAs, the valuation of traditionally un-priced landscape impacts haven been attempted brought into the valued domain through the use of international benefit transfer methods (as there are still very few comprehensive Norwegian studies to lean on) (see Box 5.6 for an example). 
Box 5.5 Example of a CBA of transmission line upgrades and removals going through forest (Nordmarka) and cultural landscapes into Oslo

In a recent CBA of potential upgrades of the transmission lines through the Nordmarka forest north of Oslo (see map below), which involved the option of removing one set of lines, Vista Analysis (2014) conducted an economic assessment of the landscape and other impacts for different users. The primary tradeoff was between removing a line with more impacts in a residential area (line to the left in the map) or in an area with more of the prime recreation forest and fewer residents (line to the right). Vista used implicit valuation (i.e. how much would the users need to be willing to pay for their option to have highest net benefit) and a review study of how much property prices are reduced in the proximity to power lines and facilities, to conclude that it most likely would be best to remove the line to the left. There were also differences in the investment costs. A general EIA for the lines concluded that the landscape impacts were slightly more positive removing the line to the west (due to a more varied landscape, more cultural elements etc.). However, the decisive factor on the benefit side was that the number of users affected by the line to the east would have to be quite high (or the valuation per user high) to outweigh the property value and other benefits of removing the line to the west.

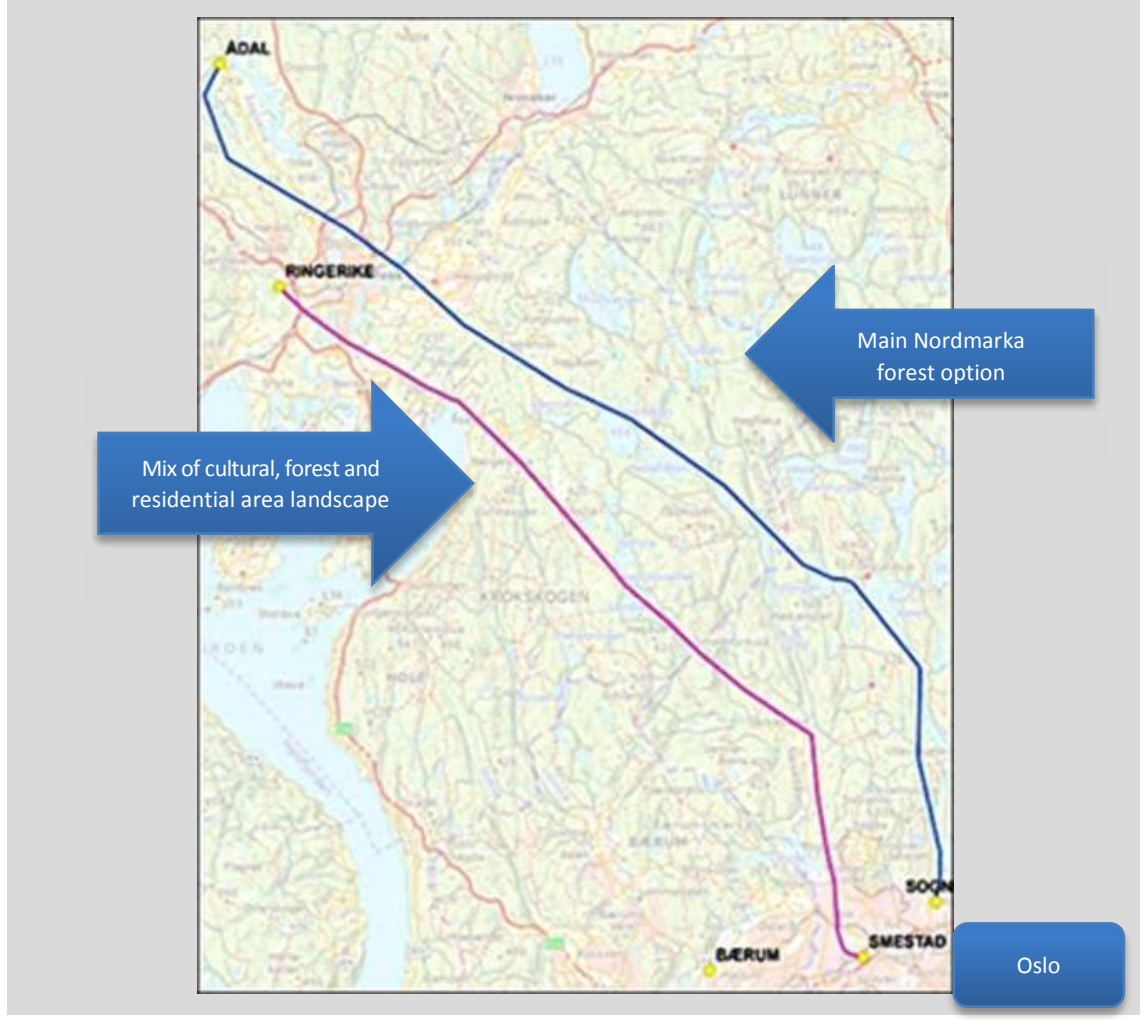

Source: Vista Analyse (2014) 


\subsubsection{Impact assessment and cost-benefit analysis for road projects}

While EIAs are required for all large infrastructure projects, in some sectors full cost-benefit analysis (CBA) is also carried out. The law (utredningsinstruksen) states that all reforms or measures are required to have their economic, administrative and other substantial consequences for the government and for society at large assessed. How this official requirement is interpreted seem to vary between sectors, types and sizes of public projects etc., as we have also touched upon above. In the road sector, there is a tradition for carrying out both an EIA and CBA for most road projects. It is common to carry this out in combination, therefore there is a central guideline to both EIA and CBA ("impact analysis") in one for road projects issued by the Norwegian Public Roads Administration (Statens Vegvesen 2014; revised version of the former Handbook 140). ${ }^{49}$ This guideline has lead the way for other public sectors to follow. The practice in different sectors generally seems to follow this guideline, more than the recent guidelines from the Environment Agency reviewed above. We will look at how landscape experiences and impacts are treated in the framework for assessing road impacts.

\section{Landscape assessment in an EIA format}

The first part of the guideline takes very much an EIA approach, where the so-called "un-priced impacts", typically environmental impacts, are assessed in non-monetary terms. Other impacts, such as the benefits of the new road for transport users (including for example value of saved travel time and reduced accident risks), the costs of construction etc. are typically valued in monetary terms. The currently "un-priced" impacts are divided into five themes: Landscape (landskapsbilde/bybilde), local environmental quality and outdoor life/recreation, nature, cultural environment, and natural resources. This division follows the EIA tradition. The cultural services we discussed in chapter 3 and 4 derived from landscape qualities may be found under several of these themes, not just the landscape category. Hence, the division may be hard to use for assessing values of landscape experiences.

The section on landscape is written with the aim of incorporating especially the aesthetic or visual impacts of roads outside cities and within. The scope is limited explicitly compared to some of the other

${ }^{49} \mathrm{http} / /$ /www.vegvesen.no/Fag/Veg+og+gate/Planlegging/Grunnlagsdata/Konsekvensanalyser 
themes to avoid "double counting" of the same impact under different themes. Direct use of an area for recreation, for example, is included under the theme local environment (but in that section such impacts are not closely related to the landscape features as such). The delimitation between themes is not so easy in practice, though the guidelines have a table which shows which elements belong to each theme. The section on landscapes was written before the guidelines from the Environment Agency on landscape characterisation and valuation reviewed above and is in any case more directly written for the analysis of impacts from road projects. Even so, it is commonly used in other sectors. In the same way as the other guidelines, the landscapes that are affected are characterised by noting elements of landform/terrain, vegetation, water, built environment and other elements (power lines, view points, land marks etc.). After registering the affected landscape according to the aspects above, it is also described and categorised in types of landscapes of different "visual character", i.e. whether it forms a whole / is similar, consists of different landscape types or contain areas of "unclear structure".

The next step is valuation of landscape's aesthetic character. There are two dimensions. One is whether the landscape is dominated by natural features, is located in areas with medium or low population density or whether it is within a densely populated area or city. The second dimension, the value dimension, is whether the area is considered to have small, medium or high value. This valuation is combined with the extent of the impact, measured from large positive to large negative (5 point scale). These two are then combined in a figure assigning a total consequence score for the aesthetic impact of the road. There is a section specifically devoted to how the traveller on the new road will view the landscape (as opposed to those who live within sight of the road or who use the landscape for other purposes).

\section{From EIA to CBA}

The assessments of landscape and other "un-priced" impacts are then brought into the CBA framework together with the other effects, many of which are quantified in monetary terms. The priced effects are put together and compared, to the extent possible, with the un-priced effects given scores in number of + and - (from ----- to +++++). It is difficult both to compare the categories and to sum across them, and to know how they should be considered when compared to the priced effects.

As noted, the aim of the guideline is to satisfy requirements both for EIA and CBA. This means that both to some extent suffer. If the starting point was CBA, it is likely better to take the welfare perspective from the 
start, i.e. focusing on the services derived from the landscape (and the road) and classify, measure and to the extent possible value these in monetary terms using some of the methods discussed in chapter 4.2.

The general guidelines on CBA in Norway (the most recent being DFØ 2014) generally follow Statens Vegvesen (2014) in the assessment of unpriced effects. Hence, many of these impacts, including the landscape effects, remain in the un-priced category and are not deliberately and consciously assessed with people's welfare in mind. This is also the case for the potential impacts on landscape experiences. Some of the unpriced impacts could be valued in monetary terms, or at least be considered more systematically in terms of ES and welfare impacts.

\subsubsection{Assessment of how landscape experiences are taken into account in Norway}

There is a certain awareness in Norway about the importance of landscapes and the benefits humans derive from landscapes, as reflected in various laws, including the Nature Diversity Act, which acknowledges the importance of the diversity of landscapes. There is a large landscape mapping and characterisation exercise ongoing and two guidelines issued by the Nature agency for landscape analysis and valuation. This provide a promising basis for assessing how landscape impacts may affect the values people derive from landscape experiences. The guidelines issued by the Public Roads Administration on EIA and CBA seems to be more used in practice, across many sectors. The guidelines for characterizing and valuing landscape from the Environment Agency, reviewed above, has an even less clear definition compared to other impact themes making it even harder to make a clear distinction in practice of value of landscape experiences compared to the other impact themes (which may also include impacts related to landscape).

The guidelines reviewed are somewhat decoupled from the explicit assessment of the specific services people derive from landscapes and their preferences, and the value of these services, and how valuation of landscape impacts may be used to make better decisions. The landscape analysis advanced by the guidelines comes from an EIA and planning tradition, and is therefore not immediately useful for the considerations of interest in a CBA. In other words, a CBA particularly concerned about assessing the loss of benefits from landscape change, would perhaps start out by linking the landscape characteristics more directly with the cultural services generated, and then (ide- 
ally) value some of the loss by the use of economic valuation methods. This would enable the comparison of the loss of landscape experiences from landscape degradation with the usually monetized benefits of a transmission line, wind power project or similar. And CBA is a potentially a more useful tool for prioritising between different projects, with more or less serious landscape impacts, as it has an explicit grounding in welfare economics.

To date, the CBAs of landscape changing projects have yet to value such changes in monetary terms in Norway, partly because the tradition of using categories of un-priced effects (including landscape effects) has been adopted from EIA (especially in the case of road projects, though other sectors have done the same) and partly because the number of studies valuing landscape impacts explicitly as part of CBAs or as separate studies are few and far between. Hence, there is little basis in the literature to for example transfer benefits or costs to a relevant decision-context in need of assessing the costs of landscape degradation. Some more recent CBAs try to be more explicit about what such costs may account to. The Norwegian Ministry of Finance's guidance on CBA over the years has largely followed the guideline from the Public Roads Administration in terms of treating impacts as unpriced, but have gradually become more positive to value such impacts in monetary terms.

Many of the studies reviewed in chapter 4 include forest and agricultural landscapes that are impacted by forestry and other activities. While some of the guidelines and practices discussed above typically include larger projects such as power lines, roads etc., there is also a potential to manage the agricultural and forest land more in line with people's preferences when it comes to other human uses. Nordmarka forest in and around Oslo, for example, the most important forest area for recreation in the whole of Norway in terms of number of users, have few and loose restrictions on commercial forestry activities in the recent "Marka law". Hence, the studies assessing people's preferences for both forest and agricultural landscapes do to some extent differ from the landscapes that are the results of at least the more industrial practises of forestry and agriculture (as discussed in chapters 4.3.1 and 4.4.1). There is a potential to differentiate laws and regulations to better account for different users, including the landscape experiences derived from forests and agricultural landscapes near areas where many people live.

Finally, a challenge in Norway, as in other countries, is that some of the responsibility for management of landscapes is given to municipali- 
ties that are also in need of generating economic activities (as comes out quite clearly in the aims of municipal planning above). As the municipality typically is most concerned about its immediate constituency (i.e. its residents), the priorities about landscape management may not take into account that some landscapes are public goods of regional and national importance.

\subsection{Examples from Sweden, Finland and Iceland}

This chapter provides shorter examples and reviews of the other three Nordics; Sweden, Finland and Iceland. The aim is not to be comprehensive but to provide certain examples and perspectives that supplement the more in-depth reviews of Denmark and Norway in the previous two sub-chapters and add to a fuller picture of how landscape experiences and impacts are considered in various contexts. Some of the laws, procedures and guidelines have similar content in all five countries (all countries have for example ratified the Landscape Convention, have requirements for EIAs of projects with significant environmental impacts etc.) and we do not repeat these here.

\subsubsection{Sweden}

The Swedish government ratified the European landscape Convention in 2011. The responsibility for the convention is held by the Swedish Ministry of Culture, which delegates issues of following up implementation to the National Heritage Board. As noted by Gren (2013), there is no "real landscape policy" in Sweden. Rather, landscape has historically been a factor that is dealt with in different sector policies (forestry, transport, regional development etc.), often in different ways and often not in a coordinated manner. In order to ensure a more cohesive Swedish landscape policy in line with the Convention, the Natural Heritage Board has taken the initiative to create a national coordination group (nationell samordnignsgrupp) consisting of relevant authorities from different sectors (environment, forestry, transport, agriculture etc.). In 2012 the group established a working group preparing for development of a national strategy in Sweden ensuring that efforts to preserve landscapes become more consistent and coordinated in line with the goals of the Convention.

Municipalities have the main responsibility for physical planning. Municipal planning is governed by the Building Act. In recent years, the 
Building Act has been strengthened in several aspects with regards to taking landscape into consideration. First of all, the ratification of the Convention itself means that the parts of the building Act referring to the responsibility to ensure sustainable use of natural resources (soil and water), to take landscape into consideration in a holistic manner and to ensure democratic involvement in planning processes have been strengthened. In 2011, the Building Act was adjusted to ensure that the physical planning to a larger extent integrates the "big picture" and becomes more coherent and strategic (Åkerlund 2013). The changes include the responsibility of municipalities to explicitly describe how they integrate national and regional concerns and priorities, especially those related to sustainable development. Landscape is a typical example of an issue that often transcends municipal borders and where larger landscape effects of local development may easily be overlooked in local planning (As is also the case in Norway, as noted in chapter 5.5.6). As a Swedish landscape policy is further developed at national and regional levels in the coming years, the revised Building Act will help ensure that this policy is taking into account down to the municipal level.

\section{Integration of landscape in cost benefit analysis of road projects}

The Swedish Transport Administration has a comprehensive set of guidelines for cost-benefit analysis of road projects. The material is based on many of the same general principles and elements as the Norwegian guideline reviewed in chapter 5.5.5. ${ }^{50}$ However, one difference seems to be that the Swedish guidance material is not combining EIA with CBA, as the Norwegian guideline does. The result seems to be that there is little guidance about how to analyse landscape impacts within the CBA framework. Chapter 16 (Markanvändning) of the guideline "ASEK 5.1 - Samhällsekonomiska principer och kalkylvärden", for example, provides a brief description about the difficulty of assessing landscape impacts from road projects. There is also a discussion about the methodological challenges of using monetary valuation studies in the assessment of such impacts. But it is also acknowledged that some types of methods and studies may be useful. A suggestion is made to capture people's preferences with using direct monetary valuation by comparing the saved travel time from a new road with the level of impacts on nature and landscapes. This is in our view a possibility, but it is not a satis-

\footnotetext{
${ }^{50}$ See details at: http://www.trafikverket.se/Foretag/Planera-och-utreda/Planerings--och-analysmetoder/ Samhallsekonomisk-analys-och-trafikanalys/Gallande-forutsattningar-och-indata/
} 
factory approach for projects with substantial landscape impacts and impacts on potential landscape experiences both for travellers, residents and recreationists.

\section{Landscape in long-term planning - a project by the Swedish Transport Administration}

The Swedish Transport Administration (Trafikverket) has started a project looking at "Landscape in long-term planning". The project was conceived when the authority should make an assessment of the environmental impacts of the plan for development of the transport system in Sweden 2010-2021. The authority realized that with current methods, they had no way to assess the effects of the plan at an overall landscape level (Trafikverket 2014). As a result, the Swedish Government requested the Transport Administration to further develop methods for environmental assessments of plans and programs.

The "Landscape in long-term planning" project emphasises that landscapes must be understood in a holistic manner and cannot be handled by different sectors separately. (This often leads to conflicts at a late stage in the planning process as interests of different parties may be overlooked, which leads to delays and increased costs.) In the project, a participatory methodology for landscape character analysis was developed, with a focus on data gathering and characterisation of different landscape areas through a series of field trips and workshops involving professions with different technical skills as well as representatives of interested parties (see figure 5.6). This process would lead to a common understanding of the landscape(s) and the landscape values in a certain region, as well as trends, vulnerability and potentials. Documented in a report, such a regional assessment can then be used by different authorities at different levels as a basis for the planning in a certain region. 
Figure 5.6: The process of landscape character analysis developed in the "Landscape in long-term planning" project of the Swedish Transport Administration (in Swedish)

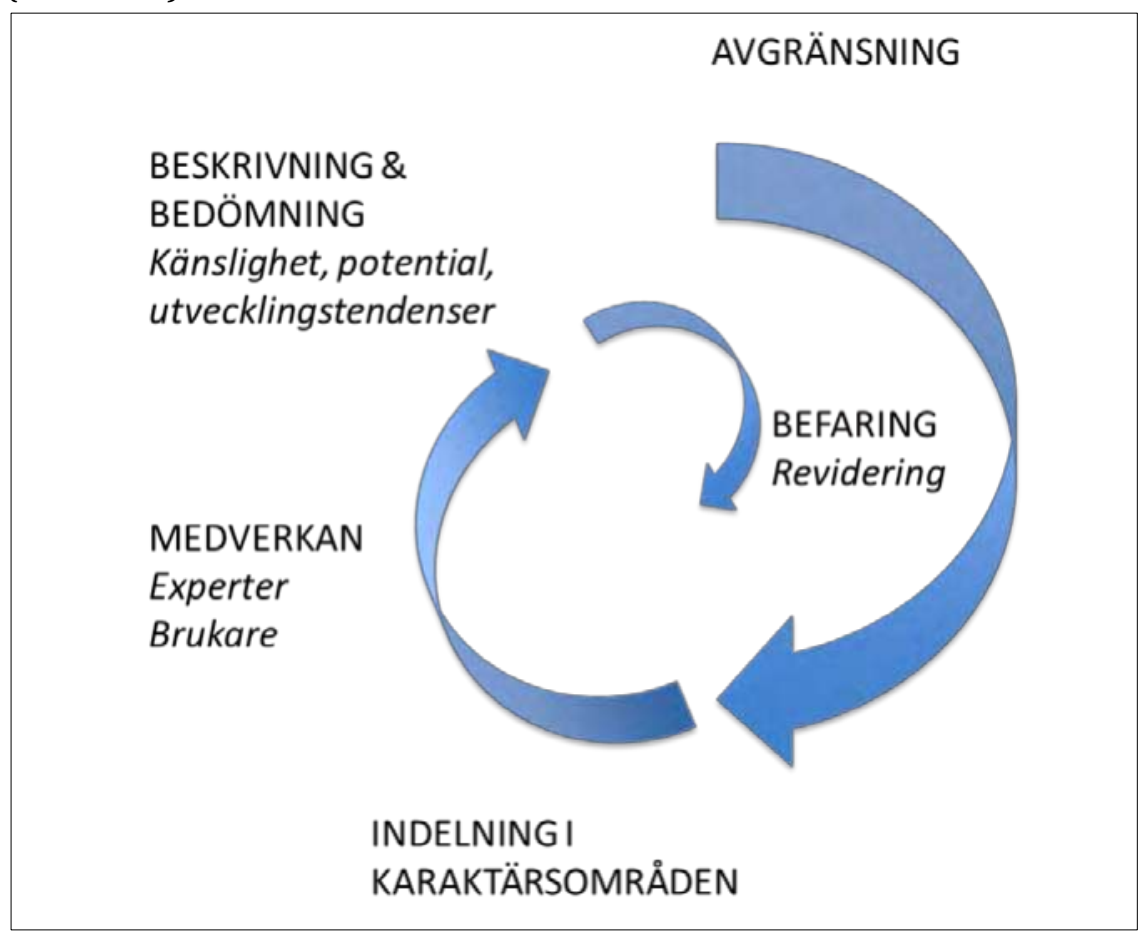

Source: Trafikverket 2014.

The methodology was tested in two regions; Västra Götaland and Västmanland (figure 5.7). One finding from the pilot in Västra Götaland, was that it is much easier to assess landscapes and values if society has expressed (in the form of a landscape policy or other) goals for the development of the landscape in the area in question. The response from planners at the county level in Västmanland, was that the project was very constructive and the result easy to use when discussing development plans with the municipalities. 
Figure 5.7: Example of landscape characterization and zoning in Västra Götaland

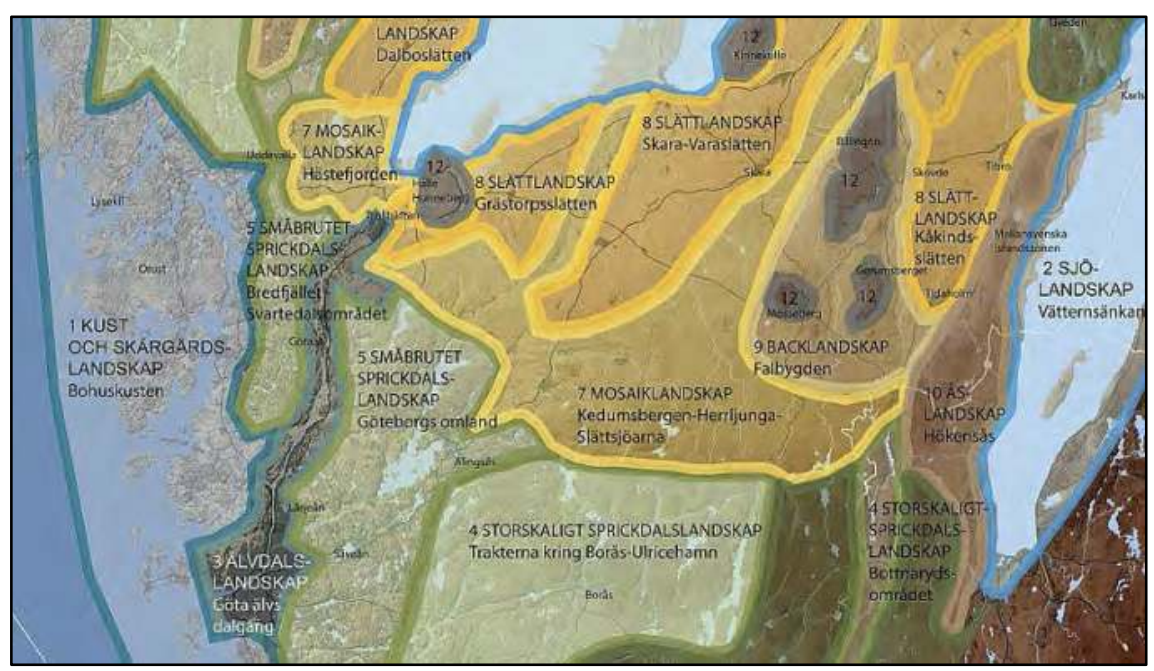

Source: Trafikverket (2014).

\section{Wind power: Area planning and landscape assessment practises}

In Sweden, municipalities have the main responsibility for physical planning. Areas that are particularly suited for certain types of activity shall, however, be identified and noted as areas of "national interest" (riksinteresse). The Swedish Energy Agency is responsible for identifying the areas of national interest for wind energy production (SEA 2014). By 2013 , areas of national interest for wind energy production consisted of 281 areas on land and 29 areas at sea (or in lakes). The total surface area is $7,868 \mathrm{~km}^{2}$. The main criteria for selection of land are; sufficient wind resource, area larger than $5 \mathrm{~km}^{2}$ (land) and distance from churches and housing (>800 meter, land). Certain areas are exempt for designation as area of national interest for wind energy production; protected areas (National parks, Natura 2000 sites, nature reserves) and areas designated "national interest unbroken mountain" or "national areas unbroken coast". To some extent, consideration of landscape is included in these exemption categories.

Gren (2013) points out that the planned phase out of fossil fuels and scaling-up of renewable energy such as wind power and biofuels in Sweden over the next decades, will represent a paradigm shift in how the Swedish landscape is used. Gren emphasises that the consequences this will have for the Swedish landscape will be huge, and that it at present is difficult to foresee how it will affect landscape qualities.

A recent report (Mels and Mels 2014) published as part of the Vindval program (a cooperation program between the Swedish Energy 
Agency and the Swedish Environmental Protection Agency) has assessed how landscape is taken into account in planning for wind energy in Sweden today. The study questions how existing landscape analyses are developed, what knowledge is considered to be relevant, and what impact today's landscape analyses have for participation and dialogue.

The authors point to several problematic features with the way landscape analysis is currently conducted in Sweden. They note that often landscape analyses are characterized by a technological interpretative prevalence. The prevalence occurs because landscape analyses tend to emanate from a predominantly specialist-driven process (as was noted as the case in Norway as well). The landscape is emerging as a formal category, which can be mapped and described with the help of seemingly neutral concepts (string, structure, landmarks, landscape spaces, etc.), maps and images, and end up in an official and scientific "landscape character assessment". The result is a distinct interpretation of the landscape as a visual landscape, an image, and to a much lesser extent, an overall interpretation of the landscape as an everyday place in which the local population lives their lives and use the landscape for various experiences.

The authors note that non-expert interpretations of landscape greatly affect local opinion about wind power, but are easily sidelined in "scientific" landscape characterization processes and less visible in formal documents. Empirical studies show that for non-experts, the interpretation of the visual landscape is strongly influenced by a variety of values, such as the links to commercial aspects, use value, accessibility, the design of the planning process, the ability to influence planning, adjustment of interests, etc. Understanding and managing such contexts and aspects thus becomes crucial for describing landscape values in a way that makes the landscape assessment relevant for the affected population.

The authors argue that landscape analysis as a method used in Sweden today needs to be further developed in order to be able to seize and include public landscape interpretations and values, i.e. people's preferences. The report introduces the concept of participatory landscape analysis. Participatory landscape analysis has strong ties to specific developments in current planning theory and practice, but also to developments in landscape research. With regard to landscape it tones down earlier emphasis on quantitatively measurable spaces and promulgates considerably more place-oriented, qualitative interpretations and holistic perspectives. In a broader planning context, both in academic literature and in Swedish and international policy development, it highlights 
concepts such as participation, communicative planning, and the importance of everyday knowledge, cognitive and affective values. This is in line with the European Landscape Convention, which reaffirms the need for a communicative turn in practical planning. It would also be in line with the ecosystem service approach, which is oriented towards direct human benefits.

We cannot here judge to what extent Mels \& Mels' critique of current landscape planning practices related to wind power in Sweden is valid. (In the sub-chapter about Finland below, a short description of an expert-driven landscape assessment for a wind energy project is described.) What does seem clear, however, is that there is a need felt in many cases to ensure that a technical and expert-driven landscape character assessment processes to a larger extent is complemented by methodologies allowing for inclusion of the perspective of non-experts and locals. This trend is also exemplified by the Swedish Road Authority's "Landscape in long-term planning' project".

\subsubsection{Finland}

There are many traditions of researching, classifying and evaluating landscapes in Finland (Ymparisto 2014a). The most important regulations promoting landscape protection are included in the Nature Conservation Act and the Land Use and Building Act. In Finland, areas can be designated as landscape conservation areas under Finland's Nature Conservation Act. According to the national land use objectives set in the Land Use and Building Act, valuable landscapes must be taken into account in land use planning. For example, they must be marked in the Regional Land Use Plans.

\section{Valuable landscapes}

In 1994, the Finnish Ministry of the Environment celebrated Finland's 75 years of independence by selecting 27 National Landscapes. The National Landscapes of Finland represent the special environmental and cultural features of the country. The National Landscapes are recognized to have great symbolic value and widely recognized significance in cultural and historical terms, or in the popular image of nature. A National Landscape working group under the Ministry of the Environment selected the areas. The 27 National landscapes have no fixed boundaries, which means they do not have a special role, legal or otherwise, in land use planning. However, the "national landscapes" are considered immensely important for tourism, for example. Many of the landscapes are 
considered unique attractions and their status as National Landscapes implies that any overall changes to them should be kept to a minimum.

There are 156 areas in Finland that have been classified as Nationally Valuable Landscapes. They represent the cultural landscapes of Finland, and their value is based on culturally significant natural diversity, cultivated agricultural landscapes and traditional architecture. In 1995, the Finnish Government designated the areas with a decision-in-principle. The aim of designating certain landscape areas as valuable was to secure prominent and viable rural landscapes and to arouse public interest in landscape management and preservation. The assessment of the Nationally Valuable Landscapes was based not only on particular features and special characteristics, but also on the regional landscape division. In 1992, a Landscape Area group set up by the Ministry of Environment divided Finland into ten regional landscapes, based on the regional variation of natural and cultural characteristics. The Nationally Valuable Landscapes were selected in order to represent the most important features of each region. The division into regions also ensured flexibility at the regional level with regards to how to secure Nationally Valuable Landscapes within the region.

At the moment, the Finnish Ministry of the Environment is updating the assessment of Finnish landscapes. In addition to Nationally Valuable Landscapes, Regionally Valuable Areas are also included in the inventory project, which runs from 2010 to 2014. The updating takes place in cooperation with the National Board of Antiquities, the Centres for Economic Development, Transport and the Environment, the state enterprise Metsähallitus and the Ministry of Agriculture and Forestry. In 2015, the Finnish Government will renew its decision-in-principle regarding valuable landscape areas.

\section{Wind power and landscape in Finland}

Particularly valuable landscapes are protected through designation of a certain area as a "landscape area", and generally restrictions are somewhat gentler and more flexible than the laws that are connected to a conservation area. As we have seen above, the Ministry of Environment establishes areas to be considered Nationally Valuable Landscapes. Regionally Valuable Landscapes are established by the regional state authority (the ELY-centre; Centre for economic development, transport and the environment), based on proposals from the regional council. In certain cases the regional ELY-centre can grant exceptions from the regulations that concern the landscape area (Medwind 2014).

For the most part, wind power construction is in Finland subject to the same regulations as other construction (Ymparisto 2014b). The con- 
struction of wind power plants should always be based on the land use plans drafted in accordance with the Land Use and Building Act. This means that the areas fit for wind power construction are defined in the plan. The planning of wind power plant sites is currently very active. There are a number of local master plans that steer the construction of wind power directly, in accordance with the 2011 amendment to the Land Use and Building Act. The currently effective regional plans allow the construction of around 6,000 MW of wind power, mainly on the sea, and the pending regional plans pave way for the construction of 14,000 MW of wind power on land. Building permits are always required for wind power construction.

The Land Use and Building Act specifies that the best suited placed for wind power should be pointed out at the regional planning level and that is preferable that wind power facilities are clustered in larger wind farms (Voimamylly 2012). In Finland, wind farms are not in the list of project types that require an Environmental Impact Assessment. However, larger wind projects that involve a minimum of 10 wind turbines or a total power generation of $30 \mathrm{MW}$ or more have to undergo the EIA procedure. This was for instance the case in the Humppila-Urjala project in Southwest Finland (involving more than 10 wind turbines). The regional state authority (the ELY-centre) oversees the need for an EIA and the EIA procedure itself.

The EIA program for the Humppila-Urjala project (Voimamylly 2012) in Southwest Finland deals with three alternatives: Option 0 (no wind farm), Option 1 (25 wind turbines of capacity 2-5 MW and hub height of 100-120 meters) and Option 2 (40 wind turbines of the same size as Option 1). The project is in accordance with local master plans in the area, which is characterized by forests and agriculture. The program notes which culturally valuable landscapes that are to be found in the project area or in close proximity; in the South the regionally valuable cultural landscape of Venäjä-Myllynkulma is located partially within the project area, and to the Northeast one finds Urjala's cultural landscape. The program also describes how impacts on landscape will be assessed. Visual effects on landscape are to be assessed within a radius of $15 \mathrm{~km}$. An analysis of the impact of the scenery is to be used using GIS software, showing how the wind turbines will be visible in the landscape from different angles. 
The English summary of the EIA (Voimamylly 2013) 51 presents two viable options; not implementing the project (Option 0 ) or implementing Option 1 with some adjustments (a maximum of 21 turbine units of 2,5-4 MW and hub heights of 120-140 meters. Option 2 (up to 40 wind turbines) was considered unsuitable for social and ecological reasons. With regards to landscape impacts, the strongest impacts were found to be in the immediate surroundings and to the closest settlements (for instance the municipality of Tourunkulma). With regards to the nationally and regionally valuable Venäjä landscape, ${ }^{52}$ it is noted that it will gain a new chronological layer when modern wind power plants become part of the landscape". The impact is considered tolerable: It is noted that the landscape change will be strongest from the main road 2 and south from there. It is noted that the "significant points" of the landscape area (estates, Humppila central and Myllynkulma) do not suffer from significant effects since there are no significant views opening from these points towards the wind farm. It is recognized that in greater distances, the turbines can change the landscapes identity in Jalasjoki cultural environment. However, due the long distance it is considered that the impact on the landscape remains small.

\subsubsection{Iceland}

As a sub-arctic island on the boundary between diverging tectonic plates in one of the world's most volcanically active regions, Iceland has a varied geology that provides the foundation for landscapes not found elsewhere in Europe. Glaciers, canyons, vast floodplains, fjords, lava fields, sub-glacially produced volcanic forms (such as hyaloclastite ridges and table mountains), colourful high temperature geothermal areas and an interior highland of $40,000 \mathrm{~km}^{2}$ that has never been settled by man, are examples of the visually diverse and unusual Icelandic landscapes. Only about a quarter of the island (along the coast) is inhabited, with about two-thirds of the population concentrated around the capitol Reykjavik in the western part of the island.

Iceland became party to the European Landscape Convention in 2012. The Planning Act was revised the same year, highlighting "land-

\footnotetext{
51 The full EIA (in Finnish) is available at: http://www.ymparisto.fi/humppilan-urjalantuulipuistoYVA

52 We note that in the English summary of the EIA program Venäjä is referred to as a "regionally valuable cultural landscape" and that it in the summary of the EIA itself is referred as a "nationally and regionally valuable landscape". This may be due to translation discrepancies from the Finnish originals.
} 
scape" in the preamble by noting that one of the goals of the act is to ensure preservation of landscape qualities. The current area planning strategy (landsplanstrategi) based on the revised Planning Act separates between the highland in the interior and the more cultural landscapes along the coast. Large and relatively untouched plateaus characterize the highland, and the aim is to ensure larger areas maintaining the untouched quality of wilderness. Along the coast, the cultural landscapes are influenced by inter alia migration from rural areas to cities and urban development, which has increased the awareness in Iceland in recent years of the necessity of planning that takes into account landscape preservation (Thors 2013).

No standard or single methodology is used to assess the impact of projects on landscape. Planners and consultants typically use internationally recognized methods while adapting them to an Icelandic context (Thrastarson and Bjarnadottir 2013; Loftsson 2013). The stronger legislative basis for landscape preservation in Iceland that has come in place in recent years has been complemented by a stronger interest in landscape at universities and among planners and consultants.

\section{The Icelandic Landscape Project}

As noted by Thorhallsdottir et al. (2013), much of Iceland has either sparse vegetation cover or is desert like. Thus, Iceland fits poorly into vegetation-based landscape classifications that reflect either agricultural or other land uses. In order to address this issue, The Icelandic Landscape Project started in 2006 with the aim to a) develop methods to describe and classify Icelandic landscapes and b) produce a classification of major landscape types for the whole country (except for urban and built-up landscapes). Field data were collected at a predetermined central GPS sampling point within a systematic $10 * 10 \mathrm{~km}$ grid system $(\mathrm{N}=114)$. The classification was based on the visual qualities of the physical characteristics of the land through a quantitative assessment of 23 variables on a 5-point scale. The variables included landscape depth, elevational range, shapes, forms and lines, patterns, textures and colours. The method does not include aesthetic or perceptual evaluations (such as attractiveness, intimacy or tranquillity). A cluster analysis produced 11 major landscape groups: 1: Glaciers, 2: Sandy plains and barrens close to glaciers and high mountains, 3: Sandy and gently rolling barrens, 4: Hilly and stony barrens, 5: Dry, sparsely vegetated highlands, 6: Rocky terrain and lavafields, 7: Fjords, including a subgroup of three coastal sites with nearby high mountains, 8: Flat coastal areas and islands, 9: Well vegetated but homogeneous lowlands 
and heathlands, 10: Deep, well vegetated valleys and 11: Areas of high visual diversity, mostly well vegetated.

\section{The cultural importance of landscape in Iceland}

In the recent masterplan for hydro and geothermal energy, extensive work was done to classify and evaluate landscape features and types in Iceland. The former Minister of Environment (Svarvadottir 2013) has noted that the studies showed that people in Iceland tend to have different perceptions of landscapes and its attractiveness and conservation value. While some valued verdant and gentle landscapes, others ranked landscapes that are raw and forbidding the highest. Svarvadottir noted that this shows how complicated the topic of landscape is, and that "landscape" is not only "out there" but is also a perception in the minds of the Icelanders (as we also discussed in chapter 3 ).

Icelandic painting and poetry are infused with praise of landscapes. In Njal's saga, one of the most famous works of saga literature, the Viking Gunnar is outlawed from Iceland. As he rides his horse towards the ship that will take him abroad, he takes a last look at his farm, the pastures and the hillsides and is struck by the beauty of the landscape. He cannot leave this land and stays to meet his death. Svarvadottir notes that the appreciation of landscapes is interwoven with the national Icelandic identity and the Icelander's sense of themselves. Icelanders for instance identify with Fjallkonan (the Mountain Woman), as a symbolic figure embodying the land and the love of the land. At the national holiday celebrations $17^{\text {th }}$ of June, poems are recited to Fjallkonan.

\subsection{Summary and some key points}

The aim of this chapter has been to review how landscape and landscape experiences are treated in guidelines, practices and examples in the Nordic countries, and whether there are weaknesses in terms of including the (monetary and non-monetary) values expressed by people and as reviewed in chapter 4 . We have provided more comprehensive reviews of Denmark and Norway, supplemented with a presentation of selected areas from Sweden, Finland and Iceland. It has not been the aim to be comprehensive about all possible ways landscapes may be treated. We have primarily looked at spatial planning, environmental impact assessments and cost-benefit analysis. We have particularly emphasized the larger infrastructure projects, which are generally important landscape changers in all the Nordic countries. There are also other land use changes that may be important that we have not reviewed specifically 
here, such as changes in the agricultural practices (more industrial farming), mining activities, and development of recreational homes along coasts and in the mountains.

Before the reviews, we provided a "quick and dirty" look at the common notions and images of landscape as reflected by Google searches. There are of course clear differences in the physical characteristics of the countries, but there are also differences displayed in common Google images that have more to do with cultural conceptions and preferences of people. Despite having a lot of forest, Norwegian "landscapes", for example, is typically looked at more as containing mountains and fjords. While the landscape profiles of Norway, Finland, Denmark and Iceland are quite distinct, Sweden's landscape images are more diverse. Differences in both geography and culture will have bearings on the appropriate ways to incorporate values of landscape experiences in guidelines, assessments and decision-making at national and local levels.

All the Nordic countries have ratified the European Landscape Convention and work in various ways to implement its intentions. Based on the more comprehensive reviews of Denmark and Norway, we made brief assessments of how landscape experiences are taken into account.

In Denmark, landscape impacts are gradually taken more into account. Recognising the increasing pressure on the Danish landscape, for example, the Danish Ministry of Environment initiated a process from 2003-2005 to develop a systematic and coherent assessment using the framework of landscape characters. While it is voluntary to apply the landscape character method, the State urges local authorities to carry out the method, which is becoming widespread as a support tool for local decision making. The landscape character method is made for and by experts, not aimed at the larger public. To counter this bias, the Ministry of Environment pioneered a Landscape Atlas in 2014 in cooperation with a municipality and local stakeholders in order to illustrate landscape mapping in a popular way and increase the public interest in the quality of local landscapes.

The development and increasingly widespread application of the landscape character method shows an emerging recognition of landscape forming a whole as opposed to an area of separate functions. Danish municipalities are starting to take up the new approach and to make the connections between service, place of living, production and landscape in their planning. Despite a clear division between towns and the countryside in the physical planning, the Danish rural landscape is de facto in a process of urbanisation, especially close to urban areas: Since the 1990s, non-agricultural enterprises are allowed to establish them- 
selves in existing farm buildings and to expand these and part time farming is on the rise. Both tend to plant, change and cover previously open vistas. This development can make it more difficult to "read" and understand a landscape. An example of the scale of this phenomenon is the rural area around the village Sengeløse close to Copenhagen, where more than $50 \%$ of agricultural buildings are no longer used for agriculture but for various industrial purposes. These trends towards an increasing urbanisation of the rural landscape and subsequent changes to the visual character cannot be regulated through Local Plans as these are excluded in the open land according to the Planning Act.

Projects that require an Environmental Impact Assessment need to consider impacts on the landscape. A Ministerial guideline exists since 2008 on how to incorporate landscape considerations in the different phases of EIAs, describing and exemplifying how to assess landscape impacts in the three EIA phases: Screening, Scoping and the full EIA. However, Ministerial manuals on carrying out Cost Benefit Analyses in the area of transport and energy do not require impacts on landscape to be quantified and valued in monetary terms, potentially leading to false conclusions.

In terms of (cultural) ecosystem services, current tools in landscape assessment do not apply this concept. There is an evident lack of inclusion of the value of landscape services, such as recreation, into environmental impact assessment or cost-benefit analysis. There is also a clear lack of studies investigating how visitors perceive landscapes, landscape changes and the importance for recreational quality.

In Norway there is a certain awareness of the importance of landscapes and the benefits humans derive from landscapes, as reflected in various laws, including in the Nature Diversity Act emphasising the importance of diversity of landscapes. A large landscape mapping exercise covering the whole country is currently taking place and several guidelines for assessing, characterising and valuing landscape (in nonmonetary terms) have been developed by the Environment Agency in the last five years. On the negative side, these guidelines are not well developed to include the preferences and values of people (not just locally) or to be incorporated in EIA, CBA or spatial planning. They are to some extent expert-driven processes emphasising especially visual and aesthetic aspects of landscapes, not so much the services or benefits derived from landscapes that can be utilised in for example CBA. The ecosystem service concept has not yet made its way into the guidelines. Using the ES approach may be a promising avenue to better emphasise human benefits over landscape aesthetics per se in landscape 
assessments and analysis. Further, very few, if any, CBAs have been carried out for large energy infrastructure projects containing appropriate monetary valuation of landscape impacts. This is a clear weakness, and is likely due to few available studies to build on and because a method for assessing such impacts as "un-priced" effects based on EIA have been well-established from road project analyses. This is also reflected in the guidance on CBA from the Ministry of Finance. In our view, there is also a potential to increase the consciousness about the landscape-sensitive management of regular commercial farming and forestry activities, as these activities are also very important for the values people derive from "everyday landscape" experiences (as we discussed in Chapter 3 and 4). It is not just the "spectacular" landscape changes, such as wind power projects and fjord-crossing power lines that are important, but also other activities and cumulative impacts that "escape under the radar" that shape landscape in ways that may oppose the preferences of the majority of people.

Finally, a challenge in Norway as in many of the other Nordics, is that much of the responsibility of landscape changing activities is delegated to the local level, when in effect many types of landscapes may be public goods of regional or national importance. The municipalities in need of economic development in the face of urbanisation and other trends, do not always have incentives to take national interests into account.

We also reviewed selected areas of landscape analysis and assessment in Sweden, Finland and Iceland.

In Sweden, landscapes have traditionally been treated by different sectors and there has, by some accounts, not been a real, overall landscape policy. There are signs that this is changing as work on a national landscape strategy was initiated in 2012. In Sweden, physical planning mainly takes place at the municipal level and is governed by the Building Act. In 2011, the Building Act was adjusted to ensure that the physical planning to a larger extent integrates the "big picture" and becomes more coherent and strategic (Åkerlund 2013). The changes include the responsibility of municipalities to explicitly describe how they integrate national and regional concerns and priorities, especially those related to sustainable development. As a Swedish landscape policy is further developed at national and regional levels in the coming years, the revised Building Act will help ensure that this policy is taking into account down to the municipal level. There is significant activity in Sweden by key stakeholders related to how landscape concerns can become better integrated. A research project under the Vindval program on wind energy, documents that landscape assessments related to wind power develop- 
ment in Sweden often fails to fully integrate the perspectives and values of the non-experts - who are often residents in the affected area. The study concludes that more participatory methods are needed in landscape assessment related to wind power development in Sweden. In the "Landscape in long-term planning" project, the Swedish Transport Administration has developed a methodology combining the more traditional and expert-driven landscape assessment approach with a participatory process. This enables regional mapping of landscape values in a way that reflects the view of experts and well as non-experts. These Swedish experiences seem relevant for other Nordic sector authorities.

Finland does have a national landscape policy. According to the national land use objectives set in the Land Use and Building Act, valuable landscapes must be taken into account in land use planning. For example, they must be marked in the Regional Land Use Plans. In 1995, the Finnish Government designated 156 areas as Nationally Valuable Landscapes. They represent the cultural landscapes of Finland, and their value is based on culturally significant natural diversity, cultivated agricultural landscapes and traditional architecture. In 1992, a Landscape Area group set up by the Ministry of Environment divided Finland into ten regional landscapes, based on the regional variation of natural and cultural characteristics. The Nationally Valuable Landscapes were selected in order to represent the most important features of each region. The division into regions also ensured flexibility at the regional level with regards to how to secure Nationally Valuable Landscapes within the region. At the moment, the Finnish Ministry of the Environment is updating the assessment of Finnish landscapes. In addition to Nationally Valuable Landscapes, Regionally Valuable Areas are also included in the inventory project, which runs from 2010 to 2014. We also briefly assessed the EIA of a wind power project in Finland, in which the landscape assessment was carried out with a scientific and expert-driven methodology.

Iceland is a thinly populated country with a very special geology and unique and varied landscapes. Landscape policy is a relatively recent issue in Iceland, but has come into focus in the academic and political milieu in recent years. The revised Planning Act of 2012 highlighted that one of the goals of the act is to preserve valuable landscapes. Iceland's unique nature and huge wilderness areas means that Iceland fits poorly into vegetation-based landscape classifications used elsewhere in Europe. With the Icelandic Landscape Project, a system has been developed to classify the main Icelandic landscape types. The system is natural science-oriented and does not take into account aesthetic or perceptual 
factors. The cultural dimension of landscape is strong in Iceland, where appreciation of landscapes is intervowen with the national Icelandic identity and Icelander's sense of themselves - according to former Minister of Environment Svarvadottir.

The survey of the Nordic countries shows many variations: The landscapes of the different countries vary, as well as the perceptions and importance attributed to certain landscapes in each country. All countries are party to the Convention, but the degree to which national landscape policies have been formulated varies, and landscape classification methods at the national level also vary. At the sector level, we see that different sectors to a limited extent (if at all) take into account the wider perspectives of landscape as an ecosystem service and the values of nonexperts - but that there are different initiatives in the direction of improving inclusion of non-expert values. At the project level, EIAs and CBAs are usually carried out without detailed guidelines for landscape assessment. Moreover, often there are no landscape policies or descriptions of landscape values for the area in which the project will take place, which makes it unclear when impacts should be considered critical. This often leads to scientific and expert-driven assessments of landscape impacts that may not always reflect landscape values held by society as a whole or the local population fully. 


\section{References}

Alsvik, K. (2013). Samfunnsøkonomisk verdi av landskapsinngrep ved veiprosjekter en Betinget Verdsettingsstudie. Economic value of landscape intervention by road projects - a contingent valuation study. Master Thesis. Norwegian University of Life Sciences.

Ayala, de. A. et al. (2014). Transferring landscape values using discrete choice experiments: Is meta-analysis an option? Working paper, European Society for Environmental and Resource Economists.

Bergland, O. (1998). Kan vi sette en pris på landskapsopplevelsen? I: Framstad, E. \& I. B. Lid (red) Jordbrukets kulturlandskap. Forvaltning av miljøverdier. Universitetsforlaget.

Bergstrom, John C. \& Ready, R.C. (2009). "What Have We Learned from Over 20 Years of Farmland Amenity Valuation Research in North America?" Appl. Econ. Perspect. Pol. (Spring 2009) 31 (1): 21-49. http://dx.doi.org/10.1111/j.14679353.2008.01424.x

Boman, M., Norman, J., Kindstrand, C. \& Mattsson, L. (2008). On the budget for national environmental objectives and willingness to pay for protection of forest land. Canadian Journal of Forest Research 38(1): 40-51. http://dx.doi.org/10.1139/X07-129

Bostedt, G. (1997). Public goods in Swedish forests: essays on nonmarket valuation and environmental policy. Ph.D. Thesis, Swedish University of Agricultural Sciences, Umea.

Bostedt, G. \& Mattson, L. (1991). Skogens betydelse för turismen: En samhällsekonomisk pilotstudie (The importance of forests for tourism: a pilot cost-benefit analysis). Arbetsrapport 141, Department of Forest Economics, Swedish University of Agricultural Sciences, Umeå.

Bostedt, G. \& Mattsson, L. (1995). The value of forests for tourism in Sweden. Annals of Tourism Research 22 (3), 671-680. http://dx.doi.org/10.1016/0160-7383(95)00007-S

Breivik og Rafoss (2011). Fysisk aktivitet; omfang, tilrettelegging og sosial ulikhet - en oppdatering og revisjon. Norges idrettshøgskole/Høgskolen i Finnmark.

Bryan, B.A., Raymond, C.M., Crossman, N.D. \& Macdonald, D.H. (2010). Targeting the management of ecosystem services based on social values. Where, what and how?, Landscape and Urban Planning 97, pp. 111-122. http://dx.doi.org/10.1016/ j.landurbplan.2010.05.002

Bryn et al. (2012). CULTOUR: Et forskningsprosjekt om reiseliv, kulturminner og gjengroing. Skog og Landskap og Bygdeforskning.

Buijs, A.E., Elands, B.H.M. \& Langers, F. (2009). No wilderness for immigrants: Cultural differences in images of nature and landscape preferences. Landscape and Urban Planning 91, pp. 113-123. http://dx.doi.org/10.1016/j.landurbplan.2008.12.003

Campbell, D., Hutchinson, W.G. \& Scarpa, R. (2009). Using choice experiments to explore the spatial distribution of willingness to pay for rural landscape improvements. Environment and Planning A, 41 (1): 97-111. http://dx.doi.org/10.1068/a4038

Caspersen, O.H. \& Nellemann, V. (2005). Landskabskaraktermetoden - et kompendium. Arbejdsrapport Skov- og Landskab nr. 20. [http://curis.ku.dk/ws/files/ 20544308/ap_sl20_001.pdf] 
Catrinu-Renström, M. D. et al. (2013). Multi-criteria analysis applied to environmental impacts of hydropower and water resources regulation projects. SINTEF report, TR A7339.

CICES (2013). CICES V4.3 (January 2013). European Environment Agency. Available at: http://cices.eu/

Daniel, T.C., Muhar, A., Arnbeger, A., Aznar, O., Boyd, J.W., Chan, K.M.A., Costanza, R., Elmquist, T., Flint, C.G., Gobster, P.H., Gret-Regamey, A., Lave, R., Muhar, S., Penker, M., Ribe, R.G., Scauppenlehner, T., Sikor, T., Soloviy, I., Spierenburg, M., Taczanowska, K., Tam, J., von der Dunk, A. et al. (2012). Contributions of cultural services to the ecosystem services agenda. Proceedings of the National Academy of Sciences of the United States of America 109(23): 8812-8819.

http://dx.doi.org/10.1073/pnas.1114773109

Bjørner, T., Jensen, C.U. \& Termansen, M. (2014). Den rekreative naturværdiaf naturområder i Danmark [The recreative nature value of natural areas in Denmark]. Danish Economic Councils Secretariat. Workingpaper2014:1.

Danish Ministry of the Environment (2002). Det nationale skovprogram [The National Forest Programme].

Danish Ministry of the Environment (2007). Vejledning om landskabet i kommuneplanlægningen [Guidance on landscape in municipal planning]. Nature Agency, Copenhagen.

Danish Ministry of the Environment (2008b). Landskab og kulturmiljø. Miljøkonsekvensvurderinger i det åbne land. Håndbog. [Landscape and cultural environment. Environmental Impact Assessments in the open land. Manual.] Nature Agency, Copenhagen. Naturstyrelsen. [http://naturstyrelsen.dk/publikationer/ 2008/dec/landskab-og-kulturmiljoe/]

Danish Ministry of the Environment (2009). Oversigt over statslige interesser $\mathrm{i}$ kommuneplanlægningen. [Overview of state interests in municipality planning].

Danish Ministry of the Environment (2012). Større sammenhængende landskaber og landskabskaraktermetoden [large continuous landscapes and the landscape character method]. [http://naturstyrelsen.dk/media/nst/Attachments/ Aproposomstrresammenhngendelandskaberoglandskabska.pdf]

Danish Ministry of the Environment (2013a). Grøn omstilling - nye muligheder for hele Danmark. Landsplanredegørelse 2013. [Green transition - new possibilities for all of Denmark. National Planning Report 2013.]

Danish Ministry of the Environment (2013b). Oversigt over statslige interesser iI kommuneplanlægningen. [Overview of state interests in municipality planning].

Danish Ministry of the Environment (2014). Landskabsatlas for Langeland commune [Landscape Atlas for the Municipality of Langeland]. [http://naturstyrelsen.dk/ publikationer/2013/nov/landskabsatlas-for-langeland-kommune/]

Danish Ministry of the Environment (Danish EPA) (2011). Biogasanlæg - arkitektur og landskab. Erfaringer og metoder til indpasning af biogasanlæg i landskabet [Biogas plants - architecture and landscape. Experiences and method to integrate biogas plants in the landscape.] Nature Agency, Copenhagen.

Danish Ministry of the Environment and RealDania (2011). Biogasanlæg - arkitektur og landskab. Erfaringer og metoder til indpasning af biogasanlæg i landskabet. [Biogas plants - architecture and landscape. Experiences and methods to incorporating biogas plants in the landscape. Nature Agency, Copenhagen. 
Danish Ministry of the Environment. (2008a). Landskabskaraktermetoden og byudvikling [Landscape Character Method and urban development]. Nature Agency, Copenhagen. [http://naturstyrelsen.dk/media/nst/Attachments/

Aproposomlandskabskaraktermetodenogbyudvikling.pdf]

Danish Ministry of the Environment. (2011). Biogasanlæg - arkitektur og landskab. Erfaringer og metoder til indpasning af biogasanlæg i landskabet. [Biogas installations - architecture and landscape. Experiences and methods to integrating biogas installations in the landscape.] Nature Agency, Copenhagen.

Danish Nature Agency (2011). Den europæiske landskabskonvention - status for det danske arbejde. [The European Landscape Convention - Status of the Danish progress] 10.11.2011. srs.

Danish Ministry of the Environment (2012). Større sammenhængende landskaber og landskabskaraktermetoden [large continuous landscapes and the landscape character method]. Nature Agency, Copenhagen. [http://naturstyrelsen.dk/media/ nst/Attachments/Aproposomstrresammenhngendelandskaberoglandskabska.pdf]

Danish Nature Agency (2011). Den europæiske landskabskonvention - status for det danske arbejde. [The European Landscape Convention - Status of the Danish progress] 10.11.2011. srs.

de Groot, R.S., Alkemade, R., Braat, L., Hein, L., Willemen, L et al. (2010). Challenges in integrating the concept of ecosystem services and values in landscape planning, management and decision making. Ecological Complexity 7, pp. 260-271. http://dx.doi.org/10.1016/j.ecocom.2009.10.006

Detr (2000). Local Quality of Life Counts. Department for Environment, Transport and the Regions, London, UK.

Directorate for Nature Management (now Environment Directorate) (DN) (2010). Landscape analysis: Approach to the assessment of landscape character and landscape value. Norway.

Directorate for Nature Management (now Environment Directorate) (DN) (2011). Method for landscape assessment in municipal planning. Norway.

Direktoratet for Økonomistyring (DFØ) (2014). Veileder i samfunnsøkonomiske analyser.

Doukas, H. et al. (2011). Electric power transmission: An overview of associated burdens. Int. J. Energy Res.: 35: 979-988. http://dx.doi.org/10.1002/er.1745

Drake, L. (1992). The non-market value of the Swedish agricultural landscape. European Review of Agricultural Economics, 19(3): 351-364. http://dx.doi.org/ 10.1093/erae/19.3.351

Drake, L. (1999). The Swedish agricultural landscape - economic characteristics, valuations and policy options. International Journal of Social Economics 26: 10421062. http://dx.doi.org/10.1108/03068299910245813

Dramstad, W. E. et al. (2006). Relationships between visual landscape preferences and map-based indicators of landscape structure. Landscape and Urban Planning 78: 465-474. http://dx.doi.org/10.1016/j.landurbplan.2005.12.006

DTU Transport \& COWI. (2014). Transportøkonomiske enhedspriser til brug for samfundsøkonomiske analyser. Version 1.5.

Emmelin, L. et al. (2005). Planering och förvaltning för friluftsliv: En forskningsoversikt. Rapport 5468, Naturvårdsverket.

Energistyrelsen (2007). Vejledning i samfundsøkonomiske analysser på Energiområdet. 
Eurostat (2011). International Year of Forests 2011. Forests cover around $40 \%$ of the EU27 land area. Half the EU27 consumption of renewable energy comes from wood. Newsrelease 85/2011.

Fredman, P., Boman, M., Lundmark, L. \& Mattsson, L. (2008). Friluftslivets ekonomiska värden. Forskningsprogrammet Friluftsliv i förändring, Rapport nr 5.

Fredman, P. \& Emmelin, L. (2001). Wilderness purism, willingness to pay and management preferences: a study of Swedish mountain tourists. Tourism Economics 7 (1), 5-20. http://dx.doi.org/10.5367/000000001101297702

Frivold, L. H. \& Gundersen, V. (2009). Skog for folk flest. En gjennomgang av kvantitative spørreundersøkelser fra Norge, Sverige og Finland. INA fagrapport 13.

Gobster, P.H. (2011). Landscape and Urban Planning at 100: Looking back moving forward. Landscape and Urban Planning 100, pp. 315-317. http://dx.doi.org/10.1016/j.landurbplan.2011.02.025

Gómez-Baggethun, E., Martín-López, B., Barton, D., Braat, L., Saarikoski, H., Kelemen, E., García-Llorente, M., van den Bergh, E., J., Arias, P., Berry, P., Potschin, M., Keene, H., Dunford, R., Schröter-Schlaack, C. \& Harrison, P. (2014). EU FP7 OpenNESS Project Deliverable 4.1. State-of-the-art report on integrated valuation of ecosystem services. European Commission FP7, 2014.

Grahn, P. \& Stigsdottir, U.K. (2010). The relation between perceived sensory dimensions of urban green space and stress restoration. Landscape and Urban Planning 94, pp. 264-275. http://dx.doi.org/10.1016/j.landurbplan.2009.10.012

Grammatikopoulou, I. \& Pouta, E. (2013). A locally designed payment scheme for agricultural landscape services. Land use policy, 32: 175-185. 86.

Grammatikopoulou, I., Pouta, E., Salmiovirta, M. \& Soini, K. (2012). Heterogeneous preferences for agricultural landscape improvements in southern Finland. Landscape and Urban Planning, 107: 181-191. http://dx.doi.org/10.1016/ j.landurbplan.2012.06.001

Gren, L. (2013). "Sverige”, in Landskap i kommuneplanering. Det nya energilandskapet. Nordiskt seminarium i Selfoss Island - samarbete och utmaningar. TemaNord 2013: 510, pp. 37-39. Nordic Council of Ministers 2013.

Gundersen, V. \& Frivold, L.H. (2008). Public preferences for forest structures: A review of quantitative surveys from Finland, Norway and Sweden. Urban Forestry \& Urban Greening 7: 241-258. http://dx.doi.org/10.1016/j.ufug.2008.05.001

Hansen, M. S. (2012). Pilgrimsvandringer gør naturen hellig, Kristeligt Dagblad 14.1.2012. http://www.kristeligt-dagblad.dk/kirke-tro/pilgrimsvandringer-gørnaturen-hellig

Hansen-Møller, J. (red.) (2004). Mening med landskab. En antologi om natursyn. Museum Tusculanums Forlag.

Hasund, K.P., Kataria, M. \& Lagerkvist, C.J. (2011). Valuing public good from the agricultural landscape - A choice experiment using reference points to capture observable heterogeneity. Journal of Environmental Planning and Management 54 (1), 31-53. http://dx.doi.org/10.1080/09640568.2010.502753

Haveraaen, E. (2015). pers. comm. 14. April 2015.

Hernández-Morcillo, M. et al. (2013). An empirical review of cultural ecosystem service indicators. Ecological Indicators 29: 434-444. http://dx.doi.org/10.1016/j.ecolind.2013.01.013

Hoen, H.F. \& Veisten, K. (1994). En undersøkelse blant brukere av Oslomarka: synspunkter på skogtilstand og skogbehandling (A survey of the users of Oslomarka: attitudes towards forest scenery and forestry practices). Skogforsk 6/94. 
Hoen, H.F. \& Winther, G. (1993). Multiple-use forestry and preservation of coniferous forests in Norway: a study of attitudes and Willingness-to-pay. Scandinavian Journal of Forest Research 8 (2), 266-280. http://dx.doi.org/10.1080/ 02827589309382776

Holøien, M. (2013). Med gudene på tur på Ammerud. Ditt Oslo 30.7.2013. http://www.dittoslo.no/lokalavisengroruddalen/nyheter-groruddalen/medgudene-pa-tur-pa-ammerud-1.7996515

Horne, P., Boxall, P.C. \& Adamowicz, W.L. (2005). Multiple-use management of forest recreation sites: a spatially explicit choice experiment. Forest Ecology and Management 207 (1-2), 189-199. http://dx.doi.org/10.1016/j.foreco.2004.10.026

Hunter, J.M. (1985). Land into landscape. London: George Goodwin.

IFRO \& Environmental Assessment Institute (2005). Motorways versus Nature. A Welfare Economic Valuation of Impacts.

Jacobsen, K. (2008). "Processions, public space and sacred space in the South Asian diasporas in Norway". In: K. Jacobsen (ed.) South Asian Religions on Display: Religious processions in South Asia and in the Diaspora, pp. 191-204. London: Routledge.

Jensen, F.S. (2003). Friluftsliv iI 592 skove og andre naturområder [recreation in 592 forests and other nature areas]. Skovbrugsserien Nr. 32. Forskningscentre for Skov og Landskab \& Miljøministeriet.

Jensen, F.S. (2014.): Friluftsliv Ii landskabet 2008 (2) Antal naturbesøg pr. år. [Recreation in the landscape. Number of visits to nature per year]. Videnblade Planlægning og Friluftsliv. Copenhagen University.

Jensen, F.S. \& Koch, N.E. (1997). Friluftsliv i skovene 1976/77 - 1993/94. [Outdoor recreation in forests 1976/77 - 1993/94.] The Research series Nr. 20. Royal Veterinary and Agricultural University of Denmark.

Jensen, F.S. \& Koch, N.E. (2004). Twenty-five years of forest recreation research in Denmark and its influence on forest policy. Scandinavian Journal of Forest Research 19(4): 93-102. http://dx.doi.org/10.1080/14004080410034173

Jensen, Inger Kristine (no year). Er det ute med utebiologien i Norge? Høgskolen i Oslo.

Jensen, C. U., Panduro, T. E. \& Lundhede, T. H. (2014). The Vindication of Don Quixote: The Impact of Noise and Visual Pollution from Wind Turbines. Land Economics 90(4): 668-682.

Kaltenborn, B. \& Bjerke, T. (2002). Associations between environmental value orientations and landscape preferences. Landscape and Urban Planning 59: 1-11. http://dx.doi.org/10.1016/S0169-2046(01)00243-2

Kettunen, M., Vihervaara, P., Kinnunen, S., D’Amato, D., Badura, T., Argimon, M. \& ten Brink, P. (2013). Socio-economic importance of ecosystem services in the Nordic Countries. Synthesis in the context of The Economics of Ecosystems and Biodiversity (TEEB). Nordic Council of Ministers, Copenhagen.

Kirchhoff, T. (2012). Letter: Pivotal cultural values of nature cannot be integrated into the ecosystem services framework. PNAS 109(46): 3146.

http://dx.doi.org/10.1073/pnas.1212409109

Kosenius, A-K., Haltia, E., Horne, P., Kniivilä, M. \& Saastamoinen, O. (2013). Value of ecosystem services? Examples and experiences on forests, peatlands, agricultural lands, and freshwaters in Finland. PTT Reports 244.

Kaae, B.C. (2004). Befolkningens natursyn og holdninger til natur. I: J. Hansen-Møller (red.): Mening med landskab. En antologi om natursyn. Museum Tusculanums Forlag 2004.

Kågeson, P. (2007). Förutsetningar för cykelturism i Sverige. Nature Associates. 
Ladenburg, J. \& Dubgaard, A (2007). Willingness to pay for reduced visual disamenities from offshore wind farms in Denmark. Energy Policy 35: 4059-4071.

http://dx.doi.org/10.1016/j.enpol.2007.01.023

Ladenburg, J. \& Dubgaard, A. (2009). Preferences of coastal zone user groups regarding the siting of offshore wind farms. Ocean and Coastal Management 52; 233-242. http://dx.doi.org/10.1016/j.ocecoaman.2009.02.002

Leskinen, P., Pykäläinen, J. \& Haara, A. (2009). Incorporation of preferential uncertainty into interval-scale priority functions - a case of multicriteria forestry decision making. Canadian Journal of Forest Research 39: 1498-1506. http://dx.doi.org/10.1139/X09-055

Lindhjem, H. (2007). 20 Years of stated preference valuation of non-timber benefits from Fennoscandian forests: A meta-analysis. Journal of Forest Economics 12, 251-277. http://dx.doi.org/10.1016/j.jfe.2006.09.003

Lindhjem, H. \& Magnussen, K. (2012). The value of Norwegian forest ecosystem services (in Norwegian), NINA Report 894. Report for the public committee on the value of ecosystem services in Norway.

Lindhjem, H. \& Navrud, S. (2008). How reliable are meta-analyses for international benefit transfers? Ecol. Econ. 66, 425-435. http://dx.doi.org/10.1016/ j.ecolecon.2007.10.005

Lindhjem, H., Sørheim: M.D. with K. Magnussen (2012). Urban ecosystem services in Norway: Status, trends, value and knowledge gaps (In Norwegian), Vista Report $2012 / 37$. Report for the public committee on the value of ecosystem services in Norway.

Loftsson, Y. (2013). Landscape in planning projects in Iceland. In: Landskap i kommuneplanering. Det nya energilandskapet. Nordiskt seminarium i Selfoss Islandsamarbete och utmaningar. TemaNord 2013: 510, pp. 46-47. Nordic Council of Ministers 2013.

Magnussen, K. \& Lindhjem, H. (2013). The social value of agricultural landscapes and other natural resources in impact assessment and cost benefit analysis of road projects. Report for the Norwegian Public Roads Administration.

Magnussen, K., Lindhjem, H., Armstrong, C., Bergland, H., Mikkelsen, E., Reinvang, R. \& Skjelvik, J.M. (2013). Økosystemttjenester i Barentshavet-Lofoten. Samfunnsmessige verier og avveiinger, Vista report 2013/08. (Ecosystem services in the Barents Sea and Lofoten: Social values and trade-offs.) Vista Report

Mattsson, L. \& Li, C.Z. (1993). The non-timber value of Northern Swedish forests - an economic-analysis. Scandinavian Journal of Forest Research 8 (3), 426-434. http://dx.doi.org/10.1080/02827589309382789

Mattsson, L. \& Li, C.Z. (1994): How do different forest management-practices affect the non-timber value of forests - an economic-analysis. Journal of Environmental Management 41 (1), 79-88. http://dx.doi.org/10.1006/jema.1994.1035

MD (2013). Landskapstyper i Norge. Ny metodikk for kartlegging av landskap. Miljødirektoratet (Norwegian Environmenta Agency) and Faggruppe NiN Landskap.

Medwind (2014). Landscape. Vaasa Energy Institute \& Vindkraftföreningen rf. Available at: http://www.vindkraft.fi/ medvind/public/index.php?cmd= smarty\&id=59_len\&PHPSESSID=tv1s5maadcsoo3050lrnvg6pl6. Retrieved: 28.12.2014.

Mels, T., Mels, S. (2014). Deltagande landskapsanalys för vindkraft. Vindval rapport 6625, July 2014. 
Miljødirektoratet et al. (2013). Landskapstyper i Norge. Ny metodikk for kartlegging av landskap. Miljødirektoratet, Artsdatabanken, Nordland Fylkeskommune, Miljøverndepartementet.

Millennium Ecosystem Assessment (MEA) (2005). Ecosystems and Human Wellbeing: A Framework for Assessment. Island Press, Washington.

Mitchell, M.G.E. et al. (2013). Linking Landscape Connectivity and Ecosystem Service Provision: Current Knowledge and Research Gaps. Ecosystems. http://dx.doi.org/10.1007/s10021-013-9647-2

Moen, E. (2015). pers. comm., March 2015.

Mourato, S., Atkinson, G., Collins, M., Gibbons, S., MacKerron, G., Resende, G. et al. (2010). Economic Analysis of Cultural Services Final Report. December 2010, UK NEA Economic Analysis.

Myllyviita, T., Hujala, T., Kangas, A. \& Leskinen, P. (2011). Decision support in assessing the sustainable use of forests and other natural resources - a comparative review. The Open Forest Science Journal 4: 24-41. http://dx.doi.org/10.2174/ 1874398601104010024

Navrud, S. \& Ready, R.C. (2002). Valuing Cultural heritage: Applying Environmental Valuation Techniques to Historic Buildings, Monuments and Artefacts. Cheltenham: Edward Elgar Publishing. http://dx.doi.org/10.4337/9781843765455

Navrud, S., Ready, R.C., Magnussen, K. \& Bergland, O. (2008). Valuing the social benefits of avoiding landscape degradation from overhead power transmission lines - Do underground cables pass the benefit-cost test? Landscape Research 33:281-296. http://dx.doi.org/10.1080/01426390802045921

Nordic Council of Ministers (NCM) (2003). Nordens Landskap. Forprosjekt for oppfølging av den europeiske landskapskonvensjonen. TemaNord 2003: 550, Nordic Council of Ministers.

Nordic Council of Ministers (NCM) (2007). Nordic Environmental Valuation Database. TemaNord 2007: 518.

Nordic Council of Ministers (NCM) (2013). Landskap i kommuneplanering. Det nya energylandskapet. Nordiskt seminarium i Selfoss Island - samarbete och utmaningar. TemaNord 2013:510

Nordiskt seminarium i Selfoss Island - samarbete och utmaningar.

Norman, J., Mattsson, L. \& Boman, M. (2011). Rekreationsvärden i Skånes och Blekinges skogar hur viktig är ädellövskogen? Fakta. Skog; 2011:2.

Norwegian Environment Agency (2010). Landskapsanalyse. Framgangsmåte for vurdering av landskapskarakter og landskapsverdi. Versjon februar 2010.

Norwegian Environment Agency (2011). Veileder Metode for landskapsanalyse $i$ kommuneplan.

Norwegian Ministres of Environment and Oil and Energy (2007). Retningslinjer for planlegging og lokalisering av vindkraftanlegg.

Ode, Å., Fry, G., Messager, P., Miller, D. \& Tveit, M. (2009). Indicators of perceived naturalness as drivers of landscape preference. Journal of Environmental Management 90, 375-383. http://dx.doi.org/10.1016/j.jenvman.2007.10.013

Ode, Å., Hagerhall, C. \& Sang, N. (2010). Analysing visual landscape complexity: theory and application. Landscape Research 35, 111-131. http://dx.doi.org/10.1080/ 01426390903414935

Ode, Å., Tveit, M. \& Fry, G. (2008). Capturing landscape visual character using indicators - touching base with landscape aesthetic theory. Landscape Research, 33, 89-118. http://dx.doi.org/10.1080/01426390701773854 
Ode, Å., Tveit, M.S. \& Fry, G. (2010). Advantages in using different data sources in assessment of landscape change and its effect on visual scale. Ecological Indicators 10, 24-31. http://dx.doi.org/10.1016/j.ecolind.2009.02.013

Olafsson, A.S. (2013). GIS-based Recreation Experience Mapping: Development, Validation and Implementation. PhD thesis. Forest and Landscape, Faculty of LIFE Sciences, University of Copenhagen.

Olsen, S.B. (2009). Choosing between internet and mail survey modes for choice experiment surveys considering non-market goods. Environmental and Resource Economics 44 (4): 591-610. http://dx.doi.org/10.1007/s10640-009-9303-7

Olsen, S.B., Ladenburg, J., Petersen, M.L. Lopdrup, U., Hansen, A.S. \& Dubgaard, A. (2005). Motorways versus Nature. A Welfare Economic Valuation of Impacts. ISBN: 87-7992-035-7.

Petersen, L.S. (2013). Cykelturister i Danmark. Turistprofil. Viden \& Analyse, VisitDenmark.

Pouta, E. (2003). Attitude-behavior framework in contingent valuation of forest conservation. Ph.D., University of Helsinki.

Pouta, E. (2004). Attitude and belief questions as a source of context effect in a contingent valuation survey. Journal of Economic Psychology 25, 229-242. http://dx.doi.org/10.1016/S0167-4870(02)00170-8

Pouta, E. (2005). Sensitivity to scope of environmental regulation in contingent valuation of forest cutting practices in Finland. Forest Policy and Economics 7, 539-550. http://dx.doi.org/10.1016/j.forpol.2003.09.002

Price, C. (1978). Landscape economics. London: Macmillian.

Price, C. (2008). Landscape economics at dawn: An eye-witness account. Landscape Research 33(3): 263-280. http://dx.doi.org/10.1080/01426390802045897

Price, C. (2012). Subjectivity and objectivity in landscape evaluation: an old topic revisited. In: Van der Heide, M. and W.J.M. Heijman (eds.) (2012): The economic value of landscapes. Routledge.

Rekola, M. \& Pouta, E. (2005). Public preferences for uncertain regeneration cuttings: a contingent valuation experiment involving Finnish private forests. Forest Policy and Economics 7, 635-649. http://dx.doi.org/10.1016/j.forpol.2003.12.003

Research Box, Land Use Consultants and Rick Minter (2009). Experiencing Landscapes: capturing the cultural services and experiential qualities of landscape, Natural England Commissioned report NECR024. Natural England.

Ribe, R.G. (2005). Aesthetic perceptions of green tree retention harvests in vista views. The interaction of cut level, retention pattern and harvest shape. Landscape and Urban Planning 73, pp. 277-293. http://dx.doi.org/10.1016/ j.landurbplan.2004.07.003

Ryan, R. L. (2011). The social landscape of planning: Integrating social and perceptual research with spatial planning information. Landscape and Urban Planning 100, pp. 361-363. http://dx.doi.org/10.1016/j.landurbplan.2011.01.015

Sandsbraten, L. (1997). Verdsetting av miljøgoder i Oslomarka: en betinget verdsettingsundersøkelse i privat og kommunal skog i Indre Oslomarka (Valuation of environmental goods in Oslomarka: a contingent valuation survey of private and municipality owned forest in inner Oslomarka). Master Thesis, Norwegian University of Life Sciences.

Santos (2007). Transferring landscape values: How and how accurately? In: Navrud, S. And R. Ready (eds): Environmental Value Transfer. Springer. 
SEA (2014). Riksinteressen för vindbruk, at www.energimyndigheten se. Available at: http://www.energimyndigheten.se/Om-oss/Var-verksamhet/Framjande-avvindkraft/Riksintresse-vindbruk-/ Retrieved: 28.12.2014.

Simensen, K. \& Wind, M. (1990). Holdninger til og betalingsvillighet for ulike skogbehandlinger i fjellskog: En empirisk undersøkelse av hirkjølen statsallmenning (attitudes and wtp for different forestry practices in mountainous forests: a survey of the hirkjolen common). Master Thesis, Norwegian University of Life Sciences.

Skagestad, E. (1996). Friluftsliv og Skogbruk - En spørreundersøkelse blant turgjengere i ytre Oslomarka, Romeriksasen, pa vinterstid (Recreation and forestry - a survey of hikers in the outer Oslomarka, Romeriksasen, in the winter time). Master Thesis, Norwegian University of Life Sciences.

Statens Vegvesen (State Road Administration of Norway) (Statens Vegvesen) (2014). Håndbok V712. Impact assessment guidelines.

Statnett (2014). Håndbok i samfunnsøkonomiske analyser.

Strumse, E. (2012). Psykologisk forskning om miljøestetikk: bare om smak og behag? In: A. Fyhri et al. (red.): Norsk miljøpsykologi. Mennesker og omgivelser. SINTEF Akademisk Forlag, 2012.

Svarvadottir, S. (2013). Opening address. In: Landskap i kommuneplanering. Det nya energilandskapet. Nordiskt seminarium i Selfoss Island - samarbete och utmaningar. TemaNord 2013: 510, pp. 19-20. Nordic Council of Ministers 2013.

Swanwick, C. (2009). Society's attitudes to and preferences for land and landscape. Land Use Policy 26S, pp. S62-S75. http://dx.doi.org/10.1016/ j.landusepol.2009.08.025

Swanwick, C., Hanley, N. \& Termansen, M. (2007). Scoping study on agricultural landscape valuation. Final report to DEFRA.

SÖT (2013): S:T Olavsleden. Find your way and yourself. A pilgrimage route from Selånger to Trondheim. Cultural Routes of Europe. Published by Sundsvall, Östersund and Trondheim municipalities (SÖT).

Termansen, M., McClean, C.J. \& Jensen, F.S. (2013). Modelling and mapping spatial heterogeneity in forest recreation services. Ecological Economics 92; 48-57. http://dx.doi.org/10.1016/j.ecolecon.2013.05.001

Termansen, M., Smart, J.R.S., Piil-Damm, A., Ladenburg, J., Fonnesbech-Wulf, A., Fuglsang, M. \& Hasler, B. (2012). Welfare effects of wind turbines in the landscape: a segmented market hedonic approach in Denmark. Paper presentated at EAERE 19th Annual Conference, 2012, Prague.

Thorhallsdottir, T.E. (2013). A visual approach to landscape classification: The Icelandic Landscape Project. In: Landskap i kommuneplanering. Det nya energilandskapet. Nordiskt seminarium i Selfoss Island - samarbete och utmaningar. TemaNord 2013: 510, pp. 71-73. Nordic Council of Ministers 2013.

Thors, S. (2013). Island. In: Landskap i kommuneplanering. Det nya energilandskapet. Nordiskt seminarium i Selfoss Island - samarbete och utmaningar. TemaNord 2013: 510, pp. 36-37. Nordic Council of Ministers 2013.

Thrastarson, R.H. \& Bjarnadottir, J. (2013). Landscape analysis and assessment of impacts of geothermal power plants and transmission lines in NE Iceland. In: Landskap i kommuneplanering. Det nya energilandskapet. Nordiskt seminarium i Selfoss Island - samarbete och utmaningar. TemaNord 2013: 510, pp. 61-62. Nordic Council of Ministers 2013.

Trafikministeriet. (2003). Manual for samfundsøkonomisk analyse - anvendt metode og praksis på transportområdet.

Trafikverket (2012). Landskap i långsiktig planering. 
Trafikverket (2014). Landskap i långsiktig planering, www.trafikverket.se. Available at: http://www.trafikverket.se/Foretag/Planera-och-utreda/Planerings--ochanalysmetoder/Miljobedomning/Ett-mangsidigt-verktyg/. Retrieved 28.12.2014.

Tveit, M., Ode, Å. \& Fry, G. (2006). Key concepts in a framework for analyzing visual landscape character. Landscape Research, 31, 229-255.

http://dx.doi.org/10.1080/01426390600783269

Tveit, M.S., (2009). Indicators of visual scale as predictors of landscape preference; comparison between groups. J. Environ. Manage. 90, 2882-2888.

http://dx.doi.org/10.1016/j.jenvman.2007.12.021

Vacher, M. (2011). Consuming Leisure Time. Landscapes of Infinite Horizons. Social Analysis 55,2, pp. 45-61. http://dx.doi.org/10.3167/sa.2011.550203

Van Berkel, D. B. \& Verburg, P.H. (2014). Spatial quantification and valuation of cultural ecosystem services in anagricultural landscape. Ecological Indicators 37: 163-174 http://dx.doi.org/10.1016/j.ecolind.2012.06.025

Van der Heide, M., Heijman \& W.J.M. (eds.) (2012). The economic value of landscapes. Routledge.

Van Zanten, B.T., Verburg, P.H., Koetse, M.J. \& van Beukering, P.J.H. (2014). Preferences for European agrarian landscapes: A meta-analysis of caste studies. Landscape and Urban Planning 132; 89-101. http://dx.doi.org/10.1016/j.landurbplan.2014.08.012

Vejre, H., Søndergård Jensen, F., Jellesmark, Thorsen, B. et al. (2010). Demonstrating the importance of intangible ecosystem services from peri-urban landscapes. Ecological Complexity 7, pp. 338-348. http://dx.doi.org/10.1016/j.ecocom.2009.09.005

Vista Analysis (2014). Costs and benefits of transmission line upgrades to Oslo. Draft.

Vistad, O. I. \& Vorkinn, M. (2012). The Wilderness Purism Construct - Experiences from Norway with a simplified version of the purism scale. Forest Policy and Economics 19: 39-47. http://dx.doi.org/10.1016/j.forpol.2011.12.009

Voimamylly (2012). Humppila-Urjala Wind farm: Summary, Envrionmental impact assessment program. Voimamylly Ltd. 2012.

Voimamylly (2013). Humppila-Urjala Wind farm: Summary Environmental impact assessment report. Voimamylly Ltd. 2013.

Waltert, F. \& Schläpfer, F. (2010). Landscape amenities and local development: A review of migration, regional economic and hedonic pricing studies. Ecological Economics 70: 141-152. http://dx.doi.org/10.1016/j.ecolecon.2010.09.031

Ween, G. \& Abram, S. (2012). The Norwegian Trekking Association: Trekking as Constituting the Nation. Landscape Research 37,2, pp. 155-171. http://dx.doi.org/10.1080/01426397.2011.651112

Ween, G.B. \& Lien, M. (2012). Decolonization in the Arctic? Nature Practises and Land Rights in the Norwegian High North. Journal of Rural and Community Development 7, 1, pp. 93-109.

Wild, R. \& McLeod, C. (2008). Sacred Natural Sites: Guidelines for Protected Areas Managers, IUCN World Commission on Protected Areas Task Force on Cultural and Spiritual Values of protected Areas and UNESCO Programme on Man and the Biosphere. IUCN \& UNESCO, Gland, Switzerland.

Wylie, J. (2007). Landscape. Routledge.

Ymparisto (2014a). Landscapes. Joint website of Finland's environmental administration. Available at: http://www.ymparisto.fi/en-US/Nature/Landscapes. Retrieved: 28.12.2014. 
Ymparisto (2014b). Wind power construction. Joint website of Finland's environmental administration. Available at: http://www.ymparisto.fi/en-US/Living

environment_and_planning/Living_environment/Wind_power_construction. Retrieved: 28.12.2014.

Zandersen, M., Termansen, M. \& Jensen, F.S. (2007). Evaluating approaches to predict recreation values of new forest sites. Journal of Forest Economics, Vol. 13, Nr. 2-3, p. 103-128. http://dx.doi.org/10.1016/j.jfe.2007.02.003

Åkerlund, U. (2013). Svenska kommuners planering i ett landskapsperspektiv översiktsplaneringes möjligheter för gjenomförande av den europeiska landskapskonventionen i Sverige. In: Landskap i kommuneplanering. Det nya energilandskapet. Nordiskt seminarium i Selfoss Island - samarbete och utmaningar. TemaNord 2013: 510, pp. 45-46. Nordic Council of Ministers 2013. 



\title{
Sammendrag - norsk
}

\author{
Bakgrunn og motivasjon
}

Kulturelle økosystemtjenester (ØT), en av fire hovedkategorier $\emptyset \mathrm{T}$, er anerkjent som svært viktige, men er ofte ikke behandlet videre i forskning eller grundig i prosjektvurderinger. De varierte opplevelsene mennesker får fra landskap utgjør en vesentlig del av slike kulturelle tjenester. En gjennomgang av resultater fra studier som undersøker folks preferanser for landskap i Norden og internasjonalt kan være nyttig for å forstå hvordan og hvor mye folk verdsetter ulike typer landskapsopplevelser. Dette er nødvendig for å få til en bedre inkludering av slike verdier i relevante beslutningsprosesser. Gitt de store landskapsendringene som skjer i mange av de nordiske landene, er det et økende behov for å finne måter å bedre inkludere verdien av (ofte kumulative) landskapsvirkninger i relevante beslutningsprosesser som påvirker landskap.

\section{Mål og avgrensinger}

Denne rapporten har som mål å syntetisere tilgjengelig kunnskap om omfanget og verdien av folks landskapsopplevelser som en kulturell økosystemtjeneste (ØT) i nordisk sammenheng, og undersøke gjeldende praksis og eksempler på hvordan landskapskonsekvenser er innarbeidet (eller ikke) $i$ prosjektvurderinger og beslutningssammenhenger. Til slutt trekker vi ut lærdommer av relevans for å begynne å bygge bro til en bedre praksis.

\section{Diskusjon og konklusjoner}

Den Europeiske Landskapskonvensjonen (2000) bruker en bred forståelse av landskap i sin definisjon: "Landskap betyr et område, som oppfattes av mennesker, hvis karakter er resultatet av handlinger og samspill mellom naturlige og / eller menneskelige faktorer." Konvensjonens artikkel 5 vektlegger en forpliktelse til å sikre deltakelse fra publikum i fastsettelse og gjennomføring av landskapspolitikk, og krever at partene i konvensjonen etablerer nødvendige prosedyrer for å oppnå dette. Med 
andre ord bør folks preferanser for landskapsopplevelser derfor telle (mer) i politiske prosesser som kan gi betydelige landskapsendringer. Vi anser "landskapsopplevelse" som en form for kulturell ØT avledet fra landskap, og som er relevant for minst seks typer allment anerkjente kulturelle ØT:

- Rekreasjon: Muligheter for turisme og fritidsaktiviteter.

- Estetisk: Verdsetting av natur (annet enn gjennom fritidsaktiviteter).

- Utdanning og vitenskap: Muligheter for formell og uformell utdanning og opplæring.

- Inspirasjon for kultur, kunst, design.

- Kulturminner og identitet: Stedstilhørighet.

- Åndelig og religiøs inspirasjon.

Det er utviklet en rekke indikatorer og metoder for å kvantifisere og verdsette landskapsendringer og -attributter i økonomiske eller ikkeøkonomiske termer, basert på folks preferanser uttrykt i spørreundersøkelser eller som avdekket i deres markedsatferd. Vi undersøkte litteraturen om skog- og jordbrukslandskap og så spesielt etter økonomiske studier som kvantifiserer negative effekter av landskapsinngrep forårsaket av veier, kraftlinjer og vindmøller osv. Gjennomgangen av ikke$ø$ konomisk litteratur viser at det er mange typiske kjennetegn ved landskap som kan måles ved indikatorer og som folk har en tendens til å like (som åpenhet, utsikt, vann osv.) eller mislike (for eksempel tekniske installasjoner og veier). Den økonomiske verdsettingslitteraturen, som ikke er stor i de nordiske landene, viser at i) eksisterende metoder er nyttige for å vurdere velferdstapet ved landskapsendringer, og ii) at den $\varnothing$ konomiske betydningen av landskap for folks velferd er potensielt stor.

Kartleggingen av hvordan de nordiske landene behandler virkninger på landskap i prosjekvurderinger og beslutninger i dag viser mangfold: Landskapene varierer mellom landene og det gjør også oppfatninger om landskap og den betydning ulike landskap tilskrives. Alle landene er medlemmer av konvensjonen, men det varierer i hvilken grad nasjonal landskapspolitikk er formulert, og om og hvordan landskap er kartlagt og klassifisert. På sektornivå, ser vi at ulike sektorer i liten grad (hvis i det hele tatt) tar hensyn til ØT fra landskap og verdier uttrykt av ikke-eksperter (dvs. berørt befolkning lokalt og bredere). Men det finnes også bevegelse i retning av å bedre inkludere slike verdier basert på folks preferanser. På prosjektnivå, blir konsekvensutredninger og nytte-kostnadsanalyser ofte utført uten kvantifisering av 
landskapskonsekvenser eller vurderinger av verdien av slike konsekvenser for menneskers velferd. Videre mangler ofte en konkret landskapspolitikk eller beskrivelser av landskapsverdier for et bestemt område hvor et prosjekt planlegges, noe som gjør det uklart når konsekvensene bør vurderes som kritiske. Det er derfor klare svakheter i gjeldende retningslinjer og praksis som bør vurderes nærmere. Noen av de nødvendige verktøy og metoder er tilgjengelige, og neste skritt kan bygge på ØT-rammeverk og utnytte eksisterende monetære (eller ikke-monetære) verdsettingsmetoder som allerede er velprøvde og testet for virkelige landskapsendringer.

Dette prosjektet ble unnfanget som en del av et prosjekt med to faser. Den andre fasen, som starter i 2015, har som mål å utvikle et rammeverk i samråd med beslutningstakere basert på ØT-tilnærmingen, og utforske og teste hvordan denne tilnærmingen kan addressere noen av svakhetene vi har funnet i gjeldende praksis. 



\section{Annex I: List of interviewees}

In the table below we summarise the names and affiliations of practitioners, researchers and other resource persons we have been in contact with/interviewed for the project.

\section{Table Al.1: List of contacts}

\begin{tabular}{|c|c|c|}
\hline Name & Institution/competence/role & Date \\
\hline Trond Simensen & $\begin{array}{l}\text { Norwegian Directorate of Nature Management, Head of spatial } \\
\text { planning and county governance }\end{array}$ & 14th May 2014 \\
\hline Gertrud Jørgensen & $\begin{array}{l}\text { Professor, Department of Geosciences and Natural Resource } \\
\text { Management, Copenhagen University }\end{array}$ & 27th June 2014 \\
\hline $\begin{array}{l}\text { Anette Ginsbak \& } \\
\text { Mette Kragh }\end{array}$ & $\begin{array}{l}\text { Architect, Nature Agency, Office for the open Land "det åbne } \\
\text { land", Danish Ministry of the Environment }\end{array}$ & 17th June 2014 \\
\hline Jørgen Primdahl & $\begin{array}{l}\text { Professor, Depart of Geosciences and Natural Resource Manage- } \\
\text { ment, Copenhagen University }\end{array}$ & 8th August 2014 \\
\hline Jan Eriksen & Director, The Danish Outdoor Council & 6th August 2014 \\
\hline $\begin{array}{l}\text { Frank Søndergaard } \\
\text { Jensen }\end{array}$ & $\begin{array}{l}\text { Professor, Section for Landscape, Architecture and Planning, } \\
\text { Department of Geosciences and Natural Resource Management, } \\
\text { University of Copenhagen }\end{array}$ & 11th Nov 2014 \\
\hline Karl-Ivar Kumm & Docent, Swedish University of Agricultural Sciences Skara & 17th Nov 2014 \\
\hline
\end{tabular}





\section{Annex II: CICES classification of cultural ecosystem services}

\begin{tabular}{|c|c|c|c|c|}
\hline $\begin{array}{l}\text { Division } \\
\text { (main type of } \\
\text { output or } \\
\text { process) }\end{array}$ & $\begin{array}{l}\text { Group } \\
\text { (division split } \\
\text { in biological, } \\
\text { physical or } \\
\text { cultural type) }\end{array}$ & $\begin{array}{l}\text { Class } \\
\text { (group linked back to } \\
\text { concrete and identifiable } \\
\text { sources) }\end{array}$ & $\begin{array}{l}\text { Class type } \\
\text { (ways of } \\
\text { measuring } \\
\text { ecosystem } \\
\text { service output) }\end{array}$ & Examples \\
\hline \multirow{5}{*}{$\begin{array}{l}\text { Physical and } \\
\text { intellectual } \\
\text { interactions } \\
\text { with biota, } \\
\text { ecosystems, } \\
\text { and land- } \\
\text { /seascapes } \\
\text { [environmen- } \\
\text { tal settings] }\end{array}$} & $\begin{array}{l}\text { Physical and } \\
\text { experiential } \\
\text { interactions }\end{array}$ & $\begin{array}{l}\text { Experiential use of plants, } \\
\text { animals and land-/ } \\
\text { seascapes in different } \\
\text { environmental settings } \\
\text { Physical use of land-/ } \\
\text { seascapes in different } \\
\text { environmental settings }\end{array}$ & $\begin{array}{l}\text { By visits/use } \\
\text { data, plants, } \\
\text { animals, } \\
\text { ecosystem } \\
\text { type }\end{array}$ & $\begin{array}{l}\text { Walking, hiking, climbing, boating, leisure } \\
\text { fishing (angling) and leisure hunting }\end{array}$ \\
\hline & \multirow[t]{4}{*}{$\begin{array}{l}\text { Intellectual and } \\
\text { representative } \\
\text { interactions }\end{array}$} & $\begin{array}{l}\text { Scientific } \\
\text { Educational }\end{array}$ & $\begin{array}{l}\text { By use/ cita- } \\
\text { tion, plants, } \\
\text { animals, } \\
\text { ecosystem type }\end{array}$ & $\begin{array}{l}\text { Subject matter for research both on } \\
\text { location and via other media } \\
\text { Subject matter of education both on } \\
\text { location and via other media }\end{array}$ \\
\hline & & Heritage, cultural & & $\begin{array}{l}\text { Historic records, cultural heritage e.g. } \\
\text { preserved in water bodies and soils }\end{array}$ \\
\hline & & Entertainment & & $\begin{array}{l}\text { Ex-situ viewing/experience of natural } \\
\text { world through different media }\end{array}$ \\
\hline & & Aesthetic & & $\begin{array}{l}\text { Sense of place, artistic representations of } \\
\text { nature }\end{array}$ \\
\hline \multirow{3}{*}{$\begin{array}{l}\text { Spiritual, } \\
\text { symbolic and } \\
\text { other interac- } \\
\text { tions with } \\
\text { biota, ecosys- } \\
\text { tems, and } \\
\text { land- } \\
\text { /seascapes } \\
\text { [environmen- } \\
\text { tal settings] }\end{array}$} & $\begin{array}{l}\text { Spiritual and/or } \\
\text { emblematic }\end{array}$ & Sacred and/or religious & $\begin{array}{l}\text { By use, } \\
\text { plants, } \\
\text { animals, } \\
\text { ecosystem } \\
\text { type }\end{array}$ & $\begin{array}{l}\text { Emblematic plants and animals e.g. } \\
\text { national symbols such as American eagle, } \\
\text { British rose, Welsh daffodil } \\
\text { Spiritual, ritual identity e.g. "dream paths" } \\
\text { of native Australians, holy places; sacred } \\
\text { plants and animals and their parts }\end{array}$ \\
\hline & \multirow[t]{2}{*}{$\begin{array}{l}\text { Other cultural } \\
\text { outputs }\end{array}$} & Existence & $\begin{array}{l}\text { By plants, } \\
\text { animals, }\end{array}$ & $\begin{array}{l}\text { Enjoyment provided by wild species, } \\
\text { wilderness, ecosystems, land-/seascapes }\end{array}$ \\
\hline & & Bequest & $\begin{array}{l}\text { feature/ } \\
\text { ecosystem type } \\
\text { or component }\end{array}$ & $\begin{array}{l}\text { Willingness to preserve plants, animals, } \\
\text { ecosystems, land-/seascapes for the } \\
\text { experience and use of future generations; } \\
\text { moral/ethical perspective or belief }\end{array}$ \\
\hline
\end{tabular}


Table All.2: Accompanying CICES classification of abiotic outputs from natural systems (Provisional)

\begin{tabular}{llll}
\hline Section & Division & Group & Examples \\
\hline $\begin{array}{l}\text { Cultural settings depend- } \\
\text { ent on abiotic structures }\end{array}$ & $\begin{array}{l}\text { Physical and intellectual } \\
\text { interactions with land- } \\
\text { /seascapes [physical } \\
\text { settings] }\end{array}$ & $\begin{array}{l}\text { By physical and experien- } \\
\text { tial interactions or } \\
\text { intellectual and represen- } \\
\text { tational interactions }\end{array}$ & e.g. caves \\
& $\begin{array}{l}\text { Spiritual, symbolic and } \\
\text { other interactions with } \\
\text { land-/seascapes [physical } \\
\text { settings] }\end{array}$ & By type & $\begin{array}{l}\text { e.g. sacred rocks or other } \\
\text { physical structures or } \\
\text { spaces }\end{array}$ \\
\hline
\end{tabular}




\section{Annex III: Landscape images from the Nordic countries}

We have conducted a small survey in order to tentatively identify the most common concept of landscape in the Nordic countries.

When carrying out a web-search on google, websites that have the most links will figure at the top and follow in descending order. By choosing the function "images", one gets a list of images and not sites or documents.

We assumed that the images that figure at the top when searching the name of a country in the local language and the word "landscape" in the local language, will be indicative of what are the most typical conceptions of national landscapes.

In order to ensure that the search for each country is done on the same platform with the same types of biases, we have for each country used the local google-site. The searches where carried out on the same day (8.10.2014), on the same computer, within a 2-hour period (14.00-16.00).

For each search we identified the top-18 images, which are presented below. There was some manual screening of images, as we removed images of maps and of logos. Except for that, the lists below simply consists of the unedited lists of images for each country with number one in the left corner and number 18 in the bottom corner to the right.

We then identified the main landscape characteristics in the images, using the categories "coast", "fjord", "agriculture/rural", "lake(s)", "river", "forest", "valley", "mountain". One image may contain several landscape characteristics. The result is presented in the table below. 
Table All..1: Occurrence of main landscape characteristics in images occurring after google-search for "(country)" and "landscape" on national google websites

\begin{tabular}{lrrrrr}
\hline & Denmark & Finland & Iceland & Norway & Sweden \\
\hline Coast & $28 \%$ & $89 \% *$ & $33 \%$ & $11 \%$ & $6 \%$ \\
Fjord & - & & - & $67 \%$ & - \\
Agriculture/rural & $100 \%$ & $6 \%$ & $6 \%$ & $22 \%$ & $50 \%$ \\
Lake(s) & $11 \%$ & $89 \% *$ & $17 \%$ & $6 \%$ & $22 \%$ \\
River & $6 \%$ & $6 \%$ & $6 \%$ & $6 \%$ & $22 \%$ \\
Forest & $33 \%$ & $50 \%$ & - & - & $39 \%$ \\
Valley & - & - & $6 \%$ & $11 \%$ & - \\
Mountain(s) & - & $6 \%$ & $94 \%$ & $100 \%$ & $33 \%$ \\
\hline
\end{tabular}

* Double count (not possible to distinguish between coast and lakes).

This survey is not a rigorous and deep scientific survey, but a "quickand-dirty" survey that may be considered to provide indicative results. Many factors will influence which images of landscape that occurs in a google-search. For instance will images that are used for marketing and tourism purposes on the internet likely score high, but may not accurately reflect the main national concepts of landscape in the population as such. 
norden

Nordic Council of Ministers

Ved Stranden 18

DK-1061 Copenhagen K

www.norden.org

\section{Landscape experiences as a cultural ecosystem service in a Nordic context}

Cultural ecosystem services in the form of experiences derived from landscapes are potentially important, but often overlooked. Given the large and unprecedented landscape changes many of the Nordic countries are undergoing, there is a need to find ways of including people's preferences and the value of landscape impacts in policy assessments and decision-making processes. The project aim has been to synthesize knowledge about the magnitude and value of landscape experiences, and investigate current practices and examples of how landscape impacts are incorporated (or not) in policy assessments and decision-making contexts in the Nordics. The literature demonstrates potentially high unaccounted welfare loss from landscape change. We find clear weaknesses in current practices, that a second phase will try to address. The project was carried out by Vista Analysis in Oslo and Department of Environmental Science at Aarhus University from 2014-15. 